\title{
Learning from Third Party Certified Environmental Management Systems in Local Authority Organizations
}

\author{
by \\ Greg Davis \\ (B.E.S., University of Waterloo, 2006) \\ A thesis \\ presented to Ryerson University \\ in partial fulfillment of the requirements of the degree of \\ Master of Applied Science \\ in the program of \\ Environmental Applied Science and Management
}

Toronto, Ontario, Canada, 2009

(C) Greg Davis 


\section{Authors Declaration}

I hereby declare that I am the sole author of this thesis.

I authorize Ryerson University to lend this thesis to other institutions or individuals for the purpose of scholarly research.

I further authorize Ryerson University to reproduce this thesis by photocopying or by other means, in total or in part, at the request of other institutions or individuals for the purpose of scholarly research. 


\title{
Learning from Third Party Certified Environmental Management Systems in Local Authority Organizations
}

\author{
(C) Greg Davis, 2009 \\ Master of Applied Science \\ in the program of \\ Environmental Applied Science and Management
}

\begin{abstract}
Cities face immense environmental challenges with limited resources to implement management solutions. Relevant trends in the private sector toward third party certification to external environmental management standards have yet to be fully embraced by governing Local Authorities (LAs). As the first city in North America to obtain ISO 14001 certification, the City of Calgary is examined as a case study of the implementation of a certified Environmental Management System (EMS) from impetus through to ongoing effects on learning. Investigation demonstrates that the unique characteristics of LA organizations are important factors in considering the strengths and challenges of using a voluntary external standard to establish environmental priorities. While LAs must avoid overemphasizing the standard itself, an informed approach increases organizational transparency and accountability, and enables collective problem solving. The certification process is a motivating surrogate force for cities which typically lack the competitive pressure found in for-profit sectors.
\end{abstract}




\section{ACKNOWLEDGEMENTS}

Thanks to City of Calgary employees for the generous feedback and cooperation, and in particular to Harley Hutchinson for his consistent support.

Special thanks to Dr. Kernaghan Webb for the new mountaineering gear.

And to Laura, for four colors with accent walls 


\section{TABLE OF CONTENTS}

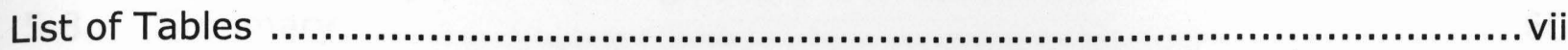

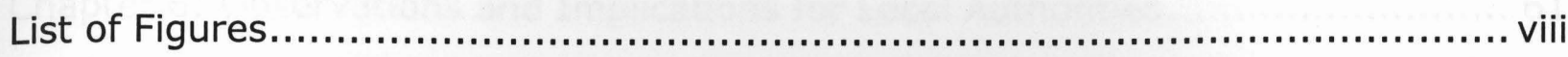

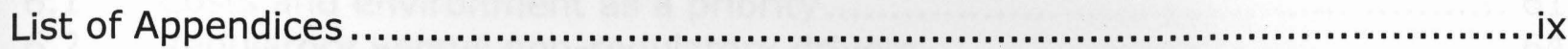

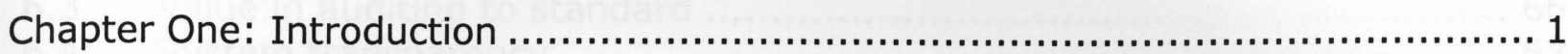

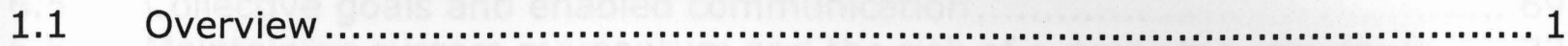

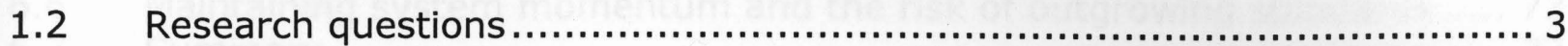

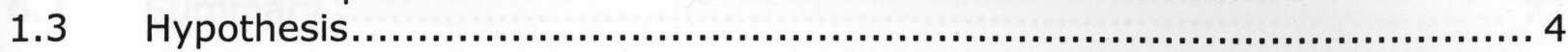

Chapter 2: Research Methodology ...................................................... 5

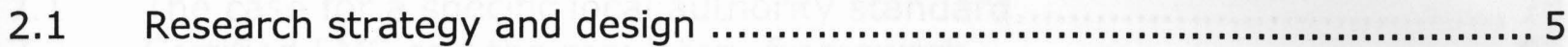

$2.2 \quad$ Literature reviewed .................................................................. 6

2.3 City of Calgary case study ......................................................... 7

2.4 Additional sources of primary information and feedback .................... 10

$2.5 \quad$ Limitations and considerations .................................................. 11

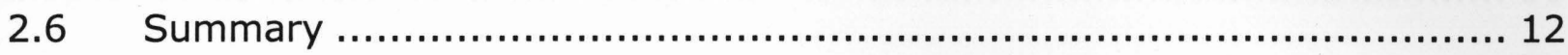

Chapter 3: EMS and Local Authorities ................................................ 13

3.1 Environmental management systems (EMS) .............................. 13

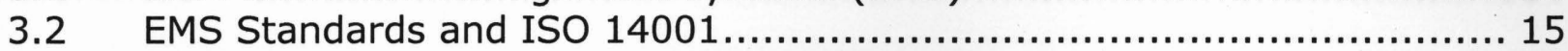

3.3 Local authority adoption of the EMS approach .............................. 19

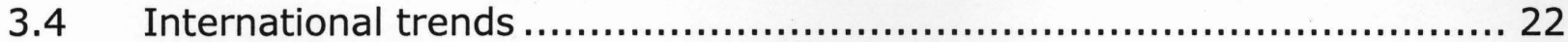

3.5 North American trends ............................................................. 25

3.6 Limited exceptional cases .................................................... 29

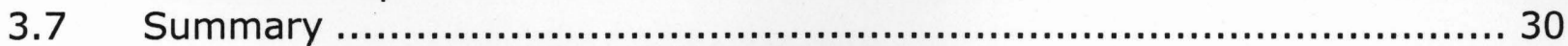

Chapter 4: Standards and Certification for Local Authorities as Learning

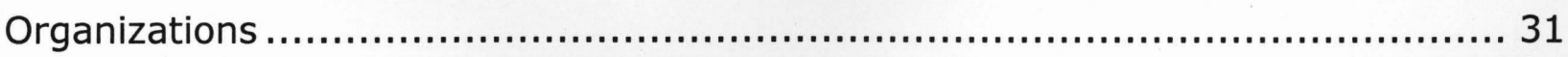

4.1 Standards and assurance through certification .............................. 31

4.2 Effective learning organizations ............................................... 33

$4.3 \quad$ Local authority characteristics ............................................... 36

4.4 Certification as a surrogate force for local authorities ......................... 40

4.5 The challenges of certification to a standard................................... 41

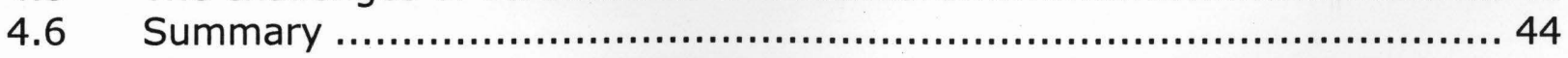

Chapter 5: City of Calgary Case Study ............................................... 45

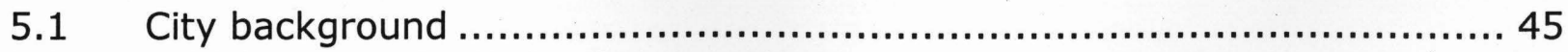

5.2 Initial driver of EMS implementation ......................................... 47

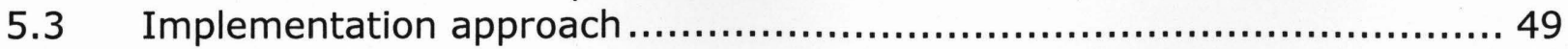

5.4 Resources and reorganization.................................................. 50 
5.5 Performance outcomes ...................................................... 53

5.6 Accountability and culture of auditing .......................................... 56

5.7 Systems integration and regulatory interactions ............................ 59

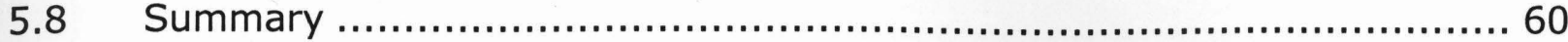

Chapter 6: Observations and Implications for Local Authorities ..................... 61

6.1 Costs and environment as a priority ......................................... 61

6.2 Regulatory versus non-regulatory drivers ..................................... 64

6.3 Value in auditing to standard ................................................... 66

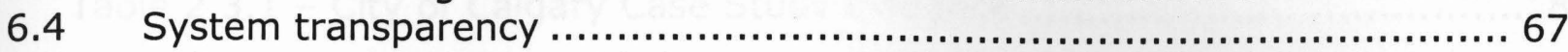

6.5 Collective goals and enabled communication ................................... 69

6.6 Maintaining system momentum and the risk of outgrowing standards ..... 73

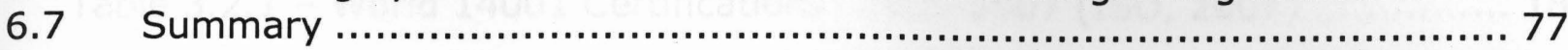

Chapter 7: Further Research Applications …......................................... 78

7.1 The case for a specific local authority standard ................................. 78

7.2 Certified EMS and the regulatory framework ................................. 81

7.3 LA cooperation and facilitation of EMS in the sector ......................... 86

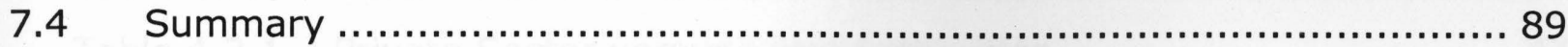

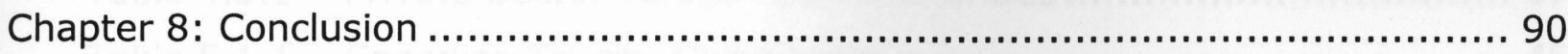

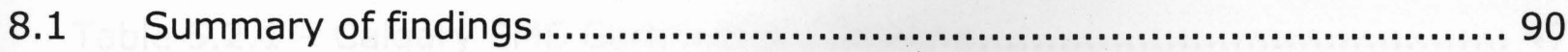

8.2 Research continuity ........................................................... 91

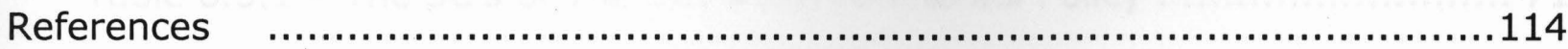




\section{LIST OF TABLES}

Table 2.1.1 - Denzin's four types of triangulation (Denzin, 1978) ................ 6

Table 2.2.1 - List of Literature Types Reviewed .................................... 7

Table 2.3.1 - City of Calgary Case Study Evidence ................................. 8

Table 2.4.1 - Local Authorities Contributing Primary Resources................... 10

Table 3.2.1 - World 14001 Certifications; 2005-2007 (ISO, 2007) .............. 18

Table 3.3.1 - Examples of LA Reported Drivers Towards Use of EMS ........... 20

Table 3.4.1 - World 14001 Certifications as of 2007 (ISO, 2007) ................ 24

Table 3.5.1 - EPA Office of Wastewater Management Study Participants ....... 26

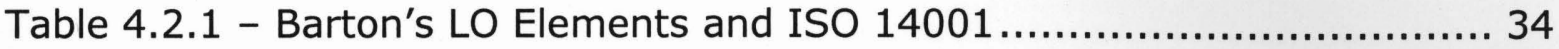

Table 4.3.1 - Private Sector versus Local Authorities ........................... 37

Table 5.1.1 - Canadian Tri-city Comparison........................................ 45

Table 5.2.1 - Calgary EMS Certification Timeline ................................ 47

Table 6.5.1 - The 3C's of The City's Environmental Policy ........................ 71 


\section{LIST OF FIGURES}

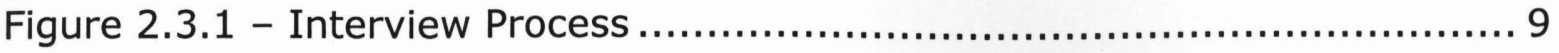

Figure 3.1 .1 - Continual Improvement Cycle ................................... 14

Figure 3.2.1 - ISO 14001 Framework (PEER, 2008) ............................. 17

Figure 4.2.1 - Types of Formalization .......................................... 34

Figure 6.6.1 - Direction of Learning Over Time .................................... 74

Figure 7.2.1 - Conclusions on EMS-Policy Interactions .......................... 85 


\section{List Of APPEndices}

Appendix A Yin's Types of Evidence .............................................. 93

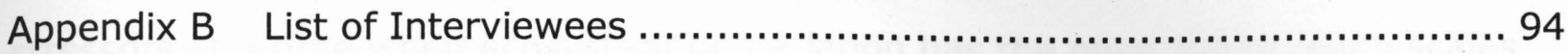

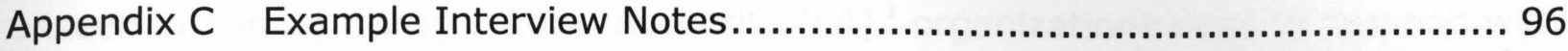

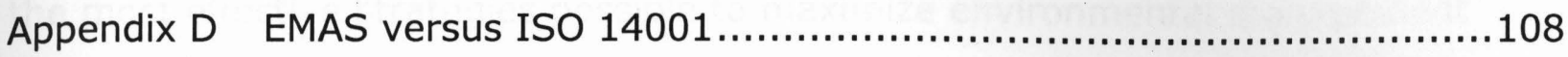

Appendix E ISO 14001 Elements ..................................................

Appendix F Selected Local Authorities: EMS Status ..............................110

Appendix G City of Calgary Organizational Structure ...............................112

Appendix H City of Calgary Environmental \& Safety Management Unit ...........113 


\section{Chapter One: Introduction}

\subsection{Overview}

Urban areas are a focal point for the center of the world's environmental stressors at a time when ecosystem degradation has the potential to reach scales unseen in human history. Local Authority (LA) ${ }^{1}$ organizations need to respond with the most effective strategies possible to maximize environmental management results and minimize harmful impacts. As is well stated in the Aalborg Charter of European Cities and Towns Towards Sustainability:

"...the city or town is both the largest unit capable of initially addressing the many urban architectural, social, economic, political, natural resource and environmental imbalances damaging our modern world and the smallest scale at which problems can be meaningfully resolved in an integrated, holistic and sustainable fashion... Therefore, cities and towns are key players in the process of changing lifestyles, production, consumption and spatial patterns."

Governments at the local level carry an incredible burden of hard service delivery with high environmental significance. In the context of growing populations, a need for infrastructure investments, and tightening budgetary constraints, LAs face unprecedented challenges.

In the private sector, a voluntary third party certified Environmental Management System (EMS) is a relatively prominent tool used particularly frequently by large companies in the private sector (ISO, 2007) with comparably intensive and environmentally significant operations. EMSs are typically voluntary in nature and give organizations the option to receive third party certification to established standards, a much different approach than command and control regulations. Drivers of EMS certification amongst private sector firms have been

\footnotetext{
${ }^{1}$ In the context of this paper, a local authority is meant to refer to the corporate administrative public organization in each city or town, and is abbreviated simply as LA.

${ }^{2}$ As approved by the participants at the European Conference on Sustainable Cities \& Towns in Aalborg, Denmark on 27 May 1994. Available at: ec.europa.eu/environment/urban/pdf/aalborg_charter.pdf
} 
normative in nature, while in the LA sector these drivers do not seem to be as compelling. Existing instances of LAs fully embracing third party certified EMSs are extremely rare. In these rare cases, initial drivers seem to have originated externally via regulatory action or government incentives, and served as a catalyst for systemic change ${ }^{3}$. Meanwhile, in the majority of instances of LA EMS usage worldwide, scope is limited to individual operational units or facilities, and many do not fully embrace the certification potential that an EMS offers.

This thesis highlights international trends but then penetrates into the North American situation. Here, a case study of the City of Calgary ${ }^{4}$ (Calgary) is used to answer research questions about third party certification of LAs and test hypotheses. Calgary is the first North American city to receive certification to the world's leading EMS standard, ISO 14001. The unique experiences of Calgary and a small set of other LAs provide a research opportunity to ask questions and test hypotheses about why they have adopted such a unique approach, how they have approached it, and what can be learned from their experiences.

Evidence to be presented suggests that a third party certified EMS is most likely to succeed in more organizationally complex LAs and where a certain level of preexisting environmental awareness and interest is present from public stakeholders. However, considerable potential is also present for adopters to misunderstand the fundamental offerings of EMS standards and third party auditing, and thereby miss out on both viable management measures and learning opportunities. An effective learning organization uses EMS certification as a tool to enhance underlying processes but continues to challenge norms. Of critical importance is an organization's recognition of the risk of losing system momentum if certification to a standard ceases to be a tool for improvement and becomes an end in itself.

Amongst LAs, peer-to-peer transmission of relevant resources and success factors has been facilitated by a limited number of government-backed projects in Europe and the US, yet it will be argued that this approach has not been emphasized enough. In Canada for instance, where LA leadership on an

\footnotetext{
${ }^{3}$ Table 3.3.1 lists the leading drivers among some prominent LA EMS examples.

4 "Calgary" is used from this point on to refer to the entire corporate entity of the City of Calgary. "The City" is also used within the case study to refer to the same meaning from a Calgary perspective.
} 
international scale exists, peers stand to benefit from additional incentives and/or cooperation.

The inherent characteristics of LA organizations that contrast with those found in the private sector are found to be relevant in identifying unique strengths and challenges for implementation. Most significantly, LAs are not subject to the same market pressure that propels the for-profit sector. Trends of increased population mobility and public environmental concern have lead to the recent emergence of cross-city comparisons, particularly on environmental performance issues, compounding the potential that competitive pressure could exert on LA organizations moving forward. Third party certification is a particularly useful discipline for LAs in this regard as it can be used as a surrogate force of competition to heighten commitment to environmental priorities; to increase transparency and accountability; and, to enable collective problem solving.

\subsection{Research questions}

The following questions are central to the research conducted and integral to the presentation of relevant literature, case study, additional research, and resulting observations.

i. What are the trends in LA adoption of third party certified EMSs?

ii. What are the driving factors behind decisions to certify?

iii. What unique characteristics do Local Authorities (LAs) have that factor in to the appropriateness of third party certified EMS for LAs in particular?

iv. What challenges do LAs face in implementation of a third party certified EMS?

v. What strategies might be used to overcome or minimize these LA-specific challenges? 
vi. How might the certification process be used to overcome organizational learning barriers or how might it reinforce them?

vii. What can an in-depth look at the unique case of Calgary reveal about these questions?

\subsection{Hypothesis}

The hypothesis being tested throughout the research paper is summarized as follows:

LAs have inherent organizational challenges which position them particularly well to benefit from third party certification to an external EMS standard. 


\section{Chapter 2: Research Methodology}

This chapter aims to provide an overview of the methodological approaches used in the conducting the research that is the basis for this paper.

\subsection{Research strategy and design}

The research strategy is built around conducting a primary case study of Calgary, supplemented by examinations of other North American cities from which similarities and differences are drawn. An initial starting point was identifying the uniqueness of Calgary's situation - as the first city in North America to receive ISO 14001 certification. Once it was clear that there was a lack of existing academic research on Calgary's situation or cities in similar situations, a strategy was devised to further explore the phenomenon through several research methods. While significant time was spent studying the Calgary experience and some observations rely significantly on this single case study, it remains only one component of the methodology employed. Interviews with a variety of actors familiar with Calgary's system were complemented by significant similar contributions from outside city counterparts.

Local authorities are complex organizations made up of a hierarchy of officials, managers, and staff. In order to study how they are responding to internal and external pressures, a variety of perspectives must be considered. A multifaceted approach has been recognized in the social sciences as a superior way to address complex research questions (Becker, 1996) and is the approach taken here. In particular the concept of triangulation is employed, which has been defined as an "attempt to map out, or explain more fully, the richness and complexity of human behavior by studying it from more than one standpoint" (Cohen \& Manion, 1986). According to Altrichter et al. (1996), triangulation "gives a more detailed and balanced picture of the situation", and Stake (1995) has stated that proper triangulation can ensure accuracy and enables the exploration of alternative explanations. The concept, as we shall see, is applied to increase reliability of data within the Calgary case study as well as in gaining broader insights about the 
framework of local authority organizations and other applications of the ISO 14001 standard relevant to the research questions.

Table 2.3.1 presents Denzin's (1978) four basic types of triangulation.

Table 2.1.1 - Denzin's four types of triangulation (Denzin, 1978)

\begin{tabular}{|l|l|}
\hline Data triangulation & involves time, space, and persons \\
\hline $\begin{array}{l}\text { Investigator } \\
\text { triangulation }\end{array}$ & $\begin{array}{l}\text { involves multiple researchers in an } \\
\text { investigation }\end{array}$ \\
\hline Theory triangulation & $\begin{array}{l}\text { involves using more than one } \\
\text { theoretical scheme in the } \\
\text { interpretation of the phenomenon }\end{array}$ \\
\hline $\begin{array}{l}\text { Methodological } \\
\text { triangulation }\end{array}$ & $\begin{array}{l}\text { involves using more than one } \\
\text { method to gather data }\end{array}$ \\
\hline
\end{tabular}

It was not possible to utilize the second type, because the research for the paper was conducted by one person. However, by looking extensively at other case studies in the literature reviewed it was possible to compare and contrast findings with the primary Calgary case study using theoretical replication logic (Yin, 1994) of case study methodology.

The remaining three types of triangulation were employed to the greatest extent possible. The first and fourth types, data and methodological, are discussed in subsequent sections. In this paper, theory triangulation proved to be an optimal research approach as it enabled the combined use of theoretical lenses of management systems; standards and certifications; and, learning organizations; thus, theory generated significant contributions to the paper.

\subsection{Literature reviewed}

Literature reviewed focused on the fields of EMS, private standards, learning theory, and where these fields overlap with LA organizations and operations. Table 2.2.1 introduces a list of the types of literature that were explored in order to draw as complete a picture as possible representing the issues discussed in this paper. 
Table 2.2.1 - List of Literature Types Reviewed

\begin{tabular}{|l|}
\hline Peer reviewed journal articles \\
\hline Books on fields of focus \\
\hline Internal local authority documents and reports \\
\hline Publicly available local authority information- websites, annual reports \\
\hline EMS certification survey data \\
\hline Higher level government documents with local level implications \\
\hline Municipal EMS feasibility studies \\
\hline
\end{tabular}

Peer-reviewed journal articles were a preferred source of information where possible. However, many of the questions being asked required information of a qualitative nature, which is unavailable in published articles. Further, the relatively recent emergence of EMS standards in the local authority sector made it necessary to seek out the most current data possible. Therefore screening criteria was opened to include unconventional literature sources in the form of certification surveys, local authority reports, and higher level government reports, which were drawn from as a necessary recourse for primary sources.

Moreover, it was decided rather than include a separate "Literature Review" chapter to cover all relevant literature in one section, it is most effective to cover the most relevant literature in both chapters 3 (EMS and Local Authorities) and 4 (Standards and Certification for Local Authorities as Learning Organizations). In the latter it is necessary to add a degree of theoretical analysis where appropriate.

\subsection{City of Calgary case study}

A case study approach was used to assess the experience of a third party certified EMS in Calgary. Yin (1994) asserts that single cases may be used to confirm or challenge a theory, or to represent a unique or extreme case (Yin, 1994). Calgary's case offers a real opportunity to reveal implications from a phenomenon that has been hitherto inaccessible (a North American city with several years experience with a third party certified EMS). The case study is an ideal methodology when a holistic, in-depth investigation is needed (Feagin et al., 
1991). In order to arrive at valid ${ }^{5}$ observations with such a limited sample, this thorough look at Calgary was necessary.

Table 2.3.2 shows an overview of the sources of evidence that comprise the Calgary case study:

Table 2.3.1 - City of Calgary Case Study Evidence

\begin{tabular}{|c|c|}
\hline $\begin{array}{l}\text { Source of } \\
\text { Evidence }\end{array}$ & Examples \\
\hline Documentation & 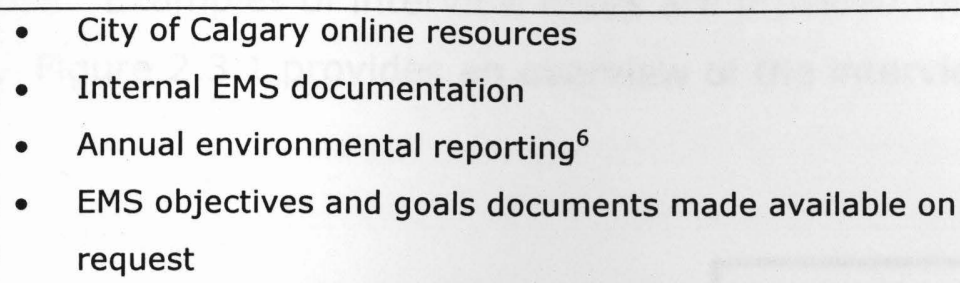 \\
\hline Interviews $^{7}$ & $\begin{array}{l}\text { - } \text { City staff from various units (Environmental \& Safety } \\
\text { Management, Water, Waste, Parks, Transit) } \\
\text { - } \text { Former employees } \\
\text { - EMS experts from other cities able to comment on } \\
\text { Calgary experience }\end{array}$ \\
\hline
\end{tabular}

The two main sources of evidence were documentation and interviews. Appendix A shows Yin's (1994) classification of types of evidence along with their associated strengths and weaknesses. It is clear that no single source has an absolute advantage; however, a review of the use of documentation and interview sources for evidence demonstrates that each has significant strengths that complement the other when used in tandem.

In addition, the ability to secure cooperation of city staff in wide ranging operational units ${ }^{9}$ was essential to realizing research potential, and in particular

${ }^{5}$ Validity has been defined by Cook and Campbell (1979) as the "best available approximation to the truth or falsity of a given inference, proposition or conclusion."

${ }^{6}$ Of which in multiple cases was provided in advance of public release.

${ }^{7}$ For a full list of people interviewed see Appendix B.

${ }^{8}$ Staff to be interviewed were identified based upon considering (a) attempting to speak with at least one person in each hard service operational area; (b) suggestions from interviewees in chronological order (asking who would be best to speak about $\mathrm{x}$ issue as issue came up); and (c) in identifying most relevant staff from documentation examined.

${ }^{9}$ For a full list of people interviewed see Appendix B. 
provided the chance to conduct interviews. Given the heavy reliance on interview data, an approach that maximized contributions to research objectives was utilized. Semi-structured interviews were employed due to the advantages of that approach: allowing spontaneity, reducing ambiguity, and facilitating follow-ups for relevant findings (Silverman, 2000). An ethics application included examples of lines of questioning, and was submitted and approved in the spring of 2008. Interview guides were then configured on a case-by-case basis depending on the anticipated interviewee area of expertise. Examples of interview notes are provided for reference in Appendix $\mathrm{C}^{10}$. Figure 2.3.1 provides an overview of the interview process:

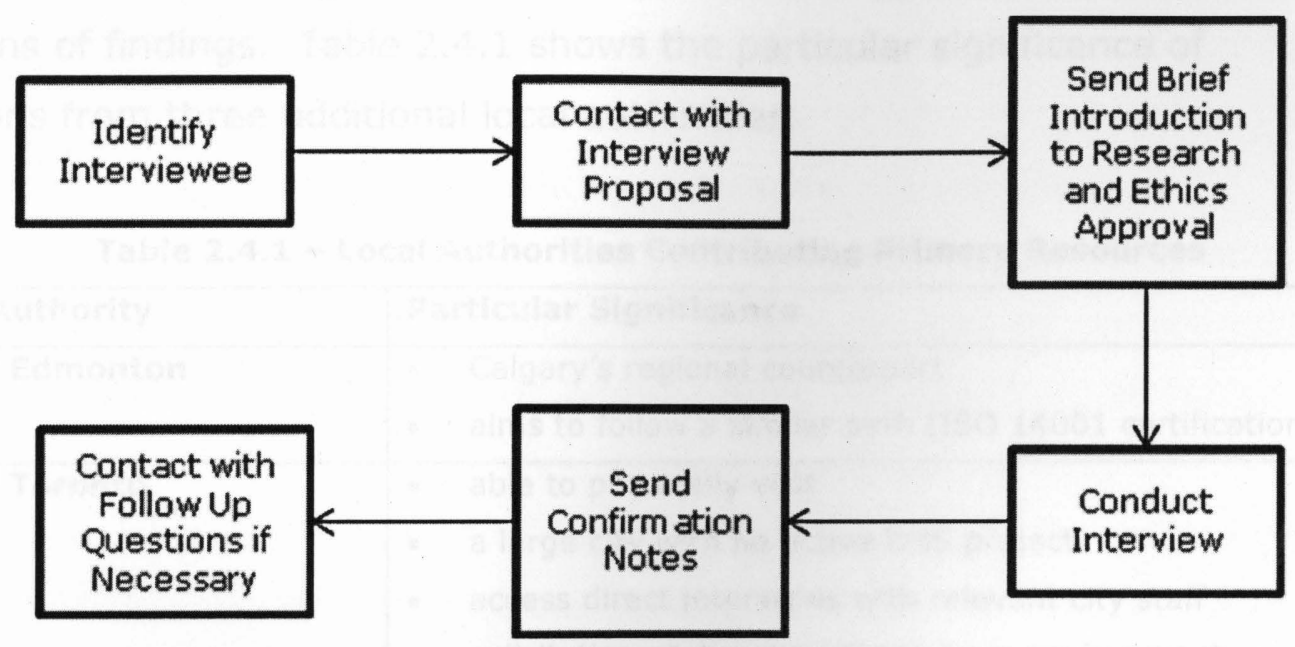

Figure 2.3.1 - Interview Process

A crucial step in the interview process was the sending of notes taken during the interview process back to the interviewee for explicit confirmation of accuracy and consent. This was seen to further ensure reliability of data collected.

One limitation of the study was the inability to physically visit the city, due to its distance from the Toronto area. However, in considering this weakness, it is not felt to be so substantial as to significantly hinder observations. Steps were taken in order to counteract the drawbacks of not conducting a site visit: (a) multiple

\footnotetext{
${ }^{10}$ Three examples are provided: one from Calgary, one from Scottsdale, and one from Edmonton. Names and personal information have been removed.
} 
interviews were conducted; and (b) investigation in to activities of and correspondence with local NGOs were considered as an additional perspective.

Overall the case study benefited from having full cooperation from Calgary officials and staff. With careful attention given to triangulate data where possible, weaknesses in direct observation were overcome. Calgary presents the situation of a medium to large sized city on an international scale, with results especially applicable to many similarly sized local authorities.

\subsection{Additional sources of primary information and feedback}

After conducting the case study with Calgary, it was crucial to gain further perspective from similar organizations in order to test hypotheses and explore explanations of findings. Table 2.4.1 shows the particular significance of contributions from three additional local authorities.

Table 2.4.1 - Local Authorities Contributing Primary Resources

\begin{tabular}{|c|c|}
\hline Local Authority & Particular Significance \\
\hline City of Edmonton & $\begin{array}{l}\text { - } \quad \text { Calgary's regional counterpart } \\
\text { - } \quad \text { aims to follow a similar path (ISO } 14001 \text { certification) }\end{array}$ \\
\hline City of Toronto & $\begin{array}{l}\text { - } \text { able to physically visit } \\
\text { - a large city with no active EMS project } \\
\text { - } \text { access direct interviews with relevant city staff } \\
\text { - } \quad \text { solicitation of direct feedback from environment } \\
\text { committee on preliminary findings }\end{array}$ \\
\hline City of Scottsdale & $\begin{array}{l}\text { - second city in North America to implement city-wide } \\
\text { EMS } \\
\text { contrasts Calgary's approach in not seeking third-party } \\
\text { certification }\end{array}$ \\
\hline
\end{tabular}

The three cities all have contrasting situations shown under Table 2.4.1's "Particular Significance" column, which bring complementary perspectives to this paper. Sources of evidence in the cases of Edmonton and Scottsdale comprised of phone interviews of at least an hour length each. For Toronto, multiple physical 
visits were possible as well as a presentation ${ }^{11}$ to the Executive Environment Team $^{12}$. Appendix $B$ includes a complete list of persons interviewed.

\subsection{Limitations and considerations}

Significant research limitations can be categorized into three groups: (1) heavy reliance on local authority staff testimony; (2) jurisdictional differences in local authority government structure; and (3) language barriers in the literature.

Given the first limitation, a degree of skepticism is called for in examining information provided voluntarily, for there are potential biases. In particular with respect to assessing the value of EMS standards, interviewees could be influenced by a "rhetoric of success" described by Zbaracki (1998) as an opaque veil of politically correct statements behind which any weaknesses in the system could be dissimulated. That is not to say that all reported information is to be discounted; only that alternative explanations should be considered as possible.

Second, when drawing conclusions about the state of local authority adoption of standards and environmental management in general, it must be considered that government structures at the local and higher levels influence local authority organizations. The inter-city differences can vary in degree but may be relevant to any comparisons drawn. Examples of possible relevant differences include varying degrees of political representation versus bureaucratic authority; influence and/or control from higher levels of government; legislative and regulatory frameworks; and the ability to generate revenues.

Third, literature review conducted, as well as contact with relevant local authorities, was restricted to correspondence in the English language. Potentially valuable information in other languages could not be considered valid and represents an interesting avenue for future study. For example, in section 3.4 Asia

${ }^{11}$ Presentation took place on Tuesday June 17 2008, was roughly 20-30 minutes in duration, and was executed with Dr. Kernaghan Webb from Ryerson University.

12 More information on this Toronto committee is available at http://www.toronto.ca/teo/environment-team.htm "The Executive Environment Team provides strategic leadership on environmental sustainability issues for the City of Toronto. Chaired by Deputy City Manager Richard Butts, the team includes senior managers from all City Divisions, Agencies, Boards and Commissions with responsibility for significant environmental initiatives including Toronto Water, Transportation and Solid Waste." 
is shown to be a major area of growth in ISO 14001 certifications; yet, it is difficult to obtain relevant English documentation on possible local EMS applications.

\subsection{Summary}

A multifaceted research strategy has been devised and employed that builds on the case study approach used to explore the Calgary experience. Triangulating evidence was obtained from a review of relevant literature and considering feedback from additional local authorities and experts. Some weaknesses and limitations of the research methodology have been identified and have been considered in the presentation of subsequent observations. 


\section{Chapter 3: EMS AND Local Authorities}

The goals of this chapter are fourfold: (1) to define EMSs and explore their most important concepts; (2) to introduce the significance of the most prolific standards; (3) to explain why and how local authorities are currently using EMSs; and (4) to explain why the incidence of LAs with fully scoped and certified EMSs is very limited.

\subsection{Environmental management systems (EMS)}

Increasing public concern for environmental degradation over the last century and the corresponding higher regulatory standards has precipitated a response by organizations of moving towards proactive environmental management practices. The term "environmental management" does not mean that the environment can be managed, rather that institutions and organizations can be managed so as to achieve desired environmental outcomes (Krut \& Gleckman, 1998). Command and control regulations in the 1970 s, risk management efforts in the early 1980 s, and attempts to fashion international environmental protocols in the late 1980 s led organizations to recognize that preventing pollution is preferable to mitigation after the fact (Block, 2006). In seeking out tools to implement change, organizations have looked for the environmental equivalent to what has been used with regards to quality, in management systems. Management systems aim primarily to ensure that organizations have a structured approach for ensuring that objectives are established. It follows that plans are made to achieve those objectives, those plans are implemented, and the results are measured in order to track achievements of planned objectives. This creates an environment in which, correction and improvement can take place, where organizations can learn from mistakes in order to continually improve.

EMSs are a subset of management systems in general, essentially "formal structures of rules and resources that managers adopt to establish organizational routines that help achieve corporate environmental goals" (Coglianese \& Nash, 2001). The structured approach aims to successfully integrate continual 
improvement of environmental management. Figure 3.1.1 illustrates the theory behind the continual improvement approach as applied to EMS.

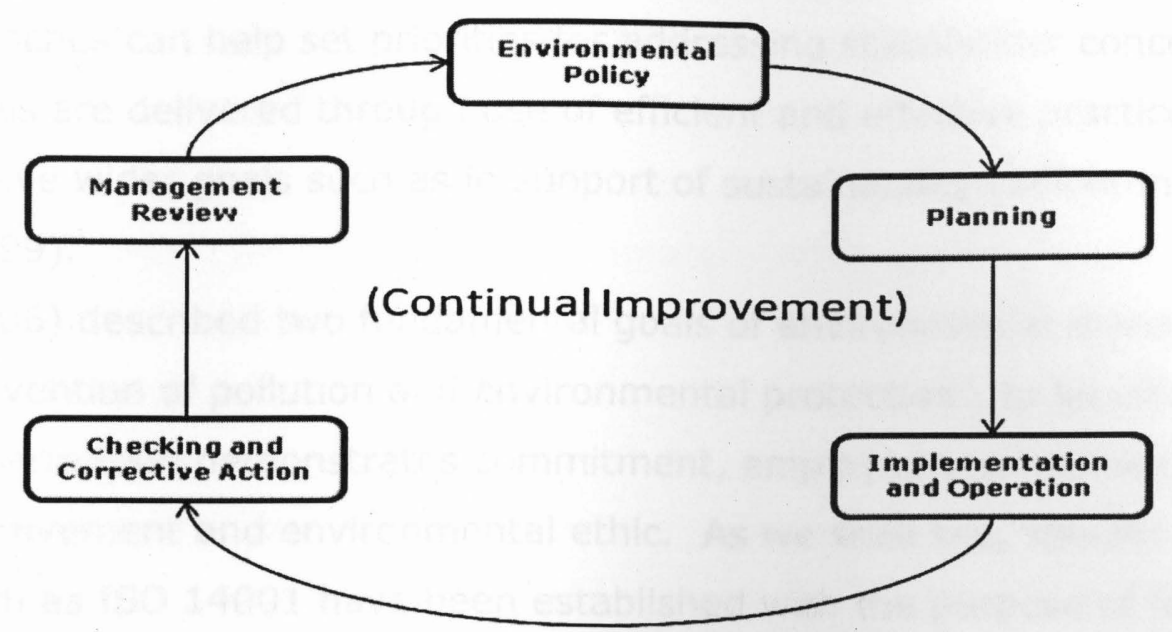

Figure 3.1.1 - Continual Improvement Cycle

Processes represented in these five stages fit the definition of an EMS as a transparent, systematic process, applied by setting and implementing goals, policies and responsibilities, as well as regular auditing of included elements (Steger, 2000). This formal, but voluntary, approach to dealing with environmental aspects enables an organization to work towards customized policy goals and in particular enhance risk management as defined by the organization.

EMSs have become a commonplace tool for environmental managers in the private sector (ISO, 2007). As with any management system, it is a tool, and outcomes depend entirely on inputs and implementation. Commentators have noted that adopting an EMS does not necessarily lead to environmental performance gains (Burström, 2000). It is well documented that implementing an EMS does not necessarily mean establishing absolute targets or even absolute legal compliance (Keen \& Sullivan, 2005). That said, underlying the use of EMSs is the tacit assumption that there is value in any organization adopting a formal framework for decision-making and action in addressing environmental impacts (as opposed to an entirely informal and ad hoc process). According to the International Organisation for Standardisation (ISO), potential benefits from the use of EMSs include reduced waste management costs; savings in consumption of energy and 
material; lowered distribution costs; improved image among regulators, customers and the public; and a framework for continual improvement of environmental performance (ISO, 2009). Commentators have also suggested that management system approaches can help set priorities for addressing stakeholder concerns, ensure services are delivered through use of efficient and effective practices, and can help achieve wider goals such as in support of sustainability (Bekkering \& McCallum, 1999).

Block (2006) described two fundamental goals of environmental management systems, "prevention of pollution and environmental protection", to be effective only if the organization demonstrates commitment, employee involvement, continual improvement and environmental ethic. As we shall see, specific standards such as ISO 14001 have been established with the purpose of facilitating an assurance to managers and stakeholders that these concepts are being implemented.

\subsection{EMS Standards and ISO 14001}

The increasing use of EMS has relied on external standards to provide a framework from which systems are ultimately developed internally. Standards can be used to assure outsiders that certain elements are contained within the system. At this point an understanding of the most successful EMS standards is necessary. A more theoretical discussion of standards is found in Section 4.1.

Two generic ${ }^{13}$ EMS standards stand out as the most used and cited: ISO 14001 standard and the European Union's Eco-Management and Audit Scheme (EMAS). Appendix $D$ shows the specific differences between the two standards. The sum of the differences can be summarized in labelling EMAS as a standard with greater emphasis on consultation and reporting to the public. EMAS has mainly European

\footnotetext{
13 "Generic" is meant to exclude industry specific standards such as the American Chemistry Council's Responsible Care program. In the case of Responsible Care members have two certification options, one of which is RC14001, which combines the original Responsible Care Management system and ISO 14001 into a single process. Per American Chemistry Council website, Responsible Care Management Systems and Certification, at: http://www.americanchemistry.com/s_responsiblecare/

* It is also not uncommon for sector specific environmental standards to explicitly draw on ISO 14001.
} 
regional significance ${ }^{14}$, and still uses an approach that expressly draws on ISO 14001.

ISO 14001 is part of the ISO 14000 series of environmental management systems standards developed by the International Organization for Standardization (ISO). The 14000 series of standards attempt to formally structure voluntary efforts to go beyond what is required by law. Corbett and Kirsch (2000) emphasize that while the ISO 14001 standard should ultimately affect environmental performance, it is firstly a business standard used to manage one aspect of operations. The organization uses its own discretion to determine how the standard elements are specifically designed to fit in to the rest of its activities.

A brief introduction to the standard provides a context for further discussion and the criticisms that have been levied. Using key headings from the standard itself, the table in Appendix E provides an indication of the key elements underlying the ISO 14001 approach, including the establishment of an appropriate framework for decision-making and operation (through policies, plans, legal compliance, objectives and programs), followed by implementation (from training, communication, and emergency preparedness, through to measuring, monitoring, verifying, documenting, and improving). Figure 3.2.1 shows how these elements are conceptually linked together in the standard.

${ }^{14}$ The EMAS standard is more commonly found in European countries, For example, when measured in June 2001, Germany had 2666 of the 3937 EMAS registered site in Europe. (Morrow \& Rondinelli, 2002). This is likely because of endorsement by EU governments who have given the standard special recognition in their respective legal frameworks. 


\section{ISO 14001 Framework}

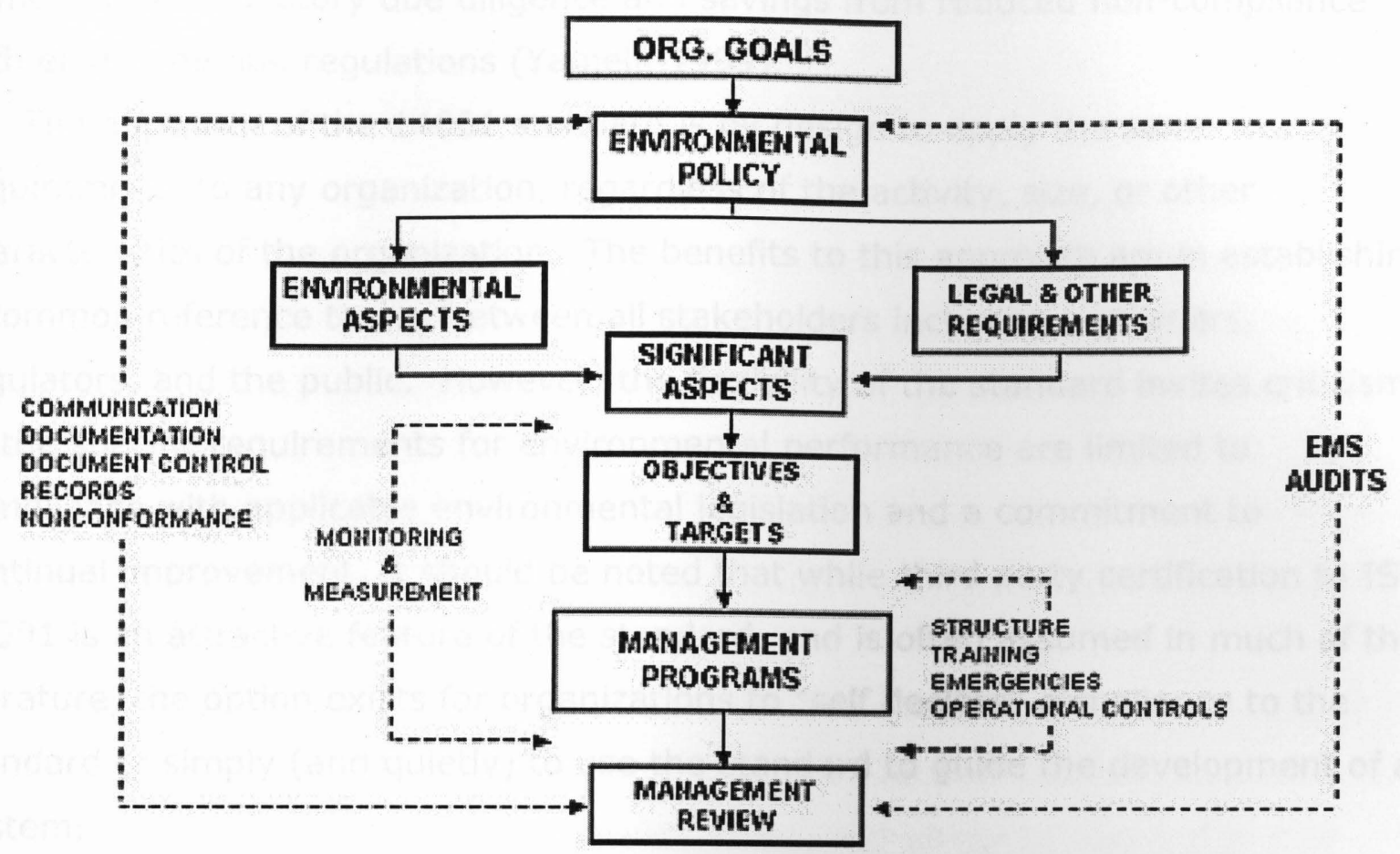

Figure 3.2.1 - ISO 14001 Framework (PEER, 2008)

The figure makes clear the feedback loops between monitoring and reporting against objectives and targets, leading to management review, appropriate midcourse corrections of the overall environmental process, and eventually, a resulting reflection in the adjustments in the organization's environmental policy.

The most prominent criticism of industry adoption of EMSs using the 14001 standard is that the standard has no absolute performance improvement requirements (Netherwood, 1996; Sheldon, 1997; Von Malmborg, 2003; Keen \& Sullivan, 2005). Levett (1996) was one of the first to point out that with regards to actual environmental performance; outcomes are highly dependent on subjective decisions about what constitutes system inputs. An organization can choose what to include in their system policy and scope. This complicates the possibility of objectively measuring effects on environmental performance. A preliminary investigation launched after the standard had been in use for several years found only some data to support the conclusion that environmental performance gains 
can be realized through EMS certification to any extent (Steger, 2000). A typical reported benefit associated with implementing ISO 14001 has been an ability to demonstrate regulatory due diligence and savings from reduced non-compliance with environmental regulations (Yamell, 1999).

The approach of the 14001 standard is by design to apply the same requirements to any organization, regardless of the activity, size, or other characteristics of the organization. The benefits to this approach are in establishing a common reference to use between all stakeholders including customers, regulators, and the public. However, the flexibility of the standard invites criticism as the specific requirements for environmental performance are limited to compliance with applicable environmental legislation and a commitment to continual improvement. It should be noted that while third party certification to ISO 14001 is an attractive feature of the standard, and is often assumed in much of the literature, the option exists for organizations to "self declare" compliance to the standard or simply (and quietly) to use the standard to guide the development of a system.

In the early 2000s evidence emerged that ISO 14001 had become the leading EMS standard used in the world (Morrow \& Rondinelli, 2002). Broadly across sectors, the use of the ISO 14001 standard worldwide continues to grow, with registrations increasing over 5\% per year since 2005 (as shown in Table 3.2.1).

Table 3.2.1 - World 14001 Certifications; 2005-2007 (ISO, 2007)

\begin{tabular}{|l|l|l|l|l|}
\hline \multirow{2}{*}{$\begin{array}{l}\text { World } \\
\text { Results }\end{array}$} & \multicolumn{2}{|c|}{ Dec 2005 } & \multirow{2}{*}{ Dec 2006 } & Dec 2007 \\
\cline { 2 - 5 } & total & $\begin{array}{l}\text { Of which } \\
\mathbf{1 4 0 0 1 : 2 0 0 4}\end{array}$ & 128211 & 154572 \\
\hline World total & 111162 & 56593 & 17049 & 26361 \\
\hline $\begin{array}{l}\text { World } \\
\text { growth }\end{array}$ & 21225 & 107 & 140 & 148 \\
\hline $\begin{array}{l}\text { Number of } \\
\text { countries / } \\
\text { economies }\end{array}$ & 138 & & & \\
\hline
\end{tabular}

This suggests the standard is proving useful, at least in industry, and will have longevity as a tool for environmental management. ISO 14001 will for the most 
part be the standard focused on in this paper, although European use of EMAS will be revisited when broadening to an international scope in section 3.4.

\subsection{Local authority adoption of the EMS approach}

The average population size of the world's one hundred largest cities has more than tripled since 1950 . The next thirty years is likely to see an additional two billion people added to cities in the developing world alone (World Bank, 2008). By 2010 more than half the world's population will live in urban areas, of which seventy five percent will be in more developed countries (United Nations, 2007). Cities and the respective local authorities will have to contend with the effects of growth in population and local consumption and the resulting immense demands and pressures on regional ecosystems.

At least in North America, one can currently identify a trend of devolution of powers to the municipal level. In Canada, the delegation of federal and provincial responsibilities to municipalities has constrained their ability to respond to new stresses while investing in infrastructure renewal. Reforms across the country have tended towards "downloading" of responsibilities, often without financial compensation, and also a shifting of governmental authority to the regional level (Greenbaum \& Wellington, 2008). In the United States, the limited capacity of cities to finance urban physical infrastructure has contributed to what has been within the US itself described as an "infrastructure crisis" (Pagano \& Perry, 2008). These trends are likely to continue as the public sector contends with growing deficits and debt.

Within the broad category of public sector organizations, local authorities are in many ways on the "front line" in terms of addressing environmental impacts: municipalities often have significant responsibilities with respect to such activities as: water supply; waste-water treatment; public transportation and overall transportation infrastructure; recycling; garbage collection and disposal; energy supply; parks maintenance; and land use planning. Given the high environmental and regulatory burden associated with these hard services, it is logical to expect 
local authorities to look to the same tools as any other set of organizations facing similar pressures.

EMS is one such tool available to local authorities, yet it has traditionally seen the majority of its use in the private sector. An indication of this lies in the fact that while certification to ISO $14001^{15}$ is well known in the business community, it is considerably less common among local government authorities (UNEP, 2000). Internationally, studies indicate that the number of local authorities with an EMS registered with a certifying body is very small compared to organizations in the private sector (UNEP, 2000). An organizational analysis of the suitability of EMS standards for LAs follows in Chapter 4. At this point, it is enough to make clear that there appear to be no insurmountable barriers for municipalities and cities to achieve benefits from the use of EMS.

Anecdotal (case study) evidence suggests that the number of local authorities adopting EMSs is increasing, particularly in Europe and North America (Lozano \& Valls, 2007; Emilsson \& Hjelm, 2002; Burström, 2000; Bekkering \& McCallum, 1999). Primary and secondary research suggests two different driving reasons for this: (a) EMS offers a diligent way to respond to regulatory pressures; and (b) use of EMS is a political decision by City Council or in response to political decisions made by higher levels of government. Table 3.3.1 cites local authority examples for adopting an EMS approach.

Table 3.3.1 - Examples of LA Reported Drivers Towards Use of EMS

\begin{tabular}{|l|l|}
\hline City / Region & Leading Drivers \\
\hline New Zealand (various) & Evidence of due diligence, identify \\
& resource cost savings, improve \\
& resource consent management \\
processes, set example, assist with \\
legislative compliance (Cockrean, \\
$2000)$
\end{tabular}

${ }^{15}$ The terms "certification" and "registration" are often used interchangeably in the industry to refer to an EMS that has successfully been audited by a third party against a standard such as ISO 14001 or EMAS. In this article we use "certification" for this purpose, and "registration" in a broader sense to include other potential recognition of an EMS such as local government regulatory recognition. 


\begin{tabular}{|l|l|}
\hline Vasteras, Sweden & $\begin{array}{l}\text { "To obtain more comprehensive and } \\
\text { appropriate" environmental } \\
\text { management (Burstrom, 2000) }\end{array}$ \\
\hline Newcastle (UK) & $\begin{array}{l}\text { City Council decision; mainly } \\
\text { external, (indirect) pressure from } \\
\text { national level encouragement } \\
\text { (Emilsson \& Hjelm, 2004) }\end{array}$ \\
\hline Gothenberg (Sweden) & $\begin{array}{l}\text { Internal City Council decision } \\
\text { (Emilsson \& Hjelm, 2004) }\end{array}$ \\
\hline City of Edmonton & $\begin{array}{l}\text { PCB release and subsequent } \\
\text { charges }{ }^{16} \text { created internal impetus } \\
\text { (Manager, Environmental } \\
\text { Management Group, personal } \\
\text { communication, July 3 2009) }\end{array}$ \\
\hline City of Calgary & $\begin{array}{l}\text { Chlorine release conviction } \\
\text { sentencing (R. } v \text { Calgary, 2000) }\end{array}$ \\
\hline Scottsdale, AZ & $\begin{array}{l}\text { In order to join EPA Performance } \\
\text { Track Program (Senior Environmental } \\
\text { Coordinator, personal } \\
\text { communication, July 8 2009) }\end{array}$ \\
\hline $\begin{array}{l}\text { Faced an EPA Consent Decree at } \\
\text { service center facilities associated } \\
\text { with storm water activities and the } \\
\text { Resource Conservation and Recovery } \\
\text { Act (RCRA) 17 }\end{array}$ \\
\hline TX
\end{tabular}

In Europe local authorities are more likely to report political reasons as driving forces, while in North America there seems to be more focus on the regulatory response. The table in Appendix $\mathrm{F}$ shows further selected data from local authority examples of EMS usage, highlighting the scope and standard used. It is common practice amongst municipalities to have a selective EMS that follows some, but not

${ }^{16}$ (According to personal communication with Manager, Environmental Management Group, City of Edmonton): A significant incident took place during World Championship in Athletics in 2001, when there was a PCB release resulting from problems with lighting fixtures. This led to charges from Alberta Environment from being laid but they were later (several years) found not guilty; however, the incident created questions internally about the ability to deal with environmental and related legal responsibilities.

${ }^{17}$ As explained in an interview available online: http://www.peercenter.net/ewebeditpro/items/073F17261.pdf 
all, of the ISO 14001 elements. Key elements implemented are typically related to regulatory compliance, emergency preparedness and documenting roles and responsibilities, in order to better manage risks and evidence due diligence (Leetham \& MacLeod, 2004).

There is a disproportionate representation in the data of operational units subject to high degrees of regulation, such as waste and water services.

\subsection{International trends}

Beginning with a look at the experience in European countries, it can be said that a more multilateral approach to LA solutions has been attempted in Europe. This is not surprising given the tendency for European multilateralism, as evidenced by joint involvement in European Union institutions and commitment to United Nations (UN) initiatives. The UN's Agenda 21 sustainability declaration is no exception. Chapter 28 of the declaration was intended to call for action at the local level and has become known as "Local Agenda 21" (LA21) (United Nations, 2005). Although international in scope, the LA21 is more commonly referenced in European research (Burstrom, 2000; Emilsson \& Hjelm, 2002; EURO-EMAS, 2001) and appears to be a leading driver of a search for local sustainability tools. More recently, in January 2006 the European Commission released "The Thematic Strategy on the Urban Environment" in an attempt to coordinate the exchange of experiences with environmental management among regional and local authorities. Among the proposed measures was one that advocated for integrated EMS implementation in cities of over 500,000 in population (European Commission, 2006).

In the 1990s the development of an EMAS standard specifically for local use, LA-EMAS, suggested a possible trend of European countries officially endorsing EMS usage at the local level (Riglar, 1997). The greater role of central governments is especially evident in the UK, where in 1999 the national government initiated a project aiming to adapt EMAS for use by local governments (EURO-EMAS, 2001). The UK government looked to EMS to help with managing local environmental impacts in a systemic way as well as fulfill Agenda 21 responsibilities (McIntosh \& Smith, 2001). The outcome was an adapted UK regulation, a pilot project named 
"EURO-EMAS" involving seven EU local authorities, and a publication providing guidance on the implementation of EMAS by local governments, known as "LAEMAS" (EURO-EMAS, 2001). LA-EMAS makes the assumption that local governments should be applying the EMAS EMS framework with special considerations for public consultation and accounting for the indirect effects of services provided. Building on the establishment of the LA-EMAS, a "peer review for cities" program began in 2001 where professionals from experienced municipal areas travelled to other potential urban areas in the EU to share their expertise and advice on implementation of LA-EMAS (European Council, 2001). Although the LAEMAS standard was later rendered obsolete when changes to EMAS made it flexible enough to be used ubiquitously, there was a subsequent Euro-EMAS project encouraging EMAS usage across $11 \mathrm{EU}$ participant cities along with a cooperative system of peer-review (LIFE98, 2001). The evidence from Europe shows a clear active role of government in the encouragement of EMS as a tool for local authorities to adopt.

The trend in usage can be generalized to be most commonly within a narrow scope limited to a specific organizational unit, with a few outliers (see Appendix F). The number of cities taking on a formal EMS for their whole organization appears quite low, when looking at the small number of European exceptions in Appendix $F$. All of the original seven pilot cities involved in the EURO-EMAS project opted to apply their EMS only to operational units. Sweden is arguably the leading European public sector adopter of EMS standards and even there it is rare for the scope to include whole organizations (Von Malmborg, 2003). Rarer still is to see local authorities follow through with third party certification. Consider that Swedish municipalities have been implementing various forms of EMS since the mid-1990s (Von Malmborg, 2003), and it was estimated in 2003 that about half of municipal organizations had initiated some form of EMS projects. According to authors who conducted a study in 2002 concerning use of EMSs by local authorities in Sweden, while almost half of the local authorities were implementing EMSs, few intended to certify and/or register their EMS (Emilsson \& Hjelm, 2002).

In Asia the situation is less clear. High economic growth in Asian countries such as China has been matched by signs of increasing EMS usage marked by 
corresponding growth in 14001 certificates. Table 3.4.1 shows China at the top of the list for new certificates in 2006.

Table 3.4.1 - World 14001 Certifications as of 2007
\begin{tabular}{|l|c|}
\hline China & 30489 \\
\hline Japan & 27955 \\
\hline Spain & 13852 \\
\hline Italy & 12057 \\
\hline UK & 7323 \\
\hline Korea & 6392 \\
\hline USA & 5462 \\
\hline Germany & 4877 \\
\hline Sweden & 3800 \\
\hline France & 3476 \\
\hline
\end{tabular}

Taking Chinese trends as representative of other less developed countries in the Asian area prompts a look at the local level for the implementation of EMS. Unfortunately there is very little accessible data on actual implementation by local governments. It could be assumed that in a country with a more centralized command and control economy, uptake of EMS in this sector could be quite rapid. One sign of EMS being on the agenda of authorities is the fact that entire "economic development zones" are emerging, such as Hangzhou Economic and technological Development Area (Mazzini Consultants, 2007). Despite potential in countries such as China, the leader in Asia is limited to Japan.

Japan is a big player Asia-Pacific player in terms of marginal growth in ISO 14001 certificates (see Table 3.4.1) and absolute numbers. Not surprisingly, Japan's biggest urban area, Tokyo, has been using ISO 14001 to some degree for quite some time. The Tokyo Metropolitan Government, as well as two smaller municipal areas (defined as "prefectures and wards"), have implemented ISO 14001 EMSs (Srinivas \& Yashiro, 1999). There is no discussion of modifying the standard, as in Europe, for this particular application. The smaller defined areas, Gifu Prefecture and Shiroi Town, have applied the system (and received third party 
certification) to all organizational activities (Srinivas \& Yashiro, 1999). However, the status of the larger Tokyo Metropolitan example is uncertain, with scope issues still "under discussion" (Srinivas \& Yashiro, 1999). Due to the unavailability of English-language documentation, preliminary analysis appears to suggest a lack of follow-up research, suggesting that Japan has yet to embrace a leadership role in advocating for formal EMSs at the municipal level.

In New Zealand a project was initiated in 1997 to provide resources for local governments to implement ISO 14001 EMSs (Cockrean, 2000). Even with wholesale support from the national government, EMS implementation was limited in scope to individual city functions such as water supply or soil conservation and none of the case study LAs chose to pursue third party certification (Cockrean, 2000). A study of eight New Zealand LA participants revealed a number of successes and failures (Cockrean, 2000) that have been considered in later observations.

Aside from Japan and New Zealand, it remains to be seen if other cities in the Asia-Pacific area will look to EMS as a framework for urban environmental management. There is a disappointing lack of accessible research or other data on the use of ISO 14001 or EMAS by other international players such as Australia. Other frameworks may exist and may be being adopted on the international scene, but these are unlikely in the short term to emerge as prominently as ISO 14001.

\subsection{North American trends}

The US federal government has endorsed the use of EMS in the public sector more generally when it implemented initiatives to encourage its usage. The most significant of these is Executive Order 13148 signed in April 2000 by President Clinton (US EPA, 2008). The order required that federal facilities have an EMS implemented at applicable facilities by the end of 2005. In 2002 the White House Council on Environmental Quality reported that nearly 200 US federal facilities had an EMS in place modeled on ISO 14001, and many more were developing agency policies, training, and EMS implementation tools (Connaughton, 2002). In 2006 a top EPA Administrator signed a new EMS Position Statement reaffirming the agency's commitment to the 2000 order (US EPA, 2006). However, the majority of 
affected agencies did not seek third party certification and limited their EMS in scope to on-site facilities (Block, 2006). The initiative's predominant use appears to have been as a tool to manage facility environmental aspects and less as a broader public sector organizational tool.

At the local level, the US Environmental Protection Agency (EPA) has been involved in at least one initiative to encourage LA uptake of EMS. The EPA's Office of Wastewater Management and Office of Compliance is currently sponsoring an initiative to evaluate implementation at six municipalities, one county, and one state organization. Table 3.5.1 shows the participants in the study and their "fence line" (scope of the system).

Table 3.5.1 - EPA Office of Wastewater Management Study Participants

\begin{tabular}{|l|l||}
\hline Participant & Fence line \\
\hline \hline Town of Londonderry, New Hampshire & Public Works \\
\hline \hline City of Lowell, Massachusetts & Wastewater Treatment Facility \\
\hline \hline Wayne County, Michigan & Wastewater Treatment Facility \\
\hline City of Indianapolis, Indiana & Public Works \\
\hline Massachusetts Department of & Wastewater Treatment Facility, Power Plant, \\
\hline Corrections & Industries \\
\hline City of Gaithersburg, Maryland & Public Works \\
\hline \hline Lansing Board of Water \& Light, \\
Michigan & Power Plant \\
\hline \hline City of Scottsdale, Arizona & Transit Authority \\
\hline \hline New York City, New York & \\
\hline
\end{tabular}

Source: United States Environmental Protection Agency ${ }^{18}$

Preliminary findings from the pilot study have been that all LAs "that participated in the EMS pilot project realized most if not all of the environmental

18 "Implementing ISO 14001 Environmental Management Systems at the Municipal Level" project information is available through the EPA website at http://www.epa.gov/owm/iso14001/impiso.htm 
goals that originally prompted their participation" (GETF, 2000). Final conclusions of the study, when released, could speed up the growth of EMS usage at the municipal level in the US if benefits can be proven. To this end, an organization and corresponding website has been set up by the EPA and a partner, the Global Environment \& Technology Foundation (GETF). The Public Entity EMS Resource (PEER) Center does not explicitly endorse a particular EMS standard, but provides resources for local governments to embrace a continual improvement framework such as embodied in EMS (PEER, 2009).

Even with explicit involvement of government, at least to some degree, LA EMS use in the US is still limited mostly to individual operational units. Case studies on the PEER website show only operational unit implementations, signalling a lack of available information concerning a more broadly scoped EMS at the LA level. Scottsdale stands out in Table 3.5.1 as the only EPA program participant that has expanded its scope to the whole municipal government. It is one of only two cities in the entire US to have such a widely scoped EMS. Dallas, Texas, is the other outlier city (PEER, 2008). Of the two only Dallas has received third party certification to an external standard (ISO 14001) ${ }^{19}$.

In Canada, ISO 14001-based EMSs have been identified as a growing trend in the public sector for close to a decade. A 1999 Canadian paper reported a small but growing number of municipal administrations were using the ISO 14001 standard (Bekkering \& McCallum, 1999). By 2004 it was cited that over 125 municipal entities in North America are active with some form of EMS (Leetham \& MacLeod, 2004). However, it was noted then and still holds true that most municipal environmental management efforts have focused on the delivery of hard services, such as water or waste, and not on an organization as a whole. For example, in Ontario, no municipality has applied an EMS to their whole organization while several have done so for hard services alone. Examples are cited in Appendix F.

In 2004 a benchmarking survey was undertaken by the City of Toronto to identify EMS experiences of LAs in Canada and the US (Leetham \& MacLeod, 2004).

${ }^{19}$ Scottsdale chose to self-declare 
Findings showed that although an EMS can be implemented across an entire organization, of the 20 municipalities surveyed, the results were:
i. 13 were active with an EMS for Wastewater;
ii. 9 were active with an EMS for Water Supply;
iii. 8 were active with both Water and Wastewater; and
iv. 9 were active with an EMS for Solid Waste

Twenty-six Canadian cities were known to have some sort of active EMS, with nine of them having some part of their operations certified to ISO 14001, nine in progress, and eight in planning stages (Leetham \& MacLeod, 2004). As was the case in 2004, there remains only one city in Canada with an all encompassing third party certified ISO 14001 EMS, the City of Calgary (City of Calgary, 2008). However, Calgary, the subject of a case study that follows, is being closely followed by the City of Edmonton, its provincial counterpart. Edmonton has had seven of nine operational units certified, with plans to have nine units with environmentally significant operations certified by 2010 (Manager, Environmental Management Group, personal communication, July 3 2009). It is worth noting that Edmonton's following of Calgary's example suggests that one reason LAs have not previously embraced certified EMS is that it takes a (in this case regionally) competitive dynamic between cities for the approach to spread.

LA EMS in Canada seems to parallel the US situation: both have outlying city leaders but share a general tendency to rely on narrowly scoped systems aimed at operational units or facilities. A major difference between the two countries is in the existence of support from outside institutions: Canada lacks cohesive support from government or another institutional form that is found in the US. Leetham and MacLeod (2004) remarked that it was clear "the US EPA has lent significant support to municipal EMS.." while "Environment Canada and the MOE have done almost nothing." 


\subsection{Limited exceptional cases}

It has been shown that local-level EMS can be generally characterized as most commonly applied individually to hard service operations or facilities within an organization. Although significant literature exists regarding EMS use by LAs, relatively scarce studies deal either with (a) LAs that have applied EMS to their whole organization; and/or (b) the significance of third party certification on their systems and organization. Cases and therefore studies examining both are extremely rare.

Lozano \& Valls (2007) looked at the exceptional case of Ohanes, Spain, which was the first European municipality to have its entire corporation ISO 14001 certified. They found significant economic and environmental benefits from the EMS implementation and certification. It was actually possible to correlate increased economic activity and reduced environmental impacts after implementation. However, any implications drawn from the case are difficult to extrapolate from based on such a small ( 800 inhabitants) and unique (within the Natural Park of Sierra Nevada) jurisdiction.

In the UK there have been two LAs, Hereford City and Leeds City, that have received EMAS certification for their whole city organizations (McIntosh \& Smith, 2001). Reported benefits focus on improved engagement with citizens and the introduction of beneficial environmental programs such as city-wide education and recycling programs (McIntosh \& Smith, 2001). The other notable UK case is the City of Newcastle, which has applied an EMS to all city units, though it has sought certification only for a minimal number of units (the Regulatory Services and Public Protection units) (New Castle City Council, 2009).

In Sweden the two most relevant LAs with regards to LA-wide implementation are Gothenberg and Vasteras. Gothenberg decided in 1996 to require all departments to implement EMS but has not placed an emphasis on certification (Emilsson \& Hjelm, 2004). Similarly, the second example, Vasteras, has shown little ambition for certification (Burstrom, 2000).

In North America only Calgary and Dallas have had their entire corporations certified to an EMS standard (ISO 14001). No significant studies or reports on their 
experiences have been published. This paper uses the Calgary case study along with other underrepresented examples to shed light on their important experiences.

On the basis of research conducted, very few municipalities, worldwide, have fully embraced such a broadly scoped, certified EMS. Fewer still have accumulated many years of experience on which to report.

\subsection{Summary}

While there is debate surrounding the environmental performance benefits of EMSs and the ISO 14001 standard, it is clear that they stand as a viable option for an organization's management to respond to increasing regulatory demands. ISO 14001 has emerged as the clear leader in EMS standards and has experienced continued recent growth, suggesting value is to be found in its approach. Internationally, EMS use is most common in European countries, with North America shown to be active in the local authority sector. In Europe, local authorities are more likely to report political reasons as driving forces, while in North America there seems to be more focus on the regulatory response. Overall considering all jurisdictions, cases where cities have fully embraced EMS and certification are extremely rare. 


\section{Chapter 4: Standards and Certification for Local Authorities as LEARNING ORganizations}

Two theoretical reviews are conducted before connecting the theory to local authority applications. First, the significance of external standards and the certification mechanism available for EMS standards is investigated; and second, theories of effective learning organizations are introduced. Then local authorities are examined as organizations, and the benefits and drawbacks of certification to an external standard laid out.

\subsection{Standards and assurance through certification}

In the public realm, standards are commonplace. They exist in accepted forms ranging from explicit laws and regulations applied to organizations and individuals, to implicit norms such as in the concept of a "reasonable person" used in common law in countries such as Canada. For a more technical definition of standards, ISO offers that they refer to "rules, guidelines or characteristics for activities or their results, aimed at the achievement of the optimum degree of order in a given context" (ISO, 2004b). While straightforward enough conceptually, there is considerable controversy surrounding which standards should apply to a particular circumstance, along with associated questions such as who sets the standard, the role of government versus non-governmental organizations, and how one ensures standards are effective and credible (Webb, 2009). Therefore types of standards must be evaluated on a case by case basis in order to assess where and how they can be applied most effectively.

Privately, organizations have increasingly looked beyond public standards to further direct their relationship with the environment where governments do not (Stripple \& Lövbrand, 2008). A new class of standards known as voluntary codes has emerged, defined by Webb (2002) using four characteristics:

i. commitments not required by legislation or regulations;

ii. agreed to by one or more individuals or organizations; 
iii. intended to influence or control behavior;

iv. to be applied in a consistent manner or to reach a consistent outcome.

Certified management standards are a subset of voluntary codes that include two fundamental elements: first, they codify a set of standard practices; and second, they provide a certification system for organizations to communicate their adoption of these practices (King et al., 2005). Of significance in the latter element is the provision a level of assurance, through third party verification, which is not found in other forms of standards.

It is possible for organizations to internally develop and implement their own codes or standards (to apply internally or to external relationships such as suppliers). However, standards sourced externally have two key benefits: they have already been developed (and thus save resources that would otherwise have be spent on development); and, most importantly, they are more likely to earn organizational recognition through certification. The certification process also adds monitoring by independent third-party auditors, who certify that an organization has complied with the requirements of a standard. As Webb (2002) contends, "a code without mechanisms to ensure its application is simply a statement of intent." The potential virtues of certification particularly useful to local authorities are explored in section 4.4 .

For the most part, existing literature on the use of standards focuses on their voluntary nature. The literature suggests that firms have opted to "self regulate" to respond to criticisms of taking advantage of cross-country differences in government regulations (Christmann \& Taylor, 2006). Whether it is a reflection of the difficulty governments have had in regulating environmental interactions, or whether it is due to the increasing environmental concern from concerned citizens, private standards have proliferated amongst large organizations concerned about the environmental aspect of their operations. Despite the increased importance of standards on the international stage, their function within organizations and other important questions surrounding the motivating forces that propel firms towards selecting standards and their subsequent effects on behaviour remain largely unknown (King et al., 2005). At the local authority level even less analysis is 
available on the incentives involved in the selection of standards specifically for these types of organizations.

\subsection{Effective learning organizations}

At this point it is useful to introduce the concept of effective learning organizations as a conceptual model. Models of effective learning can be used to test the potential success or failure of certified EMS in implementing change in a LA. According to Yin (1994) such models are particularly useful for the collection of defined information and its later discussion and analysis. Yin (1994) further explains that this approach allows facts to be explained through theory and is most importantly well suited for the comparison of entities (organizations).

Management literature has made various attempts to define organizational learning. Some definitions are rather vague, such as the one in Senge's (1990) book The Fifth Discipline: "an organization that is continually expanding its capacity to create its future". Tsang (1997) points out that the closely related terms "organizational learning" and "learning organization" are often used interchangeably. This paper capitalizes on the more useful definition of an effective learning organization offered by Leonard Barton (1995), which consists of three main elements:

i. a shared vision that facilitates and promotes systematic team problemsolving;

ii. a feedback process that efficiently transfers knowledge and information about the organizations' own experiences, experimentation, and others' experiences and best practices;

iii. a review process that evaluates, challenges, and adapts prevailing practices and strategies in light of new information.

The degree to which these are present in an organization gives an indication of the effectiveness of learning taking place inside that organization. The questions asked here are: Does third party certification to the ISO 14001 standard enable or 
hinder learning in a local authority organization? This question is a test of the hypothesis that LAs stand to benefit from third party certified EMS.

It is not difficult to transpose Barton's three criteria onto the elements found in EMSs based on the ISO 14001 framework, as shown below at a high level in Table 4.2.1.

Table 4.2.1 - Barton's LO Elements and ISO 14001

\begin{tabular}{|l|l|}
\hline (Leonard-Barton, 1995) & (ISO 14001: 2004) \\
\hline shared vision & $\begin{array}{l}4.2 \text { Environmental policy; } 4.3 .3 \text { Objectives, } \\
\text { targets and programme(s) }\end{array}$ \\
\hline feedback process & 4.4 .2 Competence, training and awareness \\
\hline review process & 4.5 .5 Internal audit; 4.6 Management review \\
\hline
\end{tabular}

The aligning of specific criteria from the standard with learning organization theory shows a formalized attempt to meet the criteria of an effective learning organization.

Adler and Borys (1996) argue that there can be only two types of formalization: enabling and coercive. Essentially it depends on which rules and how rules are implemented. Figure 4.2.1 below shows Adler and Borys' (1996) two-dimensional matrix that conceptualizes the idea of how a system of formalization can either be beneficially enabling or coercive and mechanistic.

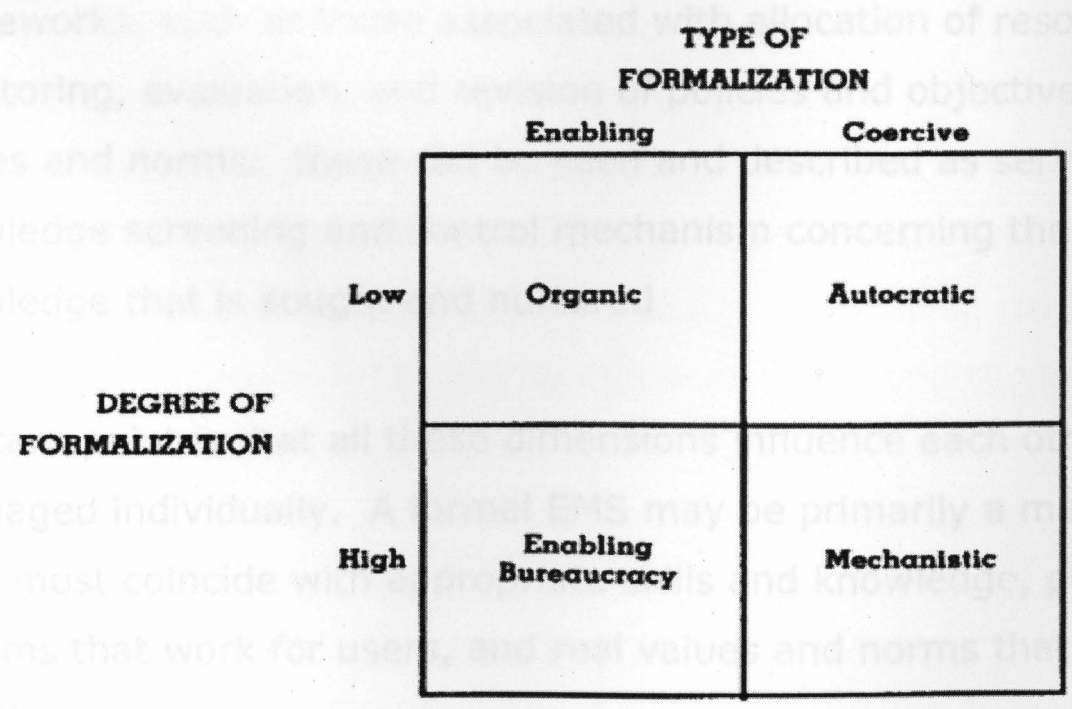

Figure 4.2.1 - Types of Formalization 
According to Adler and Borys (1996), the most important forces leading to coercive logic are asymmetries of power in the organization and the absence of reality checks. Countervailing forces on the other hand, which encourage enablement, avoid making outcomes seem inevitable, intensify competitive pressure on the organization, and use performance pressure to design jobs to require more skill and discretion. These enabling and coercive factors resurface in later observations on specific approaches used by local authorities.

This is not the first time Leonard-Barton's organizational learning concepts have been applied in the context of a formalized, EMS approach. Epstein and Roy (1997), in an article specifically exploring how ISO 14001 can improve organizational learning, summarize another useful concept found in a text by Leonard-Barton. Knowledge assets or capabilities can be described as four interrelated dimensions in an organization:

i. skills and knowledge: as reflected in the expertise and qualifications of management and staff;

ii. physical technical systems: as codified in procedures, manuals, software and databases

iii. managerial systems: this includes decision making and action frameworks, such as those associated with allocation of resources, monitoring, evaluation, and revision of policies and objectives; and

iv. values and norms: these can be seen and described as serving as a knowledge screening and control mechanism concerning the type of knowledge that is sought and nurtured

The important point is that all these dimensions influence each other and cannot be managed individually. A formal EMS may be primarily a managerial system; yet, it must coincide with appropriate skills and knowledge, physical technical systems that work for users, and real values and norms that guide system direction over time. 
An additional useful concept for the purposes of this paper is cited by Epstein and Roy (1997): single and double loop learning. Argyris and Schon (1978) define single loop learning as "when members of the organization respond to changes in the internal and external environments of the organization by detecting errors which they then correct so as to maintain the central features of organizational theory-in-use." Essentially, in this type of feedback loop a deviation from procedural norm is corrected by reverting back to the norm. A double-loop process, in contrast, invites challenges to the norm and considers changing processes by considering why a deviation may have occurred. The latter is more challenging in that strategy, policies, and procedures must constantly or periodically be in a state of potential flux, as opposed to a static ideal. It is possible for a formal EMS and/or third party certification to play a significant role in determining whether single versus double loop learning is occurring. It is important, however, to recognize that there is a difference between short term double loop learning and double loop learning as a long term institutional norm. This concept will be revisited in the context of case study examples in Chapter 6.

These theories of effective learning organizations present themselves as tools in the analysis of the organizational costs and benefits of EMS certification, as well as highlighting the most effective strategies for implementation.

\subsection{Local authority characteristics}

It has already been shown that EMS standards are more prevalent in the private than public sector, especially with regards to third party certification. In theory, there is no reason to assume that the organizational usefulness of EMS certification is limited to applications to private sector operations. In fact, arguments can be made that local authority characteristics lend themselves particularly well to third party certified EMSs. There is a general need for a systematic, well-structured and documented decision-making and implementation approach to ensure consistent, efficient and effective delivery of water supply, treatment, waste disposal, transportation and other services with significant environmental dimensions to large populations over large geographic areas. 
In comparison with for-profit firms, local authorities typically have a distinctive and resource-intensive geographic footprint, and operate in different legal and economic contexts with unique organizational constraints and features. None of these distinctive features or characteristics act to rule out the application of the ISO 14001 certification for LAs. Table 4.3.1 presents a summary of the differences between private for-profit organizations and local authorities.

Table 4.3.1 - Private Sector versus Local Authorities

\begin{tabular}{|c|c|}
\hline Private for-profit organizations & Local Authorities \\
\hline \multicolumn{2}{|l|}{ Size \& Scope } \\
\hline $\begin{array}{l}\text { Normally have limited geographic presence, } \\
\text { often have multiple locations. }\end{array}$ & Large contiguous geographic area \\
\hline $\begin{array}{l}\text { Varying in employee \#s, departments, } \\
\text { functions }\end{array}$ & $\begin{array}{l}\text { Typically large \# of employees, } \\
\text { departments/units, predictable functions }\end{array}$ \\
\hline \multicolumn{2}{|l|}{ Environmental Dimensions } \\
\hline $\begin{array}{l}\text { Provide products and services that may or } \\
\text { may not have significant environmental } \\
\text { impacts }\end{array}$ & $\begin{array}{l}\text { Provide basic services such as water, waste } \\
\text { treatment, energy, public transportation, } \\
\text { etc with heavy environmental components } \\
\text { (impact, regulation) }\end{array}$ \\
\hline $\begin{array}{l}\text { Mandate for positive environmental aspects } \\
\text { within the parameters of an entity designed } \\
\text { to make profit }\end{array}$ & $\begin{array}{l}\text { Mandate for positive environmental aspects } \\
\text { within the parameters of legal authority and } \\
\text { tax base }\end{array}$ \\
\hline $\begin{array}{l}\text { Varying degree of regulatory obligations, } \\
\text { depending upon product/activity }\end{array}$ & $\begin{array}{l}\text { High regulatory obligations (must manage } \\
\text { waste, water, transit) }\end{array}$ \\
\hline \multicolumn{2}{|l|}{ Nature \& Incentives } \\
\hline Basically, a competitive model & Basically, a monopolistic model \\
\hline Products and services & Mostly services not products \\
\hline $\begin{array}{l}\text { Budget generated by profits, priorities } \\
\text { determined by top management/owners }\end{array}$ & $\begin{array}{l}\text { Budget generated by taxes, transfers and } \\
\text { fees for services, priorities determined by } \\
\text { Council on basis of electoral preferences }\end{array}$ \\
\hline Typically short payback periods ( $~ 2$ years) & $\begin{array}{l}\text { Planning curve may be slightly longer-term } \\
\text { (election cycle (e.g., 4-5 years) }\end{array}$ \\
\hline Entirely profit oriented & $\begin{array}{l}\text { Profit motive less evident (to some extent, } \\
\text { fee for services can be used to create a }\end{array}$ \\
\hline
\end{tabular}




\begin{tabular}{|c|c|}
\hline & $\begin{array}{l}\text { "revenue generation" orientation somewhat } \\
\text { similar to profit orientation in private } \\
\text { business organizations) }\end{array}$ \\
\hline \multicolumn{2}{|l|}{ Organizational } \\
\hline Autocratic leadership & Democratic leadership \\
\hline $\begin{array}{l}\text { With exception of } \\
\text { owners/shareholders/investors, ability to } \\
\text { limit stakeholders unless law requires } \\
\text { consideration of others (e.g.,. obligation to } \\
\text { consult for environmental impact } \\
\text { assessments) }\end{array}$ & $\begin{array}{l}\text { Obligation to take into account and consult } \\
\text { with all taxpayers/citizens }\end{array}$ \\
\hline $\begin{array}{l}\text { Variable accountability and transparency } \\
\text { (depending on stakeholder category) }\end{array}$ & High degree of public accountability \\
\hline $\begin{array}{l}\text { Policy direction from owners/shareholders, } \\
\text { board, executives. }\end{array}$ & $\begin{array}{l}\text { Policy direction from (1) councillors (2) law } \\
\text { (3) management (4) electorate }\end{array}$ \\
\hline $\begin{array}{l}\text { Larger firms likely to have specialized } \\
\text { environmental staff and/or a separate } \\
\text { department }\end{array}$ & $\begin{array}{l}\text { For larger municipalities, likely to have } \\
\text { environmental staff and/or a separate } \\
\text { department }\end{array}$ \\
\hline
\end{tabular}

Many of these differences must be considered in making observations on the appropriateness of, and considerations for, third party certified EMSs for LAs. Thus, the differences are highlighted in discussion below and in the following section 4.4.

While it is true that all types of organizations have environmental impacts and face ecosystem-related challenges, local authorities must consistently provide basic services such as water and waste treatment. The significant impacts of and highly regulated nature of these activities would seem to compare well to private sector industries with similarly high environmental and regulatory burdens, such as the chemical industry ${ }^{20}$ which have embraced management system approaches. Von Malmborg (2003) has made the case that there are indications that standardized

20 The chemical industry is well known to have taken a proactive management system approach through the Responsible Care standard. They have also produced their own reporting requirements, first with the European Chemical Industry Council's 1993 draft "CEFIC guidelines on environmental reporting for the European chemical industry" and later through the industry specific standard Responsible Care Reporting Guidelines in 2006. 
EMSs are actually better suited for LAs than private sector companies on the basis that they often resemble industrial organizations (which are assumed to benefit from more standardized procedures). He cites Taylor's (1994) suggestion that the corporate nature of an EMS helps in getting past the problems of isolation and lack of influence confronting LA environmental staff by giving them a more clear structure, mandate, and rationale for soliciting participation from the diverse operations found in an LA. The additional structure may help managers navigate more effectively navigate LA bureaucracy. Swedish survey research has revealed greater possibilities in larger than in smaller LAs and pointed to the fact that LAs have larger organizations and geographical areas which require a coordinated framework as an explanation (Emilsson \& Hjelm, 2002b). The reported comparisons to large corporations seem to suggest that larger LAs are organizations most suited to more formal approaches.

A further aspect unique to LAs is their additional mandate to provide positive environmental impacts, through responsibilities for tree planting and other urban beautification initiatives. LAs are thus well-aligned to benefit from EMSs, given that all environmental impacts, positive or negative, are specifically addressed in the ISO 14001 standard. ${ }^{21}$ In contrast, the application of such a positive environmental aspects would be handled awkwardly in the private sector.

An observation on the overall appropriateness of EMS for LAs is found in Noren and von Malmborg's (2002) article based on two Swedish LAs, where they explicitly state "we do not think that the institutional logic of local authorities negatively influences the usability of the standardized EMS in the public sector." In examining the literature they find no institutional obstacles for the use of EMS in local authorities.

Some of the unique characteristics of local authorities as organizations will impact later observations, but it is already clear through preliminary analysis that if any type of organization can find value in a third party certified EMS, local authorities would be at the top of the list.

\footnotetext{
${ }^{21}$ Section 3.7 of the ISO 14001 standard defines an environmental impact as "any change to the environment", whether adverse or beneficial" (emphasis added).
} 


\subsection{Certification as a surrogate force for local authorities}

A remaining category of differences between the private sector and LAs shown in Table 4.3.1 under "Nature and Incentives" cites the fact that private sector organizations operate under constant for-profit market pressure while LAs do not. In most private markets customers can substitute goods or services and therefore the proverbial invisible hand is always at work exposing weaknesses and initiating change. In contrast, LAs are public sector organizations operating in a non-profit framework and therefore do not benefit from the same competitive forces found in the private market. With respect to environmental management, the problem is compounded by a lack of quantifiable targets that could serve to generate an incentive comparable to that generated by sales numbers, customer retention, or even customer surveys in for-profit sectors.

That is not to say that LAs are non-competitive. In fact, cities are looking for new ways to compete for investment and prestige. So they must also look to EMS. Arguably, technological advances and more flexible, global labour markets are increasing such competition. On the environmental front, examples of direct comparison can increasingly be cited, in which the environmental performance of cities is ranked and presumably considered by potential residents and businesses in making location decisions. For example, the Corporate Knights have published their third annual "Sustainable Cities Report," ranking Canadian cities on issues such as air quality and commuter transportation options (Corporate Knights, 2009). Similarly, Ecojustice recently published a sewage report in Ontario that specifically includes province-wide data on the amount of sewage being dumped by LAs (Ecojustice, 2009). New websites with expanding regional focus appear likely to proliferate, including sites such as Coolcities ${ }^{22}$, which showcase what cities across North America are doing to combat global warming. These types of initiatives contribute to enhancing competitive forces between LAs, but do not go far enough to match the power behind the for-profit forces that typically drive change in the private sector.

\footnotetext{
22 http://coolcities.us/ - "Begun in 2005, the Cool Cities campaign empowers city residents and local leaders to join and encourage their cities to implement smart energy solutions to save money and build a cleaner, safer future."
} 
LAs need a more effective incentive equivalent comparable to market forces to overcome their inherent organizational challenges. Certification to a third party standard could serve as a surrogate force. A third-party certification can change perceptions and let employees know environmental improvements are recognized. Where the lack of profit motive makes using incentives difficult, certification provides a rigour often missing from LA environmental management. This point is particularly relevant when discussing ISO 14001, which, in contrast to the ISO 9001 standard, explicitly states that organizations can self-declare conformity to the standard (ISO 14001:2004). Third party involvement in the review and verification of a public sector organization's compliance with a private sector standard is unusual; however, the third-party auditor's presence presents a new way to "incentivize" continual attention to environmental improvement in a public sector body. LAs would benefit from this surrogate certification force in many ways: it would propel LAs towards healthy competition with rivals to achieve the certification itself, as well as open up a typically closed organization to the external pressure that a third party (auditor) can generate. Observations along these lines are discussed in sections 6.3 and 6.4 .

As shown in Chapter 3, the certification step in LA EMS is rare, perhaps due to a lack of investigative analysis of the organizational benefits. In fact, given the absence of traditional customer-based demand, LAs may have difficulty recognizing the value in certification. In investigating the most significant factors associated with a typical organization's decision to achieve third party certification, King et al. (2005) found the presence of potential distant or foreign customers is one of the greatest determinants. For typical LAs, this particular determinant is essentially absent. Therefore, identifying non-conventional determinants for the appropriateness of third party certification is necessary.

\subsection{The challenges of certification to a standard}

The preceding section proposes that LAs are equally, if not more, suited to adopting the ISO 14001 standard than private sector organizations; however, LAs admittedly face challenges in gaining value from the process. Criticisms of a standards approach and ISO 14001 need to be considered. Depending on the 
particular LA and its selected approach, implementation could be both positive and negative.

On an organizational level, the 14001 standard has been specifically critiqued as a standard that can present as many organizational problems as it solves (Moxen \& Strachan, 2000; Boiral, 2007). Also, in terms of actual environmental performance, a survey conducted by Emilsson and Hjelm of Swedish local authorities demonstrates a need for caution. This survey shows no discernable difference in environmental performance outcomes between organizations that pursued third party certification of implemented systems and those that did not (Emilsson and Hjelm, 2002). These findings suggest that considerable attention must be paid to the prospect that certification to the 14001 standard can have drawbacks as well as benefits.

Equally worthy of consideration is the fact that as public sector organizations, LAs are inherently bureaucratic. As Max Weber articulates, a high degree of stability, discipline, and reliability are the virtues of an ideal bureaucracy (Weber, 1968). Beck and Kieser (2003) summarize Weber's point as follows: "by increasing standardization, precision, and speed of organizational processes, formal rules considerably contribute to organizational efficiency". Clearly, some of the qualities of an EMS run parallel to the virtues Weber attributes to bureaucratic organizations, such as well-defined competencies, hierarchies of responsibility, and written rules governing employees' roles.

However, Beck and Kieser (2003) also point out that Weber emphasizes a drawback of bureaucracy: the scope of actions available to individuals is constrained. On top of an existing bureaucracy in LAs, the introduction of additional systems and standards risks exacerbating this drawback by creating an overly formal environment. In studying two Swedish LAs that had received certification, Noren \& Malmborg (2002) listed among the disadvantages an increase in administrative work and a risk that the EMS becomes too detailed and hard to keep functional. For implementation to make sense, the cost-to-benefit ratio has to be held positive.

ISO 14001 has itself been singled out as potentially vulnerable to generating only superficial environmental impacts and perhaps even harmful organizational 
effects. Boiral (2007) cautions that focusing on the standard can lead an organization to ceremonious behaviour and conformity only to the standard in name, rather than to true best-practices of effective environmental management. Particularly once commitment is made to the certification step, efforts to sustain certification can lead employees and managers to place delusional value on the system in order to maintain minimum levels of commitment (Boiral, 2007). There is a risk of "cultural myopia": organizations will not be able to reach beyond the barriers that a formal system creates to the innovative, creative, and novel problem-solving techniques that are necessary to affect change (Moxen \& Strachan, 2000). Moxen and Strachan (2000) claim that following the 14001 standard brings risk of developing a "rule" culture, described by Harrison (1992) as placing too great of value on maintaining traditions, following precedents, and observing formal rules and procedures.

While there are certainly valid points to be made cautioning against the formalization associated with a standard such as ISO 14001, it is most important to consider them in the context of harm reduction. The alternative (i.e. not using the standard) could leave an organization worse off that it would be with it, despite the standard's flaws, and it is this possibility that commentators such as Boiral (2007) are perhaps not fairly emphasizing. Even extensive criticism from Moxen and Strachan (2000) is followed by an acknowledgement that conventional nonstandard approaches are still more likely to hinder organizational potential, as they call only for revisions to ISO 14001. Furthermore, Christmann and Taylor (2006) make a distinction between symbolic versus substantive implementation. Symbolic implementation occurs when efforts are only enough to "satisfy customers" and there is no economic incentive to do more than the minimum. According to such reports, LAs could find themselves without the proper signals for implementing standards substantively, since they have been shown to operate in a relatively noncompetitive environment. Factors that influence the success of standards implementation in the private sector, such as customer concern about important issues or direct monitoring capabilities (Christmann \& Taylor, 2006), would in the public sphere of LAs, have to be mimicked by active-or at least engaged-citizens. 
The experiences reported through LA case studies and for other organizations seem to present alternative optimistic cases as long as implementers recognize that the standards need to be used flexibly to fit an organizations needs. More broadly, private sector companies using EMSs have found that with time confidence can grow in knowledge of how to apply standards such as ISO 14001 or EMAS more flexibly (Pedersen \& Nielsen, 2000). In many cases second and third revisions to initial EMS manuals have resulted in decreasing their lengths by half (Pedersen \& Nielsen, 2000). As Epstein (1997) points out, programs designed only for compliance and programs which are reactive rather than proactive will miss out on the most productive organizational learning opportunities.

Finally, even if standards implementation offers greater benefits than costs, further analysis and observations demands that a few additional questions must be asked, including:

i. What happens after certification has been achieved?

ii. How long can any one standard prove useful to the organization?

iii. Are the benefits to be gained distributed equally or disproportionately at different stages of implementation?

Acquiring some understanding of these questions will illuminate the underlying research objectives.

\subsection{Summary}

Due to their particular characteristics, LAs face unique challenges and opportunities in pursuing third party certified standards. The optional third party certification process that accompanies standards is highlighted as perhaps the most important learning tool found in private versus public standards. In the public sphere of traditional LA environments, third party certification can create incentives, counter a lack of external pressure, and drive organizational change. 


\section{Chapter 5: City of Calgary Case Study}

The following is an overview of the primary Calgary case study. Further observations drawing on the Calgary experience are also found within Chapter 6.

\subsection{City background}

Calgary is one of two urban economic engines of the province of Alberta, a comparatively prosperous region of Canada, due largely to the province's vast energy resources. With a population of over one million and an operating budget in excess of two billion dollars, the City has been one of the fastest growing urban regions in Canada (see Table 5.1.1). From 2001 to 2006 its population grew quickly, at 12.4 percent over the five year period, in a province growing 10.6 percent over that same time ${ }^{23}$. The resulting infrastructure demands are considerable given estimates of $100 \%$ population growth from the year 2000 to 2010 (City of Calgary, 2000). Table 5.1 .1 shows Calgary in comparison to two large Canadian cities, Toronto and Montreal.

Table 5.1.1 - Canadian Tri-city Comparison ${ }^{24}$

\begin{tabular}{|l|l|l|l|l|l|l|l|l|}
\hline City & $\begin{array}{l}\text { City } \\
\text { Population } \\
(\mathbf{2 0 0 6 )}\end{array}$ & $\begin{array}{l}\text { Geographic } \\
\text { Area }\end{array}$ & $\begin{array}{l}\text { Operating } \\
\text { Budget } \\
\mathbf{( 2 0 0 8 )}\end{array}$ & $\begin{array}{l}\text { \# of Staff } \\
\text { (approx.) }\end{array}$ & $\begin{array}{l}\text { Date } \\
\text { Inc. }\end{array}$ & $\begin{array}{l}\mathbf{5} \text { yr } \\
\text { Metro } \\
\text { Area } \\
\text { Growth }\end{array}$ & $\begin{array}{l}\text { Work } \\
\text { Transportation }\end{array}$ \\
\cline { 5 - 9 } & & & & & & Private & $\begin{array}{l}\text { Public } \\
\text { Transit }\end{array}$ \\
\hline Calgary & $1,019,942$ & $726 \mathrm{~km}^{2}$ & $\$ 2.1$ billion & 14,000 & 1894 & $13.4 \%$ & $75 \%$ & $17 \%$ \\
\hline Toronto & $2,503,281$ & $641 \mathrm{~km}^{2}$ & $\$ 8.2$ billion & 45,000 & 1834 & $9.2 \%$ & $56 \%$ & $34 \%$ \\
\hline Montreal & $1,620,693$ & $366 \mathrm{~km}^{2}$ & $\$ 4.0$ billion & 29,000 & 1832 & $5.3 \%$ & $53 \%$ & $35 \%$ \\
\hline
\end{tabular}

${ }^{23}$ 2001-2006, Population and dwelling counts, for Canada, census metropolitan areas, census agglomerations and census subdivisions (municipalities), 2006 and 2001 censuses, Statistics Canada, http://www12.statcan.ca/english/census06/data/popdwell/Filter.cfm?T=303\&GK=2

${ }^{24}$ Sources of data: 2001-2006, Population and dwelling counts, for Canada, census metropolitan areas, census agglomerations and census subdivisions (municipalities); 2006 and 2001 censuses, and 2006 Community Profiles. (Statistics Canada) 
While Calgary is in many respects comparable to most major cities in Canada and North America, its atypical characteristics are worth noting, with reference to Table 5.1.1. Calgary is:

- Less dense, considering population:area ratio;

- Has been established more recently than some of its counterparts;

- Has recently experienced a higher growth rate which could result in more available revenues.

Over comparable LAs, Calgary has some advantages, including:

- a relatively constant geographical footprint;

- comparative "youth" as a city with relatively new infrastructure (the result of recent growth);

- comparative financially sound footing, with no legacy debt to be addressed.

Like every municipality, Calgary has unique characteristics as well as unique challenges. However, it is important to note that nothing about the City of Calgary is so atypical or unusual to render its ISO 14001 certification experience so distinctive to be beyond value to municipal officials, managers in other types of public and private organizations, environmental management specialists, and academics. Quite the contrary is emphasized.

Calgary has faced significant environmental challenges associated with its rapid economic development, including pressures from the booming oil and gas sector further north. Water scarcity stands out as a leading environmental concern for the city and its residents. In 2006 a Rosenberg International Forum on Water Policy went so far as to declare in its report that Alberta as a whole could soon face a water crisis (Vaux \& Sanford, 2006). Before discussing the structure of the City, it is interesting to note that Calgary shares this heightened concern for water issues with another leading North American EMS counterpart, Scottsdale, Arizona.

The organizational structure of the City is divided among twenty-six units which report to six general managers and their respective departments. A detailed organizational chart is provided in Appendix G. 


\subsection{Initial driver of EMS implementation}

The initial impetus for use of ISO 14001 can be traced to a release of chlorine gas from the City's Bearspaw water treatment plant unit in 1998 that resulted in the City facing charges under provincial environmental legislation ( $R . v$ Calgary, 2000). Although damages were negligible and the City had recently invested hundreds of thousands of dollars in upgrading their chlorine systems, the cause was identified as a gap in standard operating procedures related to newly installed equipment.

The judge handling the case decided on a creative sentencing option. As an alternative to a hefty fine, the City was given a roughly three year deadline to have its two major water treatment plants ISO 14001 certified. Note here that a judge is using certification to a private international standard to support and reinforce compliance with a public law pollution control regulatory system, a point worth exploring later with regards to public policy implications.

At the outset, the City did not plan to seek ISO 14001 certification for its entire operations. Rather, the decision to certify the complete operations of the City to ISO 14001 was reached later in the process, after a series of incremental unit-byunit certifications were undertaken. While indicative of the City's gradual recognition of the value of EMS certification, the unit-by-unit followed by wholeoperation approach did have significant administrative repercussions, discussed later.

Table 5.2.1 provides a timeline overview of Calgary's certification to ISO 14001 process.

Table 5.2.1 - Calgary EMS Certification Timeline

\begin{tabular}{l|l|l|l}
$\mathbf{2 0 0 0}$ & November $\mathbf{2 0 0 1}$ & June 2002 & November 2003 \\
\hline \hline Systems initially & First two units & Decision made to & Entire organization certified \\
developed in & certified: & expand scope to & including corporate-wide \\
various units & Fleet and Supply & include all 13 City & "umbrella" certification \\
including water & Management and & units & (13 certifications) \\
units & $\begin{array}{l}\text { Calgary Fire } \\
\text { Department }\end{array}$ & &
\end{tabular}


The City's adoption of a formal environmental management system approach grew in scope, with the decision in June 2002 to include the whole organization: thirteen separate registrations representing the twenty-six units and one corporate system. Between November 14, 2001 and November 5, 2003, all units had adopted a formal environmental management system intended to be compliant with ISO 14001. In 2001 the city began obtaining third party certification for the units which had established an EMS. By the end of 2003, all 26 units were successfully included in the thirteen certifications to the ISO 14001 standard, with most entering their second three-year certification cycle. This incremental approach to achieving operation-wide certification seems to reflect a dawning realization of the value of having ISO certification in each unit. Along with recognition of its value, the City also demonstrated an awareness that such certification was achievable, coupled with a certain amount of momentum as unit after unit became certified.

Senior management and council "buy in" came as the EMS was sold primarily as a package for risk management based on a recognizable international standard, according to Director of Environmental \& Safety Management Dave Day. Day also points out the importance of continuous support at the highest organizational level possible, as mayor Dave Bronconnier (2001 to present) and current City Manager Dale Stanway (formerly the General Manager of Utilities \& Environmental Protection) offered to the City in this time. In Calgary's case, it would be a mistake to underestimate the role that strong support from senior staff and politicians played in driving the organization toward EMS certification: "the mayor and senior management grew tired of hearing what other cities were doing" (Team Leader, Environmental Performance Assurance, personal communication, April 10 2008). Council membership has remained relatively stable and continually supportive, which has been "crucial" to ensuring that a mandate for EMS implementation and proper allocation of resources is in place.

Beyond risk management, formal EMS certification was reported to be attractive in the sense that it could open up new opportunities for the City (e.g., make the city more attractive during bidding for "big ticket" hosting events), as well 
as add organizational benefits such as enhanced accountability, and more streamlined, effective, efficient decision making.

While in the Calgary case, the city started out similarly to other Canadian examples (see Appendix F) with a system focused on provision of a hard service (water), the system expansion has proven to be quite unique. There seems to be a clear distinction between the initial driver of certification in their Water unit (coercive, regulatory requirement) and the later decision to expand the system to cover the rest of the corporation (foreseen organizational value that could be applied to other units irrespective of their specific environmental component).

\subsection{Implementation approach}

Two general approaches to implementing an EMS across an entire organization can be distinguished. An incremental approach occurs when the system is initiated by one unit and then gradually adopted by other units, until it is finally implemented in all units in a coordinated fashion. This would be in contrast to a simultaneous or system-wide approach in which one integrated set of procedures is designed from the outset to include the whole organization. The incremental approach allows an organization to avoid making large and difficult decisions at the outset, in favour of smaller, ad hoc unit-by-unit decisions. In an incremental scenario, learning is controlled and gradual, growing as certification does from one unit to another. However, in this approach, an overall integrated and coordinated vision and framework may be missing.

The Calgary implementation approach stands in contrast to the more common limited-scope approach, or "ring fencing" of an EMS. The limited-scope approach is commonly found in LAs likely because designing and implementing a full system could be perceived as too cumbersome. Cities with a different (i.e. decentralized) structure might need to consider a different implementation approach. For example, Gothenberg, Sweden, consists of departments and town district committees with their own budgets and highly independent operations (Emilsson \& Hjelm, 2004). The degree of central versus decentralized authority plays a significant role in determining an optimal implementation approach. 
Calgary had a reported need to strike the right balance between common organization-wide policies and structures on the one hand, while at the same time accommodating the unique needs of each unit with flexibility and responsiveness (Team Leader, Environmental Performance Assurance, personal communication, April 10 2008). The size of the City's operating units vary from the very large (Water 1100-1700 staff; Transit 2500 staff) to other much smaller units (of less than 100 staff). The larger units self evidently have significant and potentially unique demands and attract significant corporate resources, perhaps at the expense of other units. Coordination by the Environment \& Safety unit, which positions unit-specific policies and procedures within a high-level common framework applied to the organization as a whole, was not complete until mid2003.

The incremental approach at the City saw units like Fleet Services and the Water units develop independently with their own sets of uncoordinated and nonintegrated policies and procedures. When asked how the approach could have been improved at the Water unit, staff suggested that it would have been preferable if there had been an overall "vision for where you want to go." (Manager, Water Services \& Water Resources, personal communication, July 20 2008). Multiple staff interviewed admitted that with the benefit of hindsight a more coordinated approach whereby each unit "builds on" to existing systems would probably have been more a more efficient and effective approach. Managers interviewed for this study reported on having developed unit-specific policies, procedures, and resources only to later have to "re-tool" and adopt corporate-level replacements. This exposes that an incremental approach to EMS implementation by a LA may be intuitive at first but not be ideal in the long term.

\subsection{Resources and reorganization}

When the EnviroSystem was initially being introduced, the City had limited internal expertise to draw upon to achieve operation-wide implementation. In 2000, the team of Environmental Management (EM) staff working on the corporate component of the system was comprised of approximately 10 employees who had previously focused mainly on reviewing development permit applications and urban 
planning related processes. Outside consultants were contracted and the initial planning and aspect identification processes were especially reliant on this outside expertise. There has since been a major effort to hire in-house personnel to fulfill all key EMS-related duties. Currently the larger Environmental \& Safety Management unit (see Appendix $\mathrm{H}$ for structure) has about 80 staff members, with an estimated 15 full time equivalent staff working to maintain and support the corporate and individual business unit environmental management systems and associated programs ${ }^{25}$. For point of comparison, Scottsdale, Arizona, with a population roughly one-quarter ${ }^{26}$ the size of Calgary, has an Environment Office staff size of eight, and gave an estimated cost of implementation cost of $\$ 100,000$ USD, over 1.5 years (Senior Environmental Coordinator, personal communication, July 8 2009) $)^{27}$.

Quantifying direct financial costs and benefits associated with Calgary's ISO 14001 implementation is difficult for many reasons. First, the new processes and definition of roles were in many cases already being done before the system was introduced. Second, the fact that certain units were consolidated during the course of EMS implementation (as discussed above) is a complicating factor. In Calgary's case, the EM group grew in size but also took over tasks of other units that were previously decentralized. Quantifying the costs and benefits associated with such consolidation is a challenge. Third, the City has experienced rapid growth over the period in question. Such factors have presented a challenge to the City and outsiders looking to use Calgary as an example to quantify EMS implementation costs in a direct and meaningful way.

Although there has been significant growth in expenditures by the City on environmental management personnel from 2001 to 2006, it should be noted that environment-related roles previously spread out amongst each operational unit have now been consolidated and redundancies reduced, with attendant

${ }^{25}$ These fall mainly within the Corporate EHS Management division (M2) and to a lesser extent, the Environment \& Sustainability Leadership (M1) division (See Appendix B for full diagram of Environmental and Safety Management organization).

${ }^{26}$ Scottsdale estimated at 240,410, Calgary 1,042,892; according to city websites: (Scottsdaleaz.gov; Calgary.ca) ${ }^{27}$ Emphasis should be placed on this being a simple estimate based on having 3.5 full time staff working over 1.5 years, and includes staff time, travel, and incidentals. 
considerable efficiencies achieved as a result. For example, instead of each unit maintaining its own documentation for applicable environmental compliance legislation, the EM unit now maintains an organization-wide compliance system that provides this information for each unit. This is a good illustration of how a uniform, organization-wide EMS document control system can produce significant cost efficiencies. The City also assigns EMS tasks to staff within each unit to carry out EMS activities and functions.

Officials from most units in Calgary, when asked, reported that they would not be able to separate out EMS-related expenses directly. Calgary Transit calls their new EMS a "cost of doing business" and points out that whether or not it sought certification, it would still need a system for addressing the environmental aspects of its operations. Calgary Parks, which at the time EnviroSystem was introduced was already devoting considerable resources to managing its environmental aspects, reported that EnviroSystem implementation did not involve significant new resources. One area consistently mentioned for cost savings was managing compliance issues. Through proactive identification and addressing of compliance issues, auditing has virtually eliminated significant enforcement issues. For example, in the Waste unit, the EMS costs so far are said by officials to be a "cost of doing business properly and meeting compliance criteria" (Environmental Control Team Leader, Waste \& Recycling Services, personal communication, August 27 2008). Leetham and MacLeod's (2004) survey of North American LA EMSs noted that cost data were only available for LAs with a fully implemented and registered EMS in a single business unit, and not for city-wide implementation. It may be the case that in a more broadly-scoped system like Calgary's, implementation changes become more systemic and more difficult to quantify.

Strategies used to keep EMS implementation costs down in Calgary included using the same consultant(s) initially to service several units, focusing on coordinated auditing, and eventually, hiring in-house, specialized EMS staff. Reflecting on being among the first units within the City to adopt and be certified to a formal EMS, and now having several years of experience, officials within the Water unit expressed regrets about not moving to tie in EMS decisions with fundamental business planning earlier. In their opinion, an earlier integration of 
EMS and business planning decisions would have resulted in greater alignment of cost expectations. As for the cost deterrent of obtaining certification, this undoubtedly is a valid concern, especially for smaller municipalities. However, according to Calgary Transit the cost of registration is a miniscule percentage of its overall budget. While many cities plan from year-to-year, staff at Calgary indicated its 3-year budget planning cycle has proved important for long term projects within the EMS.

\subsection{Performance outcomes}

In the publicly available "Frequently Asked Questions" (FAQ) component of Calgary's internet website, five major benefits associated from the EnviroSystem have been listed, two of which are (1) improving business practices; and (2) increasing economic development opportunities (City of Calgary, 2004). The City's most direct benefits to citizens have been "reduced City operating costs and a cleaner natural environment" City of Calgary, 2004). The FAQ also states that the "benefits extend to the community by improving citizen perception of Calgary as an environmental leader; attracting industry, people and business that want to associate with and live in a city that cares about its environment and assures health and safety and a high quality of life." Because the goal of an EMS should be to improve performance measures related to environmental aspects, an assessment of system benefits should look at how targets have been set and their subsequent results. According to Calgary's Environmental \& Safety Management unit, targets are set using (1) management decisions; (2) feedback from Council; and, (3) auditing cycles (Team Leader, Environmental Performance Assurance, personal communication, March 23 2009). There is a team of EMS representatives from each unit that meets annually to set and update objectives. Each team member is assigned to be a "program champion" for one or two specific objectives to drive communication throughout.

The formalized method to setting and updating targets regularly combined with regular audit cycles translates into a mandatory focus on reality. Particularly from the perspective of the EM subgroup, this system has clarified accountability at all levels. When roles and responsibilities need to be shown to be "defined, 
documented and communicated" as in ISO 14001, there is little room for pointing fingers. Especially where departmental issues may overlap, between Parks and Water departments for example, the presence of targets was reported by multiple interviewees to help make clear who takes the lead or where collaboration is required. A direct correlation between certification and performance has not yet been established in the relevant literature, and would be difficult to make based on solely Calgary's experience. However, in the case of Calgary, there were several reasons the City chose to take the additional step, reported as (1) helping with relationship with regulators; (2) establishing credibility with stakeholders; and, (3) cultivating a culture of self-assessment. Additionally, according to von Malmborg (2003), lack of trust in a local authority as a mutually dependent collaborator is a major obstacle for establishing and managing regional public/private partnerships. An independent certification is a route to overcoming such a barrier.

Articulating aggressive improvements through goals and metrics is not necessarily the best approach despite the fact that auditors will likely look in this direction. Setting baselines and establishing appropriate EMS metrics is a first step that some units had to spend considerable time on. Incorporating relevant measurement of performance factors within such a broad organizational framework is an opportunity for improvement that has been raised several times in auditing in the Parks and other units. Calgary Transit found that during the first few years of implementation, establishing appropriate EMS metrics was mostly a "fact finding" initiative. Within the Transit unit, new metrics were developed with an emphasis on opacity (of emissions) and water consumption. Clear organization-wide targets for the City's major issues like water and energy consumption have been established:

- Energy:

o Target: GHG reductions 50\% below 1990 levels by 2012

- City-wide greenhouse gas (GHG) emission data compiled in 2007 showed a 36.8 per cent decrease in GHG emissions between the 1990 baseline year and 2007. 
- A recent 2009 agreement with the City's wholly owned electrical utility to purchase more wind energy, the Corporation's electricity needs are currently supplied by $90 \%$ green sources.

- Water:

- Target:" 30 by 30": 30\% reduction of consumption below 2000 levels by 2030

- Per capita water use is down to 437 litres per day, from 451 in 2006.

(Team Leader, Environmental Performance Assurance, personal communication, March 23 2009)

Reports from the City claim there has been a threefold increased emphasis in this area: on measurable goals, monitoring and reporting environmental performance ${ }^{28}$. Audit findings ${ }^{29}$ (internal and external) have steadily declined from 2005-2007, from 119, 65, and 40 respectively, although difficulties in developing metrics for all targets persists as a finding in City audits.

Since city-wide EMS implementation, Calgary has proceeded to claim the following environmental management accolades:

- Calgary received one of 10 Sustainable Community Awards from the Federation of Canadian Municipalities (FCM) at the 2006 FCM Annual Conference and Municipal Expo in Montreal (FCM, 2009)

- both Mayor Dave Bronconnier and Calgary received the 2006 World Leadership Award in the environmental category by the World Leadership Forum $^{30}$

- ranked as the \#1 City on The Economist's 2007 City Health and Sanitation Index (Economist, 2007)

\footnotetext{
${ }^{28}$ As stated in the City's "Frequently Asked Questions" on their "Our Environmental Management System" webpage at http://www.calgary.ca.

${ }^{29}$ Findings according to ISO 14001 can be non-conformities (major) and observations (minor).

${ }^{30}$ As communicated by Team Leader, Environmental Performance Assurance, and referenced here:

http://www.calgarymayor.ca/initiatives/environment/overviewenviro.cfm
} 
The benefits realized from certification in this instance may influence future decisions to use standards in other areas. Relative to its size, Calgary has outperformed other cities in terms of its work with outside parties such as LEED certified buildings and alternative energy companies. Calgary has eleven LEED certified buildings, the second most for a Canadian city despite being smaller in population than Toronto and Vancouver. ${ }^{31}$

Beyond what can be quantified, officials at the Water Unit note that the EMS now in place clearly delineates responsibilities and reduces redundancies. Thus, if a staff member who is performing important environmental functions retires, is reassigned, or leaves the City, there is documentation in place that can assist others in assuming those responsibilities. As one Water unit official has said, "People often do good work" but "people don't often keep good records." The EMS approach ensures that good documentation is in place that improves upon the situation prior to EMS implementation, in which "not everyone knew what everyone else was doing" (Manager, Water Services \& Water Resources, personal communication, July 20 2008).

\subsection{Accountability and culture of auditing}

Auditing in Calgary's system is not unlike the auditing occurring in private sector corporate management systems. One each of an internal and external audit is performed each year, offset by six months. The program of internal audits is managed by the Environmental \& Safety Management unit and relies on support and collaborative input from all units. Auditing is carried out by three core staff in the EM group (within the Environmental \& Safety Management unit), and takes about $30 \%$ of their time (or about 1.5 full time equivalents). They have evolved in coordination with other units (financial, safety) to keep audit days to a minimum (currently $\sim 5$ days per year), essential to reducing "system fatigue". This is important as interviewees repeatedly cited alignment of audit days as a major concern about effective systems auditing. The Waste unit reported that on top of actual audit days are those requiring preparation and direct follow-up, which can

${ }^{31}$ Based on LEED certifications listed on CaGBC website http://www.cagbc.org/ as of June 2008. 
become cumbersome across safety and environmental systems if not coordinated effectively. At the very least audits should be coordinated to reduce redundancies as much as possible, for example, through using audit findings from one in the other. When internal auditing was first introduced, uncertainty necessitated a generous schedule of up to a full week per audit. However, coordinators have since honed their practice and learned that, in the interests of efficiency for all involved, no more than two audit days are necessary.

Auditing is said to be a main driver of accountability in that it essentially requires those audited to "prove or disprove what you said you were going to do." (Manager, Calgary Transit, personal communication, July 27 2008). The Waste unit offers that auditing is probably the EMS component offering the most value and "keeps you on your toes". Employees become comfortable being asked and answering questions, from senior to lowest ranking staff (Environmental Control Team Leader, Waste \& Recycling Services, personal communication, August 27 2008). While Parks unit officials reported that the term "audit" is inevitably intimidating to staff at first, if executed properly the feelings of intimidation can be something that lasts only in initial stages or rollout (Parks Environmental Specialist, personal communication, August 27 2008). Regulatory compliance auditing, like EMS auditing, has become an expectation that takes away guesswork from junior and senior staff about legal and other expectations. Prior to EnviroSystem, the Transit unit had not used compliance audits at all. Now they are commonplace, with compliance audits taking place in 2002, 2005, 2007, and 2008 (Manager, Calgary Transit, personal communication, July 27 2008).

Results of internal audits are reviewed by the City's external auditor (PricewaterhouseCoopers) to demonstrate continued conformance to the standard and continual improvement. Even Calgary, arguably an exemplary case of EMS certification, still continues to have audit findings like those associated with the difficulty of maintaining a formalized system. Control of documents continues to be the element with the largest number of nonconformities (City of Calgary, 2008). Units continue to be challenged by inadequate resources to ensure proper control (coding, update and distribution) of records and documents (Team Leader, Environmental Performance Assurance, personal communication, April 10 2008). 
The annual external audits are carried out by an accredited third party who creates a challenge function within the public organization. However, it should be noted that the external auditor operates in a constructive, non-antagonistic manner, attempting to identify opportunities for improvement, with the results being disclosed to City officials.

Employees involved with the EMS repeatedly turn to the word accountability to describe a main benefit of the EnviroSystem. The ISO 14001 standard requires measurable objectives and targets to be set which are consistent with the overall environmental policy. This requirement, coupled with the documentation requirements of the standard, moves environmental management toward being a transparent and accountable process. In effect, where metrics are established, directors tend to become more directly accountable. The continual improvement foundation of an EMS calls for demonstrated incremental refinements in line with its policy over each period of review. Interviews indicate that audits, external and internal, are major catalysts pushing officials to ensure that demonstrable results and improvements do indeed take place.

In Calgary, since the introduction of the EnviroSystem, accountability measures have been implemented, and summarized as the following:

- Compliance auditing has become the norm:

- A series of internal audits prepares the City for any real government regulatory inspections, decreasing the likelihood of legal noncompliance issues arising.

- There have been no fines from Alberta Environment since corporate-wide certification was achieved in 2003.

- Management reviews benefit from a formalized structure:

- Reviews are now done twice per year.

- Where the environmental component of management reviews previously lacked structure (were informal), the EMS framework now provides a useful structure for such reviews.

- Variable pay incentives are now impacted by certification status (i.e., salary is tied to certification and auditing results). 
- Most units manage their own certification (so that responsibility is dispersed to each unit).

In Calgary's case the accountability of its system draws substantially from the system's beginnings when the City was required to audit to the 14001 standard, and it has come to rely on a culture of accountability.

\subsection{Systems integration and regulatory interactions}

EMSs do not operate in a vacuum-systems depend on internal and external interactions. Several management systems coexist within many of Calgary's operating units; for example, in the Water unit there are two quality management systems (ISO 9001 for customer service, ISO 17025 for laboratory work), the EnviroSystem environmental management system, as well as a safety and asset management system. However, staff report that it would make sense in the long term to have one integrated management system that can handle implementation of various dimensions (e.g., health, safety, quality, environmental, and asset management). "The purpose of the management system should be to direct workflow, period, and not [just have] a series of add-ons." (Manager, Water Services \& Water Resources, personal communication, July 20 2008). Despite this recognition, officials must deal with the prescriptive nature of the health and safety system audits.

In Calgary's case, province-wide health and safety regulations apply to the City, and have connections to and implications for the City's EMS. The province offers voluntary health and safety "partnership audits," which are a joint effort between the organization, the workers compensation board (WCB) and Alberta Employment \& Immigration, to conduct audits of safety systems. A certificate of recognition ( $C O R$ ) is given to auditees meeting $80 \%$ of criteria. Incentives to participate include a rebate of up to $20 \%$ of WCB costs (Health \& Safety Audits, Environment \& Safety Management, personal communication, October 7 2008). For large organizations this rebate can be of such significance that it makes participation a foregone conclusion. Water unit officials report that the rebate system inevitably rewards independent health and safety systems whereas integrated environmental, 
health and safety (EHS) approaches might offer the prospect of greater efficiencies. While perfectly well intentioned and indeed offering WCB cost savings, the resources associated with keeping systems separate, and running independent audits have not been recognized by provincial officials.

This is consistent with findings elsewhere. Block (2006) has generalized that the majority of organizations that have chosen to implement an EMS already had in place a quality management system and gave the value of integration as a main reason for the latest revision efforts culminating in the fourth edition of the ISO 9001:2008 and the second edition of ISO 14001:2004. Emerging occupational health and safety system standards such as OHSAS 18001 and Z10 are also compatible with ISO 9001 and ISO 14001 (Block, 2006).

Director Dave Day attributes the success of the Environmental \& Safety Management unit to offering value to operating units by being more than just a technical unit. The system fills a management void by providing a framework for risk management in general, acts as a conduit for connecting corporate functions (i.e. legal resources, community outreach), and sets an example for engaging City council. It is reported that the City is looking to revise its health and safety organizations to learn from the experiences of the environmental teams (Director, Environmental and Safety Management, personal communication, March 17 2009). Regardless of regulatory hurdles, Calgary seems to be on track to leveraging its existing EMS resources to find similar benefits in other areas of management.

\subsection{Summary}

The Calgary case study has served to provide valuable insights in to an internationally relevant LA implementing a third party certified ISO 14001 EMS. Though system drivers were initially regulatory in nature, the organization has recognized value in the approach as evident in their decision to expand the scope to include the entire organization. Calgary underwent rapid organizational change and has emerged with an enhanced culture of accountability and environmental performance achievement. There is a move towards integration of other systems with the EMS that would have been hastened were it not for short sighted planning and regulatory conflicts. 


\section{Chapter 6: Observations AND Implications for Local Authorities}

This chapter uses reflections on the literature consulted thus far, and findings from the Calgary case study, to provide relevant observations designed to be useful for LA environmental management and third party certification standards.

\subsection{Costs and environment as a priority}

It is logical to start a discussion of observations with the question that is always forthcoming in the proposal of any change initiative: how much will it cost? During a presentation to the City of Toronto's Executive Environment Team ${ }^{32}$, this was the very first question posed by a committee member when the opportunity for questions arose. It is a difficult question and one that anyone interviewed (Calgary, Scottsdale, Edmonton) was reluctant to answer. A straightforward answer is actually disingenuous in that it assumes that what is being paid for is the EMS itself, and not the underlying practices that an EMS manages. The distinction is one that is worth making: it represents a fundamental misunderstanding between articulating the value of a system and spending money on additions imposed upon existing practices.

An EMS is not a blanket solution thrown upon an organization-rather, it is a different way to organize what was already informally or in a non-structured way being done. Calgary, like any municipality considering an EMS, was not starting from scratch with environmental management practices that fulfill the 14001 requirements. Many business units already had programs in place to address specific issues or respond to regulation. Similarly, when Hamilton-Wentworth undertook a gap analysis, the findings showed that about 65\% of ISO 14001 requirements were already in place before it implemented its limited EMS

32 More information on this Toronto committee is available at http://www.toronto.ca/teo/environment-team.htm "The Executive Environment Team provides strategic leadership on environmental sustainability issues for the City of Toronto. Chaired by Deputy City Manager Richard Butts, the team includes senior managers from all City Divisions, Agencies, Boards and Commissions with responsibility for significant environmental initiatives including Toronto Water, Transportation and Solid Waste." 
(Bekkering \& McCallum, 1999). What was missing in Calgary, and perhaps in other examples as well, was a consistency of practices, programs, and reporting across the corporation.

Internal EMS feasibility studies conducted by prospective LAs, such as by the City of Toronto (Leetham \& MacLeod, 2004), go to considerable lengths to quantify the costs of certification to the ISO 14001 standard. Yet a distinction must be made between a decision to certify and the decision to adopt underlying practices. King et al. (2005) arrive at this point in positing that a newly certified EMS does not necessarily specify whether practices were recently enhanced or whether performance-enhancing practices were adopted much earlier. In a hypothetical case where all the elements of a well-managed environmental system are in place, added certification would only incur minimal costs. Such a case may be rare, but it serves to illustrate the point: in cases of high EMS implementation costs, the root cause may be a pre-existing organizational inability to sufficiently prioritize environmental objectives in its underlying practices.

While generalizations about EMS implementation costs are difficult to make, economic costs associated with the implementation and maintenance of an EMS are often significant. For example, a Lozano \& Valles (2007) case study suggests that the costs of addressing compliance and documentation gaps became a major consideration. In other surveys conducted by Zutshi \& Sohal (2004) such costs rank highly among potential EMS users, whose highest concerns in considering implementation were the expected costs involved and time needed to prepare documentation. While a proper environmental management administration, once in place, may be relatively non-resource intensive, the process of explicitly recognizing and understanding requirements that meet regulatory and internal policy demands can accrue costs that may not have been anticipated or budgeted for, such as equipment or facility maintenance. Furthermore, budgeting for such uncertainties can be extremely difficult.

Clear evidence indicates that resource availability is a major concern for LAs in achieving the requirements of a system that uncovers and formalizes appropriate commitments. For example, in the government-encouraged New Zealand LA usage case (Cockrean, 2000), LAs that had tried but failed to implement an EMS cited 
insufficient resource availability as one of the three main reasons. A certified EMS is an effective way to shift resources to these environmental priorities and this may be one of the primary benefits sought by environmental managers at the local level. Managers with environmental responsibilities may have formerly been unable to articulate the consequences of ignoring issues, and certification provides a "stick" to use within the organization, essentially to say "we have to do this or we lose (or won't gain) certification."

Where significant shifts in priorities are necessary under EMS implementation, a realigning of priorities relies on leadership and top management support. The kind of change necessary for a successful EMS "may require an exceptional kind of organizational leadership that is not readily found nor easy to create" (Coglianese \& Nash, 2001). In two sets of examples at the City of Hamilton-Wentworth and New Zealand (case studies), reports indicate that one of the top barriers to effective EMS implementation was serious commitment from senior management (Bekkering \& McCallum, 1999; Cockrean, 2000). At Hamilton-Wentworth, staff expressed considerable concern about a reported gap between Council members and implementation staff who were unauthorized (or under-authorized) to make decisions (Bekkering \& McCallum, 1999). This scenario is likely manifested in other LAs where elected representatives hold significant decision-making authority over the operations of the organization. Strong leadership among environmental managers, which is critical to motivation throughout the organization, is enabled only when they have the organizational mandate that appeals to top decision makers. Bekkering and McCallum (1999) report that "the key motivator in implementing an EMS at Hamilton-Wentworth was the need to have an effective tool for implementing Council directives and to be able to show that appropriate action was being or had been taken". In Calgary, it was emphasized that development of a standardized environmental component to be added to reports going to City Council was one of the most effective tools used by the system to date (Team Leader, Environmental Performance Assurance, personal communication, April 21 2008).

In order for a system to be sustainable, the organization needs at some point to integrate decision making in a manner that accurately reflects the business 
fundamentals of the organization. Structural and/or cultural change can be positive, but they need to stand up to long term strategic interests. For example, Calgary Water unit officials indicated that environmental issues present a particular challenge in that staff have no shortage of ideas and tend to be emotionally and personally invested in environmental outcomes (Manager, Water Services \& Water Resources, personal communication, July 20 2008). In this Water unit, a formalized triple bottom line (TPL) documentation tool was one strategy used to ensure that ideas were reviewed against budgeting and cost-benefit considerations similar to other investment decisions. Whether explicitly defined in a tool such as TPL or otherwise understood by decision makers, a balance must be struck between environmental priorities and good business sense. Certification can potentially endanger this important equilibrium.

\subsection{Regulatory versus non-regulatory drivers}

In most cases the decision by LAs to subscribe to a third party EMS standard is voluntary, and not required by law or regulation. The council, mayor, and/or LA unit managers decide to use a particular standard because they have concluded that there is value in complying with that standard. The ISO 14001 standard in particular is not prescriptive and therefore does not set substantive obligations such as emissions or waste quantities for an organization's environmental impacts. All the standard does is provide a systematic approach to achieving whatever environmental objectives the organization chooses. Furthermore, any organization can decide to abandon its application of the standard at any time: because it is not a law, there is no possibility that any municipal official could be fined or imprisoned for not complying with the standard.

The 14001 standard does mandate the asking of questions such as "what are your environmental objectives?", "what are your impacts?", and "do you have a plan?", to suggest a few. Thus, any LA is in a position to select any objectives it wishes, identify any impacts it wishes, and devise its own plan to meet the objectives it chooses, and so on. These are broader, more systemic questions than those that are asked of an organization under specific command and control regulations. These non-regulated driving questions create a unique set of learning 
opportunities. It is as if they automatically incorporate Leonard-Barton's (1995) third element of effective learning organizations, by instigating a review process that "evaluates, challenges, and adapts prevailing practices and strategies".

A clear difference exists between regulatory and non-regulatory drivers; however, organizations in which an EMS has been applied most systemically (LAwide) have seen a transition from the former to the latter. For example, commentators on the Dallas experience echo other LA EMS adopters such as Calgary and Edmonton. When Dallas faced an EPA Consent Decree at 11 City facilities, it realized that it was in its own interest to expand the scope of analysis and acknowledge the absence of city-wide environmental policies and procedures, training and accountability for environmental issues (PEER, 2008). Dallas went on to certify all city operations including hundreds of facilities and 11,000 employees under its EMS (PEER, 2008). Based on the experience of Dallas and Calgary, a key component in the successful expansion of certification to the entire organization seems to be a successful transition from coercive to enabling behaviour. If Calgary had not continued to challenge the norm, it would have taken even longer to realize the benefits to be had from further expansion and integration of its system.

In Calgary's case the regulatory mandate of certifying its offending water facility served as a spark that evolved into a set of non-regulatory drivers for an expanded system scope. Under a single-loop learning process, there would be clear incentive to pursue a new static norm of a minimum required application (only water facility or unit). In other words a burst of change (learning) was bound to result from the initial regulatory sentence; however, Calgary demonstrated a more robust (double-loop) learning process in adjusting its organizational norm when doing so was arguably bound to be beneficial. In the majority of LA EMS cases where systems have remained limited to an operational unit or facility, the organization may be unable to change its central features if its culture is inflexible.

It is imperative to endow any EMS with sufficient degrees of flexibility even when the EMS must meet strict certification requirements. Experience in the City of Edmonton that parallels textbook double-loop learning is (with regards to) their use of semi-annual consultation sessions with managers. Managers are given a chance to review system procedures and are asked, "does this add value?" If the answer is 
no, an opportunity is given to make changes that work (Manager, Environmental Management Group, personal communication, July 3 2009). With competence and experience comes an ability to make the standard work for the organization rather than allow it to hold the organization prisoner. If any particular measure does not pass a cost-benefit test, the organization explores retooling to increase satisfaction, or re-examines whether that particular measure is necessary within the system.

Responding only to regulatory drivers can be characterized as single-loop learning. Incorporating those drivers that are non-regulatory in nature is more progressively double-loop. The potential role of public policy actors in shaping these driving forces is an implication of the research discussed in Chapter 7.

\subsection{Value in auditing to standard}

The auditing component of a third party certified system is particularly relevant for LAs given their high degree of accountability to the public. Additional benefits to the organization are less explicit but highly evident in Calgary's case and in other examples.

Building on the case for a culture of accountability that has developed in Calgary, Edmonton has reported other benefits. The main reported benefit of its external system audits has been "as the only real way to bring in expertise to check if best practices are being used" (Manager, Environmental Management Group, personal communication, July 3 2009). It was noted that external auditors are often industry experts who spend their time visiting and interacting with other organizations facing similar challenges. To have them come in and provide assessment and guidance is one way to leverage resources invested in the administration of a certified system.

In Scottsdale, where the city staff are relatively less sophisticated at least in terms of size than some of their counterparts, they have opted to not have their system ISO 14001 certified. Yet a representative noted that they still hold themselves to the letter of the actual standard even though in many instances it would be more convenient to be less stringent (Senior Environmental Coordinator, personal communication, July 8 2009). The reason: it allows them to audit themselves internally. The standard itself is designed with ease of auditing in mind 
and has even undergone revisions ${ }^{33}$ presumably with feedback from the many users who use it and audit to it.

\subsection{System transparency}

Related to themes of auditing and accountability is the issue of transparency, in the sense of having operations and programs open to viewing by outside parties. The ISO 14001 standard does not contain extensive requirements for informing and involving public stakeholders in decision making processes. It does, however, require that the organization's environmental policy ${ }^{34}$ be made publicly available (ISO, 2004a) and that an organization explicitly decide whether (or not) to make publicly available a list of their significant environmental aspects ${ }^{35}$.

In Calgary's case, the City decided that each unit should make its own decision whether (or not) to communicate environmental aspects externally. Approximately one-third have been made available online. The City of Scottsdale has chosen to provide all system documentation where practical (City of Scottsdale, 2009), but this may be the exception and not the rule with systems based on ISO 14001 . Edmonton falls somewhere in the middle, having offered its overarching "core" procedures online while leaving more detailed unit documentation offline (Manager, Environmental Management Group, personal communication, July 3 2009).

Simply making certification and/or EMS policies and goals public can have a powerful effect on the likelihood of adherence to commitments. Disclosing goals to the public enhances outcomes by engaging and enlisting interest from those beyond an organization's borders. This is supported by experiences in the Chesapeake Bay and lower Charles River (Boston) where EPA regional announcements of swimmable waters goals by 2005 enabled cooperation among stakeholders that resulted in dramatic increases in water quality in a relatively short period of time (Coglianese \&

\footnotetext{
${ }^{33}$ The ISO 14001 standard was originally published in 1996 by ISO and a revised 2004 edition was subsequently released.

${ }^{34}$ Defined in ISO 14001 to be the "overall intentions and direction of an organization related to its environmental performance as formally expressed by top management."

${ }^{35}$ Section 4.4 .3 of the ISO 14001 standard contains this requirement to decide whether to communicate significant environmental aspects externally. This is in contrast to the requirement to make public the environmental policy, which is not optional.
} 
Nash, 2001). This is a long recognized phenomenon in the field of social psychology, as evidenced by the often-cited quotes of Robert Cialdini:

\footnotetext{
"Public commitments tend to be lasting commitments."

"Whenever one takes a stand that is visible to others, there arises a drive to maintain that stand in order to look like a consistent person." (Cialdini, 1993)
}

A certified EMS can symbolize such public commitments, and be met with public expectations for coherent, ready answers to questions similar to those that a shareholder in a company might ask, such as: "What's the overall environmental policy? Can you show me in writing who is responsible for $\mathrm{x}$ issue? Where can I find a list of objectives and targets for the whole organization?" As more organizations and persons use ISO 14001, its terminology and approach will likely become more familiar and more used in cities' and other organizations' interactions with others. One study involving interviews with corporate managers of companies with certified EMSs in the US revealed a tendency to "set fewer, more attainable goals" (Switzer et al., 2000). As these managers point out, establishing unrealistic goals is not effective for most organizations. It simply reflects a lack of understanding of an organization's constraints and may lead to subsequent failure that may block future efforts.

In Calgary, disclosure of the City's environmental policy (as required by ISO 14001) as well as disclosure of the City's overall environmental objectives, goals and targets (which was done but not required by the ISO 14001 standard) allows for the possibility that the City's operations will be measured by members of the public against the expectations contained therein, and found wanting. Thus, this sort of public disclosure could motivate (or shame) the City to improve performance towards those goals. This recalls the success factor previously identified by Christmann and Taylor (2006), where customers' direct involvement in issues upon which they place high importance ultimately contributes to the likelihood of substantive implementation. In Scottsdale it was reported that a key factor in that 
city's program has been a citizenry highly aware of water scarcity issues, a pattern that seems to parallel Calgary's environmental situation.

Although benefits may flow from public engagement in the development and implementation of an EMS, Calgary managers have suggested that one of the keys to successful EMS implementation has been to apply appropriate limits to public involvement. In the opinion of a former policy advisor for the City who now works on public consultation projects in the area, public input should be directed towards setting high level objectives or policy, while detailed work inside the EnviroSystem should be left to professionals (Former Senior Policy Advisor, personal communication, October 23 2008). Consistent with the former policy advisor's views, the City's approach does not extend beyond public consultation regarding the setting of environmental objectives. While as noted, ISO 14001 does not emphasize public involvement in operational aspects of an EMS, City officials suggest the obligation of organizations to meet legal requirements ${ }^{36}$ is indirectly a response to public demands (Former Senior Policy Advisor, personal communication, October 23 2008). Based on the research undertaken and interviews with officials, it appears that the City has been attempting to strike a balance between engaging the public on broader substantive issues and directions, while involving the public to a lesser extent in operational details. Ensuring ongoing effective public input into the City's EMS will continue to be a challenge for the City, as it would be for other organizations (public or private sector).

\subsection{Collective goals and enabled communication}

An important foundation for a successful corporate-wide EMS is adoption of a formal organization-wide environmental policy: it can help to set the tone and drive change throughout the organization as well as assist in setting the scope of the EMS.

${ }^{36}$ Section 4.3.2 of the 14001 standard requires organizations to "establish, implement and maintain a procedure(s)" to (a) "identify and have access to the applicable legal requirements related to its environmental aspects" and (b) "determine how these requirements apply to its environmental aspects." Further, "the organization shall ensure that these applicable legal requirements and other requirements to which the organization subscribes are taken into account in establishing, implementing and maintaining its environmental management system." 
A unifying environmental policy and management system is one strategy for addressing the different challenges faced by an organization and creating a common culture (Burström, 2000). Focusing on shared goals enables multiple parties to assess skills and resources needed in pursuit of a shared goal, and agree on who can and will contribute what by when (Coglianese \& Nash, 2001). Given the tendency of many larger municipalities to be structured in comparatively independent decision-making units that isolate their environmentally relevant operations from the rest of the organization (e.g., as was the case in Calgary's water and waste departments), an overarching high level EMS policy can reduce the likelihood of inconsistencies and divergent goals and more effectively identify and address organization-wide goals. City of Calgary officials discovered that applying a water conservation objective to the whole corporation through the EnviroSystem, resulted in contributions from many units other than just the water unit. For example, the Parks unit was able to respond to the corporate mandate for water usage reductions with its own water conservation program based on an automated metering system linked to weather station information, which then tiers irrigation levels according to inputs (Manager, Water Services \& Water Resources, personal communication, July 20 2008). Previously, where the support of a prominent corporate-wide objective already approved by Council would be absent, Parks may have lacked the necessary business case to make the project viable (Parks Environmental Specialist, personal communication, August 27 2008). Having water-related environmental objectives addressed by qualified staff throughout the organization has ensured that the Water Unit does not "go forward with blinders on" (Manager, Water Services \& Water Resources, personal communication, July 202008 ) by developing an approach that only meets that Unit's unique needs and characteristics. In the UK experiences, implementation of LG-EMAS has empowered LAs with the necessary information to ask "the right people, the right environmental questions, at the right time" (Riglar, 1997), thus reducing wasted time on managing environmental issues that could and should have been foreseen.

Interviews with staff in Calgary suggest that having a simple, easily communicated corporate-wide environmental policy has gone a long way towards driving a consistent message to employees. Their "3 Cs" acronym (see Table 6.5.1 
below) has been very well received throughout and has assisted in making significant City-wide environmental improvements.

Table 6.5.1 - The 3C's of The City's Environmental Policy
Comply with applicable legislation.
Conserve resources and prevent pollution.
Continually improve our environmental
performance.

The spreading of an environmental ethic throughout the organization has been considered by some officials to be just as important as the detailed programs and targets (Parks Environmental Specialist, personal communication, August 27 2008). The need for cross-unit committees to address city-wide EMS priorities and policies has helped to break down barriers among otherwise rather insular, independent units, and has also assisted in identifying and addressing cross cutting EMS issues and priorities, such as water conservation.

These identified benefits and insights at the City of Calgary seem consistent with observations by scholars who have studied EMS implementation in other cities. For example, in a survey of 107 Swedish local authorities conducted in 2000 , the number one explanation given for pursuing an EMS was what has been referred to as "organisational reasons" (61\%), with the largest subcategory being "structure in the environmental management" (Emilsson \& Hjelm, 2002). In the same survey, when asked if they had seen any environmentally related results, the top answer given by city officials was categorized as "organisational outcomes" (Emilsson \& Hjelm, 2002). Another Swedish study in 2000 found that implementing an EMS across a whole municipality may help to bridge gaps of professional culture between the various departments and professions, and eliminate "language gaps" (Burström, 2000). The City of Calgary placed considerable value on having consistent corporate policies and objectives, especially in terms of opening corporate-wide communication with respect to environmental management.

Also important to consider is the influence on other organizations in the external environment. Although empirical support is lacking, LA adoption of 
standards recognized by the private sector could increase legitimacy and even set an example for local businesses. Evidence in the cases of Edmonton and Calgary appears to support the statement that formally defined objectives have facilitated communication with external parties, at least on two fronts: regional cooperation, and dealing with contractors.

In 2008, Alberta Transportation and the Cities of Calgary and Edmonton developed a common Environmental Construction Operations (ECO) Plan Framework which enabled the three parties involved to draw up common environmental requirements for construction projects (City of Edmonton, 2009). EMS implementation within a LA planning unit could be extremely difficult given the regional interactions in a scope of any significance. Calgary officials felt that the city's planning unit could present a scoping nightmare in the absence of clear boundaries being applied to planning functions (Team Leader, Environmental Performance Assurance, personal communication, May 16 2008). For example, an EMS process can elicit unending considerations such as how to link the City's EMS approach to that of surrounding municipal zones for which the city has no jurisdiction. In at least one example, that of Gothenberg, Sweden, it was reported that the standardized EMS in the Environment Department made it easier to communicate with companies in the region who also had an EMS (Emillson \& Hjelm, 2004). Regional planning initiatives such as the ECO plan could be one solution to these problems. Organizations familiar with EMS certification challenges may be better equipped to take advantage.

Relations with third parties and contractors saw significant change when Calgary implemented its EMS. In the context of municipal budgets and restructuring, decisions need to be made concerning the extent to which third party contractors are included in the scope of the EMS. In Calgary's case, this issue initially caused some debate and challenges within the City, such as, on the one hand, developing relevant EMS standards for the contractors to follow, and on the other, finding contractors capable of meeting those standards. The Parks Unit reported that difficulty in finding qualified contractors (due to extreme local labour shortages and demand saturation) forced them to re-evaluate their policy. The Unit had to think carefully about optimal use of the small number of qualified partner 
contractors that were available to accomplish certain tasks (with competitive, financial, and other implications flowing from this).

In revisiting Leonard-Barton's (1995) effective learning elements, there is clear evidence that the fourth, "a shared vision that facilitates and promotes systematic team problem-solving," has been demonstrated in Calgary's case and should be attainable by others through a similar approach. The third element, however, deserves additional consideration: "a feedback process that efficiently transfers knowledge and information." The rigid nature of applying one environmental policy to an entire organization could be inefficient in some situations. No evidence of this exists in the particular cases examined; however, the varied needs of different segments of LA organizations could change over time. In this situation, the policy could for some cease to be enabling and move towards the mechanistic end of the formalization spectrum. Rondinelli and Vastag (1996) suggest that large corporations need to consider at what level of the organization environmental policies and issues should be addressed, and if variations in policies should be adopted for parts of the organization having more environmental risk than others. This is one observation that should temper enthusiasm for the ISO 14001 approach to a formal environmental policy, and could necessitate further research on the matter.

\subsection{Maintaining system momentum and the risk of outgrowing standards}

Some of the potential detriments of a formal standardized approach have been highlighted in Chapter 4. Caution must be taken to avoid a system that is just as much a hindrance as a help in promoting desired change.

An initial burst of innovation (learning) is likely to take place in situations where certification is sought. Early on, the challenges to existing organizational norms can be significant. For example, Calgary shifted skills and knowledge by consolidating environmental experts and even creating a whole new department. Figure 6.6.1 is useful to visualize effects on the organizational learning curve over time. Assuming some constant initial rate of learning at the outset, an increasing rate of learning brings the organization up to the certification level. 


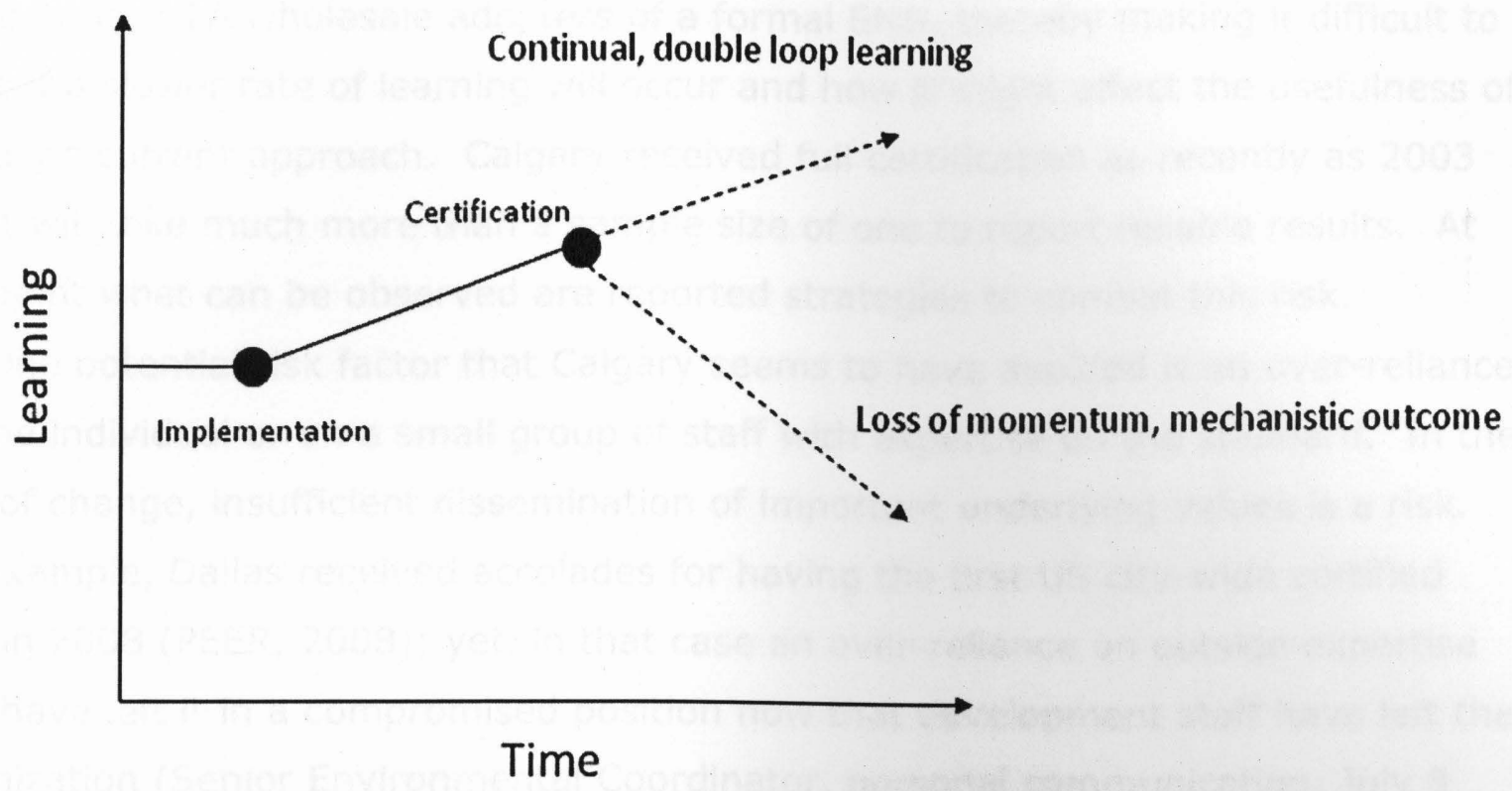

Figure 6.6.1 - Direction of Learning Over Time

There is little doubt that learning will proceed at an increased rate up until certification. Uncertainty arrives once this level has been reached: it then becomes unclear whether rates of learning will continue to increase, revert to previous levels, or worse, end up so constrained by the formalized approach that learning actually dips below pre-implementation levels. There is a real danger of a loss of momentum occurring in examples such as Calgary, and any LAs considering the EMS certification route. Pedersen and Nelson (2000) have commented on this phenomenon in the private sector: "Many of the companies in the survey experienced difficulties in maintaining momentum, year after year. This is due, among other things, to the fact that the number of obvious environmental improvements that employees make in part decreases-and immediate results are, therefore, not always noticeable." In weighing a loss of momentum against reported beneficial results, a LA should investigate whether results stem only from processes leading up to certification, or those which are being ingrained in the organization to last past that point.

In the case of Calgary and LAs in general, with their set of characteristics and unique interest in using certification as a surrogate incentive, it is difficult to accurately assess how a potential loss of momentum will play out. Calgary was one 
of the earliest LA wholesale adopters of a formal EMS, thereby making it difficult to judge if a slower rate of learning will occur and how it might affect the usefulness of Calgary's current approach. Calgary received full certification as recently as 2003 and it will take much more than a sample size of one to report reliable results. At this point what can be observed are reported strategies to combat this risk.

One potential risk factor that Calgary seems to have avoided is an over-reliance on one individual or on a small group of staff with expertise on the standard. In the face of change, insufficient dissemination of important underlying values is a risk. For example, Dallas received accolades for having the first US city-wide certified EMS in 2008 (PEER, 2008); yet, in that case an over-reliance on outside expertise may have left it in a compromised position now that development staff have left the organization (Senior Environmental Coordinator, personal communication, July 8 2009). Scottsdale is currently facing turnover issues in the face of city pressure to transition the organization from fourteen different departments to eight divisions. Scottsdale's senior environmental manager feels confident that while it would easy for voluntary programs to be lost amongst these sorts of changes, something that is "well thought out, comprehensive, and mitigates against risk" will be well received by management and therefore more likely to endure (Senior Environmental Coordinator, personal communication, July 8 2009). Pre-emptively evaluating the likelihood of issues such as turnover is wise for LAs given the high degree of uncertainty at the political level.

Training and education also deserves special attention in the context of maintaining system effectiveness, though this area is given much more focus as an priority early on, when EMS initiatives first begin. It is a major driver of change in initial stages as employees need to be introduced to new concepts, policies, and procedures. Explicit focus is placed on this in the ISO 14001 standard $^{37}$; however, the focus may not persist beyond the initial emphasis on training as new policies and procedures are introduced in early stages of EMS development. It may also be difficult to engage new employees who have not experienced the enthusiasm around achieving certification. Organizations must look to other strategies to

${ }^{37}$ Section 4.42- Competence, training and awareness (ISO 14001:2004) 
modify their training programs to maintain effectiveness. Many private sector companies change from classroom to on-the-job training or monthly or quarterly meetings based on discussions involving employees in order to achieve continued employee understanding and participation (Pedersen \& Nielsen, 2000). Other companies have found that environmental audits are the best form of employee training (Pedersen \& Nielsen, 2000). These are examples of how elements of the system must change in character over time.

Then consideration must be given to the standard itself. LAs such as Calgary that have benefited from the process of achieving ISO 14001 certification should remain aware of the potential to outgrow the standard as a challenging "yardstick" for the organization. Even if the standard is a perfect organizational fit at some point in time, other possibilities must be considered: the internal or external environment could change the cost/benefits of working with the standard; a new, superior standard could emerge; or, the organization could have internalized the major benefits from the standard and no longer stand to gain from a strict adherence to the standard. The Transit unit in Calgary reported that if the benefit is achieved in the simple pursuit of any particular certification, it will be a shortlived benefit, as several years into a system, meaning would be lost (Manager, Calgary Transit, personal communication, July 27 2008). The Transit unit notes that improved performance must be the driver for recurring value to be obtained.

Nielsen and Pedersen (1999) reported on a 1998 survey of Danish companies that had been certified to EMAS or ISO 14001 and were dealing with issues around keeping the system moving forward, and found that the leading companies in the survey tended to expand the scope of work to include a greater, more indirect level of environmental effects. It is only practical to expand system scope up to a certain point, past which it may be necessary to find different sets of performance measures beyond existing certifications. It may not be the scope that needs to change, but the system or framework itself.

For LAs as whole, however, it is possible to generalize that since they can be characterized as less dynamic (more stable in structure, purpose, etc.) than private sector organizations; they may be less prone to "outgrowing" any particular standard such as ISO 14001 . Additionally, given that regulatory drivers are such a 
prominent reason for EMS implementation in the first place, most LAs appear well placed to benefit from leading third party standards such as ISO 14001, without much risk of outgrowing them

It may be the case that third party certifications are particularly useful for LAs at a low to medium level of "self-actualization" in this regard as learning organizations, in that they need an external force to drive them towards a next stage in developing their learning capacities. However, openness must be maintained and emphasis should be placed on two elements: continual improvement and accountability. In this process, these elements-and not the standard itself-have ideally become a part of the values and norms of an organization.

\subsection{Summary}

Costs have been shown to be a major concern of LAs that are considering EMS implementation, though costs should be viewed as mostly related to underlying practices and not to the certification itself. Regulatory drivers of EMS certification can be effective but the remarkable character of leading LA examples lies in their recognition of value above and beyond compliance. Auditing, system transparency, and a set of collective goals seem to carry more benefits than negatives although in many cases enthusiasm for such measures should be combined with an understanding of business fundamentals. Perhaps the most significant observation is that maintaining system momentum after certification can be daunting. The risk of outgrowing existing standards is real, but in the case of LAs is actually unlikely to happen in a short period of time. 


\section{Chapter 7: Further Research Applications}

In this chapter three potential applications of the research are discussed. First, the viability of a LA-specific standard is critiqued. Then in two related discussions, the potential for sharing of LA experiences and making resources available to counterparts is followed by an analysis of what this all means for strategic public policy moving forward.

\subsection{The case for a specific local authority standard}

The special needs of LAs that have been highlighted here surely show that EMS is a worthwhile consideration. Commentators have gone as far as creating specific terms such as Municipal Environmental Management (MEM) (Burström, 2000). Given the aim of an extensive examination of LA EMS in this paper it would not be complete without a response to the idea found in LA EMS literature that LAs should use a sector-specific standard rather than existing standards such as ISO 14001. It is first necessary to highlight what has been argued for elsewhere, and then secondly to respond with observations from the research.

LA-specific standards have been argued as necessary through two prominent themes. Firstly, Regional Environmental Management Systems (REMS) that look regionally as well as at the organizational level would extend the scope to include more consideration of neighbouring regions (Welford, 1993). Secondly, formally adding additional public participation considerations, such as those included in Local Agenda 21 (Von Malmborg, 2003), or otherwise a "strategic perspective and special considerations for public participation" (Alshuwaikhat \& Abubakar, 2007). Alshuwaikhat and Abubakar stand out as strong proponents of the idea that the current use of EMS was developed with industry in mind and lacks a strategic perspective and special considerations for public participation (Alshuwaikhat \& Abubakar, 2007). Both call for building on the administrative EMS framework used in the private sector to include additional emphasis on stakeholder inputs. 
The category of responsibility to stakeholders in the ISO 14001 standard can be contrasted with the European Union's EMAS (which happens to be the product of a public sector organization) to reveal fewer requirements for having an open public dialogue and annual publication of an environmental statement ${ }^{38}$. It is not surprising, then, that, commentators have noted that EMAS is more rigorous than ISO 14001 with respect to issues of public accountability (Krut \& Gleckman, 1998) and that a high degree of public accountability is an integral part of EMS decisionmaking in municipalities (Alshuwaikhat \& Abubakar, 2007). In some European instances these arguments appear to have been accepted. In the UK the original EMAS standard has been modified to LA-EMAS specifically for use by local authorities. LA-EMAS included more of a focus on "indirect environmental effects" (Netherwood \& Shayler, 1996; Riglar, 1997) which amount to a broader stakeholder scope. There have also even been separate but related European frameworks introduced to address integration of political decision making. The European secretariat of the International Council for Local Environmental Initiatives has developed a so-called local environmental budgeting management system, EcoBudget, as a management system for the political decision-making process (Erdmenger, 1998). And when Vasteras, Sweden, decided to implement an EMS across the entire municipality in November 1997, they decided to use ISO 14001 but with an added requirement for public reporting (Burström, 2000). Even without looking at the specific details of each case, there are clear signs that it is possible to broaden the role of an EMS to better include public participation.

That inclusions is possible through EMS does not necessarily translate into it being the best way to include it. Enhanced public participation is surely an admirable goal yet there has to be a limit to what is managed by standard. Other demands could easily enter the picture. Noren and von Malmborg (2002) point out that one consideration they recommend for LAs implementing an EMS standard is to take care to fit the "caring and social service administrations better," mainly by

\footnotetext{
${ }^{38}$ As defined in Annex III of EC Regulation No 761/2001, and of which the aim "is to provide environmental information to the public and other interested parties regarding the environmental impact and performance and the continual improvement of environmental performance of the organization."
} 
placing emphasis on the indirect environmental effects in these areas. The lines of EMS and other management ideals begin to blur.

An emphasis on greater involvement of the public in decision making (in this case environmental decisions, but in theory it could apply to any type), could quickly become a fundamental change to the LA governance, not a management system nuance to take lightly. In the case of Calgary's current system it would be overstepping the already expanded scope and conflicting with other goals such as triple bottom line planning and management system integration. The experience in Calgary of moving towards integration between other systems (health, safety, and environment) further detracts from usefulness in a standard that would have more specificity.

It is interesting that proponents of an LA-oriented standard seem to be basing their arguments on the need to further engage citizens in decision making. Yet having a highly engaged citizenry was one of the success factors noted in Calgary and reported from Scottsdale; both where ISO 14001 is in use. Adding to this point, that Calgary and Edmonton have recently been recognized ${ }^{39}$ by media and NGOs for projects that go beyond their peers in reaching out to stakeholders. Senior EMS managers from both cities were frank, when interviewed, in denying that some sort of modified version of ISO 14001 would better serve their needs (personal communication, Team Leader, Environmental Performance Assurance, April 102008 \& Senior Environmental Coordinator, July 8 2009).

In conclusion there are good reasons for LAs to consider additional stakeholder input in managing environment matters. But there is also the danger of leading down the path of misaligning environmental and organizational priorities, which was observed in section 6.1. There is no evidence that a specific standard for LAs would have benefited closely examined North American cases and the leading adopters of existing generic standards seem to be leading the way without special added requirements.

${ }^{39}$ Calgary's Plan It program was recently praised by Globe and Mail columnist Jeffrey Simpson on June 242009 , "Here's the Plan: Calgary leads us all to a greener future". The city was also the recipient of a Sustainability Community Award for planning in 2007 for imagineCalgary, a large-scale public consultation project. (FCM, 2009) Edmonton received the same award in 2009 for its EMS. 


\subsection{Certified EMS and the regulatory framework}

Research findings present opportunities and lessons for incorporating a third party certified EMS into the regulatory framework. Firstly, it must be noted that the many potential roles EMS certifications could play in the Canadian legal framework have been recognized in the literature. Webb and Morrison (2004) provide a list of possible roles for voluntary standards, which can be applied to EMS standards, and are summarized here as follows:

- as an impetus for firms to take proactive action to avoid further legislation;

- referentially incorporated in law, with or without the approval of the original authors;

- to elaborate and refine the generality of legislative requirements;

- in regulatory enforcement actions undertaken by the government, to assist in obtaining convictions or avoiding penal liability;

- by consumers or community in a legal suit or tort to establish liability or circumstances; and

- by firms, enabling them to bring legal actions in tort or contract against other firms on the basis of a voluntary agreement.

These possibilities are attractive because the more traditional process of command and control standards-setting is onerous, expensive and lengthy, and carries a burden of scientific proof necessary to withstand legal challenge (Webb, 2009). Therefore, an understanding of the role that third party certified EMSs can play is important for policy influencers and makers to grasp.

We have seen in the case of Calgary that a provincial court used the ISO 14001 standard in an indirect way as part of a regulatory enforcement action. However, it is necessary to revisit the fact that we are dealing with LAs which are public sector entities. It should not be taken for granted that it is appropriate for a public sector entity to use or apply a private standard, and submit to third party certification and registration and auditing of its operations. Indeed, having a non-governmental third party involved in consulting and/or auditing an organization's environmental 
obligations is a significant deviation from the norm of a command and control system where the sole players are firms and the state. Arguments can be made that it is only appropriate to involve public sector officials in accessing public sector information and making decisions about the adequacy of environmental management actions on behalf of the public.

Such concerns, however, could be assuaged by the fact that any private third parties involved in auditing and assessment would be appropriately constrained by contract and confidentiality agreements signing an appropriate confidentiality agreement, just like any other consultant whose services could be called upon by that municipality. And if the concern is that there may be cases where disclosure is in the public interest, it may be possible for the legal system to access information learned by third parties through applicable disclosure laws (Webb \& Morrison, 2004). These concerns aside, and given the examples that have been examined in this research, there may be lessons to be learned for future policy efforts to ensure that the interests of LAs and other EMS adopters are accounted for.

As noted, it should be emphasized that the catalyst for Calgary becoming certified to ISO 14001 was a regulatory enforcement action to address an incident of non-compliance with provincial environmental laws, and the decision of the judge to require as part of sentencing that the City's water unit be certified to ISO 14001. This use of ISO 14001 as part of sentencing represents apparent judicial recognition that compliance with a private environmental management system standard is not problematic and in fact could usefully supplement an organization's ability to meet regulatory objectives (Webb and Morrison, 2004). Shifting the resource burden of enforcement to third parties contracted by the private or municipal sector could potentially infuse the system with a greater degree of active compliance auditing and checking. This benefit should be considered by governments when examining the prospects for recognizing the value in EMS under the regulatory framework.

With regards to how the broader legal framework that LAs are a part of would adapt under such a shift, a starting point for assessing the impact of third party certified EMS is to recognize that the existing jurisdictional laws are not altered. Local authorities are subject to all relevant environmental laws, just as are firms in 
the private sector. In Canada, several municipalities have been convicted for failing to meet water pollution laws ${ }^{40}$. One difference, however, is that LAs in many jurisdictions (Canada, for example) are actually partial entities of their parent government tier (province in Canada). Therefore when fines are given as enforcement actions, the fines are presumably going from one level to another of the same government entity. This awkward relationship provides further incentive for regulators to look to non-financial penalties such as EMS certifications. It seems to make sense for Calgary to invest its would-be fine in to its organization's environmental management rather than essentially transfer money among related government entities.

Internationally, national governments seem to have limited the incorporation of EMS in the policy framework to providing varying levels of guidance and training, as is the case in New Zealand, the UK, and Australia (Cockrean, 2000). A Swedish survey revealed that most local authorities did not have third party certification as an objective which may be caused by a lack of incentives to do so (Emilsson \& Hjelm, 2002b). Governments may want to consider providing at least minimal incentive for the actual certification step as there may be a threshold easily met that could, once passed, alleviate regulatory enforcement burdens.

Legislation in several jurisdictions provide incentives to those organizations that use ISO 14001 or other environmental management systems that meet approved international standards (Webb \& Morrison, 2004). In 2002 the Ontario provincial government introduced new legislation with requirements for drinking water providers to adopt a management systems approach. Only an "accredited operating authority" to the province's system requirements is eligible to provide drinking water services (Safe Drinking Water Act, 2002). It has been said that Ontario has one of the most rigorous and advanced water quality regimes in the world, as lawmakers in that jurisdiction have had to respond to the Walkerton water tragedy (where an improperly operated local water treatment facility led to the death of several local residents) (Leetham \& MacLeod, 2004). Thus, it is not

\footnotetext{
${ }^{40}$ For example, convictions in Canada for violating environmental laws have been secured against: the City of Kingston, the City of Hamilton, and Dawson City. See Brandes, O. and C. Ferguson (2004); Wristen and Bonner, 1999),
} 
unreasonable to think that the Ontario legislation requiring that a drinking water quality management system be put in place could become a model for similar legislative initiatives in other jurisdictions and purposes.

Wood and Johannson (2008) reach some highly relevant conclusions for regulators looking to incorporate EMS-policy interactions, based on Ontario's experience incorporating EMS into its environmental fees administration. They are worth adapting here and presenting in table format:

\begin{tabular}{l} 
Wood \& Johansonn, 2008 \\
\hline Do not reinvent the wheel. If a standard exists \\
that fulfills the objectives of a proposed \\
regulation, and the standard was developed by a \\
recognized standards body through a relatively \\
robust multi-stakeholder consensus process, \\
regulators should incorporate the standard into \\
the regulatory scheme to the extent possible and \\
appropriate.
\end{tabular}

Strive for consistency. Avoid proliferation of unexplained discrepancies between the proposed regulation and the standard.

Make any extra requirements clear. If an existing, widely accepted standard does not, on its own, meet all the public policy goals of the proposed regulation, indicate clearly how the standard is deficient and what more is required to meet public policy objectives.

Connect with the experts on the relevant standards development committees. They have been through almost every argument imaginable in developing the standard and bring a reservoir of knowledge and experience to the public policy table.

Get involved in standards development. Where

\section{Comments from Research}

ISO 14001 and/or EMAS should be used as a starting point before looking to additional requirements.

Decisions about embracing EMS in the regulatory framework should be well thought out and planned for long term. For example, the Performance Track program that was an incentive for Scottsdale in implementation needed to be something that lasted for more than just a few years.

Deciding on a certification goal at the LA level drove massive organizational shifts that would be unfair to underestimate on the regulatory end by later adding on additional requirements that might require a different standard or approach.

Actors who have been through the process of LA certification should be consulted. Especially applicable to systems and regulatory integration between safety and environment for example. 
the opportunity exists, participate directly in the work of relevant standards development committees to keep abreast of relevant issues and influence the content of standards. If committee membership is not an option, take advantage of other forms of involvement. standards (as they have in Europe), regulators should be involved in order to be part of optimizing local level interactions with higher levels of government.

Figure 7.2.1 - Conclusions on EMS-Policy Interactions

Policymakers should consider these established lessons as well as considering other non-legal steps taken in the US by regulators. For example in Scottsdale, where the compliance record is impeccable, it was made it clear there would not be the formal city-wide EMS right now were it not for the incentives granted under the EPA's Performance Track program (Senior Environmental Coordinator, personal communication, July 8 2009). The program incentives, on the basis of voluntarily providing third party audit information, included explicit commitments to relaxing regulatory hurdles and easing reporting requirements (Senior Environmental Coordinator, personal communication, July 8 2009).

Finally, it is within the scope of this paper to consider the economic climate facing Canadian regulators. Global markets and the rise of multinational business entities mean that firms being regulated are themselves international actors. Potoski and Prakash (2004) point out that globalization has recently shown crossnational convergence amongst trading partners with regards to participation in voluntary regulation, and ISO 14001 in particular. This is an important consideration as policy makers aim to include economic competitiveness as part of their goals. This "regulatory convergence" in the voluntary sector should be carried over to the public sector where literacy to international actors is an asset for attracting investment. For example, a 2003 study based on a large survey of senior mining company executives in Australia and Canada in the late 1990s concluded that a significant majority of firms consider environmental regulatory approvals to be important in determining investment strategy (Annandale \& Taplin, 2003). These same mining companies are likely familiar with the industry-practiced EMS standards and it is in this context that opportunities for regulators to utilize existing practices should be embraced. 
Experiences of EMS at the LA level contribute further to the prospects of EMS inclusion in public policy frameworks. There is potential for shifting enforcement resource burdens to auditors, more direct public monitoring, and shifting regulatory demands to be friendlier to internationally fluent norms. Policy makers have just as much to learn from studying cases of those regulated as those who are at the receiving end of enforcement.

\subsection{LA cooperation and facilitation of EMS in the sector}

Given that LAs can be said not to compete with each other to the degree found amongst businesses, especially across vast distances, and have less mobile "customers" (residents); there is a unique opportunity to cooperate in sharing knowledge and resources beyond what could be found in other sectors. LAs should be open to sharing their experiences and even resources. In the absence of deterrents to sharing information and resources, such as in industries where the most similar organizations are in direct competition, there are implicit reasons to foster cooperation. In the public sector, as in the private, when organizations join together to regulate themselves, there is the potential for new norms to be institutionalized (Gunningham and Rees, 1997). Significant opportunity exists for LAs with their similarities in service responsibilities. For example, in New Zealand a national training program was introduced based on a guidance document that specifically addressed common regulatory requirements, available for use by all local authorities as the basis for EMS development (Cockrean, 2000). New norms in LA environmental management should be documented, built on success stories.

In developing the EMS at the City of Calgary, officials looked to the experiences of other cities for environmental management ideas. One source of specific tools was Melbourne's "Principles for Sustainable Cities" and "Triple Bottom Line" (TPL) ${ }^{41}$ frameworks. The TPL has become a decision making tool used throughout the City of Calgary's operations to this day as discussed earlier. Implementation of EMS in Calgary was seen by officials as an opportunity to draw on ideas before deciding

\footnotetext{
${ }^{41}$ Defined by the City of Melbourne (http://www.melbourne.vic.gov.au) as "tools are a set of checklists, guidelines, templates and case studies for the application of TBL decision-making and reporting."
} 
what needed to be developed internally. The City of Scottsdale has reported that since its EMS implementation it has received delegates from as far as Egypt and Japan, interested in using tools that staff have developed (i.e. a tool for analyzing legal requirements) (Senior Environmental Coordinator, personal communication, July 8 2009). And Edmonton was fortunate to have been regionally located near a leading North American LA and it has used the Calgary example as a model for their own implementation (Manager, Environmental Management Group, personal communication, July 3 2009). Other potential LA users may not have the travel resources or regional counterparts that some have capitalized on, and so could benefit from more widely disseminated information.

It may even be possible for regionally connected LAs to consider joint EMS and/or certification. A group of 30 small and medium sized enterprises in Hackefors Industrial District in Sweden have adopted this approach by establishing a joint EMS with a common framework, coordination staff, and committees (Ammenberg et al, 2000). By working together, they were able to overcome resource constraints (financial and staff), while obtaining separate 14001 certifications and therefore the benefits of a third party certified EMS. This could be a viable option particularly for smaller LAs with strong regional connections. These creative examples will remain in obscurity in the absence of well established institutions or networks that are accessible by LAs.

In North America, initiatives to identify best practices in the LA sector seem to have proliferated at least to some degree in the US. Two available US-based examples are listed in Table 7.3.1.

Table 7.3.1 - Two US Examples of EMS for LAs Resources

\begin{tabular}{|l|l|}
\hline Resource & Provided by \\
\hline Best Practices Guide: Application of ISO & The Energy Group , Institute of \\
14001 Environmental Management Systems & International Education, \\
for Municipalities & 42 \\
\hline An Environmental Management System & PEER Center (support by the \\
\hline
\end{tabular}

42 Report prepared for Energy and Environment Training Program, Office of Energy, Environment, and Technology Global Bureau, Center for Environment, United States Agency for International Development. Available at: http://www.iie.org/programs/energy/pdfs/Applic\%20ISO\%2014000\%20for\%20Municipalities.pdf 


\begin{tabular}{|l|l|}
\hline $\begin{array}{l}\text { Troubleshooters' Guide for Local } \\
\text { Governments }^{43}\end{array}$ & EPA) \\
\hline
\end{tabular}

Building on experience in the US, there appears to be value in crossjurisdictional "centres of excellence" concerning EMS certification in of LAs ${ }^{44}$. The absence of like measures in Canada stands out as a particular weakness given the leadership shown by Calgary and potential to set an example for subsequent LAs.

The Federation of Canadian Municipalities (FCM, 2009) would be a logical candidate as a Canadian institution to advocate for and/or support LA EMS development. However, it does not seem to have an active interest in the area. Available resources focus on infrastructure projects (FCM, 2009) and their annual "Sustainable Community Awards" limit categories to specific city projects, and do not consider overall management. ${ }^{45}$ The fact that many Canadian municipalities have implemented EMS at least to some degree, as shown in Appendix F, reveals that many have found value in external EMS standards in spite of a lack of government support, rather than because of it. The FCM should reconsider its mandate of supporting "municipal initiatives across Canada that benefit the environment, local economies and quality of life" (FCM, 2009) to include facilitating the use of EMS. Signs exist that Canadian LAs would be receptive to such initiatives. The City of Toronto reported, after conducting its 2004 benchmarking survey of other cities' EMS usage, that just from the surveying alone, it was able to establish an informal network of colleagues working on EMS, and anticipated that it may be possible to reduce implementation costs by sharing documentation and other information about programs (Leetham \& MacLeod, 2004).

As far as organization types go, LAs are particularly well placed to provide each other with common resources that could lower the costs and increase the benefits of a standardized EMS. Looking back on the environmental challenges they face,

43 Guide published in October 2002 available at http://www.peercenter.net/ewebeditpro/items/073F1600.pdf 44 Such as the Public Entity EMS Resource Center (PEER) or National Environmental Performance Track (NEPT) program supported by the EPA.

${ }^{45}$ Award categories are limited to the following categories: brownfields, buildings, energy, planning, residential development, and transportation. (http://www.collectivitesviables.fcm.ca/FCM-CH2M-Awards/db/awards.html) 
they are arguably most in need of outside actors to facilitate the building such networks intended to spread best practices.

\subsection{Summary}

Calls for a special standard beyond the EMS norms to account for the unique characteristics of LAs are premature and conflict with evidence that existing standards such as ISO 14001 are capable of accommodating additional LA concerns. Managing stakeholder input is an identified priority for LA organizations but it is reasonable to be cautious about the practicalities of moving too quickly to change decision making processes. A role for public policy and industry advocates in facilitating LA EMS usage should be welcomed and encouraged, particularly in Canada where industry leaders are emerging. 


\section{Chapter 8: Conclusion}

This concluding chapter provides a summary of the findings that have addressed the outlined research questions and hypothesis, followed by a brief discussion of potential future research directions.

\subsection{Summary of findings}

Analysis undertaken suggests no significant theoretical or practical barriers exist in the application of a private EMS standard to a public LA entity. Riglar (1997) appears to have it right when he argues that EMS "is essential if a council is to obtain a more effective and structured organisation, it should use EMS to respond fully to sustainability". Internationally, certification to the ISO 14001 standard has emerged as a common practice in the private sector, and this implied value extends to LA organizations with their particular characteristics and challenges.

Examples have been found, though extremely rare, of LAs deciding to leverage certification across their whole organizations to obtain significant systemic benefits. The voluntary certification element can: influence LAs as a surrogate force for market competition and drive value through bringing in outside expertise; increase transparency and therefore engagement of stakeholders; and, enable connectedness across divisional lines. Identified success factors that suggest the most appropriate approach for similar LA situations have been highlighted and include the importance of an environmentally engaged citizenship and a likelihood that LAs large in size have more to gain from an external standards approach than those that are smaller.

A case study of the City of Calgary has revealed that it is most efficient to design implementation approaches to scale over the long term and that a system that integrates with other organizational aspects such as health and safety is desirable. Regulatory drivers were critical in Calgary's case in starting the City down the path of EMS certification. However, the remarkable difference that 
distinguishes Calgary from many of its peers is its recognition of the value beyond mere compliance, as it proceeded to apply the system to its entire organization.

Third party certified EMSs are also shown to fulfill the theoretical components of effective learning. As highlighted, for learning to continue after certification occurs, an organization must be willing to continually re-examine the efficacy of the approach originally taken. Auditing, system transparency, and a set of collective goals arguably offer more benefits than drawbacks, although in many cases enthusiasm for such measures should be balanced with an understanding of business fundamentals. Perhaps the most significant observation is that maintaining system momentum after certification requires concerted, organized effort. The risk of outgrowing existing standards is real, but manageable, as in the case of LAs, it is unlikely to happen in a short period of time.

LAs have been shown in particular to stand to benefit from third party certification to EMS standards. One consideration with respect to whether any aspects of the research questions have been left unanswered is that due to cases of LA certification being limited on a time scale to less than a decade old, suppositions on the long term potential of LAs to outgrow a standard remain hypothetical. In the future, municipalities seeking to certify their operations to an EMS standard should consider the challenges and success factors evident in the findings here, while examining their own unique circumstances, to determine how best to proceed with their environmental management programs.

\subsection{Research continuity}

Research results lead to several future considerations for an expanded scope of studies identified in this paper. Findings could be used as a starting point for additional academic case studies that would help to further test the research questions for other LAs or different sectors altogether using a similar methodology. Through contacts at the City of Toronto and Calgary, connections have been made with graduate students who are conducting similar research either on EMS or city environmental management. For example, Chris Fay at Concordia University ${ }^{46}$ has

${ }^{46}$ Chris Fay's 2008 thesis paper was titled "The Construction of Municipal Climate Change Policy: Calgary and Toronto's Participation in the Partners for Climate Protection Program". 
shared research on climate change actions of Toronto and Montreal and vice versa. In the future it may be possible to collaborate at the LA level on environmental research that takes into consideration organizational and/or management findings from this paper and looks at potential to deal with specific environmental issues.

Environmental managers and LA decision makers stand to benefit from the extensive literature reviewed in this paper. "Centres of excellence" such as those identified in the US, or others which might be forthcoming in Canada, could integrate this paper into available resources as a contributor to a dissemination of best practices. 


\section{Appendix A Yin's Types OF Evidence}

\begin{tabular}{|c|c|c|}
\hline $\begin{array}{l}\text { Source of } \\
\text { Evidence }\end{array}$ & Strengths & Weaknesses \\
\hline \multirow[t]{4}{*}{ Documentation } & stable - repeated review & retrievability - difficult \\
\hline & $\begin{array}{l}\text { unobtrusive - exist prior to case } \\
\text { study }\end{array}$ & biased selectivity \\
\hline & exact - names, etc. & reporting bias - reflects author bias \\
\hline & $\begin{array}{l}\text { broad coverage - extended time } \\
\text { span }\end{array}$ & access - may be blocked \\
\hline \multirow{2}{*}{$\begin{array}{l}\text { Archival } \\
\text { Records }\end{array}$} & same as above & same as above \\
\hline & precise and quantitative & privacy might inhibit access \\
\hline \multirow[t]{4}{*}{ Interviews } & $\begin{array}{l}\text { targeted - focuses on case study } \\
\text { topic }\end{array}$ & bias due to poor questions \\
\hline & $\begin{array}{l}\text { insightful - provides perceived } \\
\text { causal inferences }\end{array}$ & response bias \\
\hline & & incomplete recollection \\
\hline & & $\begin{array}{l}\text { reflexivity - interviewee expresses what } \\
\text { interviewer wants to hear }\end{array}$ \\
\hline \multirow{4}{*}{$\begin{array}{l}\text { Direct } \\
\text { Observation }\end{array}$} & reality - covers events in real time & time-consuming \\
\hline & contextual - covers event context & selectivity - might miss facts \\
\hline & & $\begin{array}{l}\text { reflexivity - observer's presence might cause } \\
\text { change }\end{array}$ \\
\hline & & cost - observers need time \\
\hline \multirow{2}{*}{$\begin{array}{l}\text { Participant } \\
\text { Observation }\end{array}$} & same as above & same as above \\
\hline & $\begin{array}{l}\text { insightful into interpersonal } \\
\text { behaviour }\end{array}$ & bias due to investigator's actions \\
\hline \multirow[t]{2}{*}{$\begin{array}{l}\text { Physical } \\
\text { Artefacts }\end{array}$} & insightful into cultural features & selectivity \\
\hline & insightful into technical operations & availability \\
\hline
\end{tabular}

Source: Yin (1994) 


\section{Appendix B LIST OF INTERVIEWEes}

\begin{tabular}{|c|c|c|}
\hline Organization / Association & Position & Note \\
\hline \multicolumn{3}{|l|}{ City of Calgary (Alberta) } \\
\hline & $\begin{array}{l}\text { Environmental Control } \\
\text { Team Leader, Waste \& } \\
\text { Recycling Services }\end{array}$ & \\
\hline & $\begin{array}{l}\text { Director, Environmental } \\
\text { and Safety Management }\end{array}$ & \\
\hline & $\begin{array}{l}\text { Manager, Water Services } \\
\& \text { Water Resources }\end{array}$ & $\begin{array}{l}\text { (includes Wastewater treatment) } \\
\text { Embedded within Water unit to } \\
\text { provide "environmental expertise" }\end{array}$ \\
\hline & $\begin{array}{l}\text { Team Leader, } \\
\text { Environmental } \\
\text { Performance Assurance }\end{array}$ & $\begin{array}{l}\text { Lead contact in coordinating } \\
\text { interviews and obtaining other } \\
\text { Calgary information }\end{array}$ \\
\hline & Manager, Calgary Transit & $\begin{array}{l}\text { One of two environmental specialists } \\
\text { in Transit Unit }\end{array}$ \\
\hline & $\begin{array}{l}\text { Parks Environmental } \\
\text { Specialist }\end{array}$ & $\begin{array}{l}\text { Director's Office } \\
\text { Started in } 2000 \text { before } \\
\text { implementation in Parks began, now } \\
\text { maintains certification }\end{array}$ \\
\hline & $\begin{array}{l}\text { Health \& Safety Audits, } \\
\text { Environment \& Safety } \\
\text { Management }\end{array}$ & \\
\hline \multicolumn{3}{|l|}{ City of Edmonton (Alberta) } \\
\hline & $\begin{array}{l}\text { Manager, Environmental } \\
\text { Management Group }\end{array}$ & \\
\hline \multicolumn{3}{|l|}{$\begin{array}{l}\text { Monica K Pohlmann \& } \\
\text { Associates (Alberta) }\end{array}$} \\
\hline & $\begin{array}{l}\text { Former Senior Policy } \\
\text { Advisor }\end{array}$ & $\begin{array}{l}\text { One of the architects of developing } \\
\text { the city-wide approach to The City } \\
\text { of Calgary's EMS when working as } \\
\text { Senior Policy advisor there } \\
\text { now works as private } \\
\text { communications consultant in } \\
\text { Calgary region }\end{array}$ \\
\hline
\end{tabular}




\begin{tabular}{|l|l|l|}
\hline $\begin{array}{l}\text { City of Scottsdale } \\
\text { (Arizona) }\end{array}$ & Senior Environmental \\
\hline & $\begin{array}{l}\text { Member of 1997 team that launched } \\
\text { EMS and has been the administrator } \\
\text { of the program ever since }\end{array}$ \\
\hline City of Toronto (Ontario) & $\begin{array}{l}\text { Director, Toronto } \\
\text { Environment Office }\end{array}$ & Met in person with Dave MacLeod \\
\hline & $\begin{array}{l}\text { Senior Environmental } \\
\text { Specialist }\end{array}$ & Toronto Environment Office \\
\hline
\end{tabular}




\section{Appendix C EXAmple INTERview Notes}

[Calgary, August 26 2008]

Parks Environmental Specialist, Director's Office

\section{Background}

- Environmental Specialist, reporting to Director

- responsibilities: maintain the Parks ISO registration

- started in 2000 arranged for business unit to have aspects review done

- in Sept. 2003 Parks received certification (before the corporate/environmental unit)

\section{Misc.}

- City departments are known as "business units" (telling?)

- term "audit" inevitably is initially intimating sounding but that is something that only lasts in initial stages or rollout

- Parks is unique in sense that they are a "green" business unit to begin with, so EMS starts in this context; hasn't necessarily raised profile of enviro issues internally, but has heightened the profile of Parks activities for other units (ie. Corporate commitment to reduce water consumption has involved Parks processes)

\section{Policy}

- "3 Cs" acronym has been very well received throughout unit- having a communicable aspect to the policy can make having all employees aware so much easier (simple, but goes a long way)

\section{Aspects}

- hired an environmental consulting company (Jacques Whitford) with the rationale of fast tracking the identification process (the consultant had done similar things with other business units)

- *lesson* if seeking assistance to conduct consulting work, it would be very helpful to use same consultant/group whom is familiar with organization

- found outside help to be beneficial as per keeping them "on track"

\section{Water Program}

- example of collaboration across units- "Green Fleet Committee"- allows people in other business units to get involved in what would otherwise be thought of as 
something only Fleet Services has to grapple with

- conservation program was implemented at Parks- tied in really well with corporate water target(s)

- Parks Water management Strategic Plan was approved by City Council in June 2007

- automated metering system linked to weather station/information (ie. Tiers watering according to weather patterns)

- may not have been the business case to make this happen if not a prominent objective to reduce water consumption-> already approved by Council (actually Parks had initiated this before Council made a commitment to water conservation

\section{Organizational}

- they have tagged on the EMS to health and safety system (HSE)

- EMS staff changes basically hiring one full-time position for environmental and increasing a safety person to full time duties

- one of the unique units in that HSE system is integrated

- when starting out, wasn't a corporate HSE policy, so they made their own; subsequently a corporate HSE policy has been created so they ended up following the corporate policy

- "enviro-network" meets every $2^{\text {nd }}$ month (coord from each unit)

- corporate unit has really taken lead, with EnviroSystem being a good reference not only for coordinators, but for anyone in organization with relevant questions or to know if City has a relevant policy (ie. Does City have a soil erosion policy? - where to look)

\section{Aspects}

- fuel consumption is now measured as it is identified by organization as a priority (i) diesel and gas tracked now as part of system

(ii) required as part of "corporate fuel management policy"

\section{Cost}

- originally EMS development did not involve a large outlay (\$)-> largely used operational budgets which were sufficient for minor costs not covered by corporate environmental group or larger business units

- compliance perspective is where the cost savings/implications would be; internal \& external audits have made enforcement issues non-existent

\section{$3^{\text {rd }}$ Parties}

- difficult to get contractors (labor shortage / demand saturation) therefore City has had to strategize in order to maximize ability to use them-> there is pressure to have contractors commit to more jobs (ie. Larger contracts) so that they aren't doing one-offs and then unavailable for a next job 
- actually fits well in context of EMS responsibility of knowing more about contractors, going through a bit of a process to ensure each one follows policies (ie. tighter relationship with fewer contractors could increase environmental management of contractors)

\section{Challenges}

- getting just one unit certified (and not others)-> looks precarious, leads to "why this one and not the other", ie. There was a Coporate commitment to have all major business units (parks, Recreation, roads, fire, corporate Properties etc.) registered and then have another group called the Corporately registered business units under one umbrella (this is made up of those business units which have minor environmental impacts (Human Resources, Bylaw Services, Planning \& Development etc.)

(if it's a good idea for one it follows that it should be good for others)

- "have to have a vision for where you want to go"

- maintaining an "internal circulation process" is important to make sure other business units are following the internal policies/plans of others (ie. If Parks comes up with a policy applying city-wide, how do you ensure other business units are aware of it when planning new programs/initiatives?)

- having a "major projects" circulation list and key planning staff across units meet regularly at high level to conduct long-term planning is crucial

- measurement of performance (environmental performance indicators EPIs or what some refer to as key performance indicators (KPIs) seems to be a weak point in the sense that it keeps coming up in auditing (not just in Parks)

- aligning environmental with other audits would go a long way

\section{Lessons}

- senior staff need to all be on board, particularly council endorsement is important as it ensures mandate and future resource allocation

- their approach of "taking it slow at first" by starting with a small manual and building on to it worked well

- long-term planning is essential- how should it look down the road? ie. HSE?

- don't just jump in to it otherwise you will create work or unnecessary challenges down the road

- don't be afraid to book audits in a tight schedule (take advantage of the days you do set aside) as it is tempting to take too much time versus striving for efficient (ie. no more than 2 days) audit scheduling (certification/registration audits aside) 
[Scottsdale, July 8 2009]

Sr. Environmental Coordinator

\section{EMS Development}

- initial driver for moving to EMS was to join EPA federal National Environmental Performance Track (NEPT) program (staff member heard of program and initiated application based on their existing ad hoc environmental programs and initiatives)

- NEPT

- cooperative approach to regulatory management by authorities

-expectation was for self-correcting compliance to begin with, then for participants

to go beyond compliance

- participant criteria:

(1)EMS for at least 1 cycle ( 1 year) with external audit

(2) document 2 environmental performance metrics +4 specific commitments over 3 year cycle

- benefits limited to $\mathrm{PR} /$ recognition of being in program, essentially a certification effect

- program recently cut with recent 2009 budget cuts

- for them it only made sense from the beginning to consider doing it city-wide, but pace to be part of NEPT program was so fast that they could only get 2 departments done first (Water, Financial Services) which ended up being their incremental approach

* note that since they did not hire new staff or use external resources, it almost makes an incremental approach necessary

- when asked if being one of first cities to apply EMS city-wide was a motivating factor (competitive advantage / bragging rights).. "Absolutely."

- there was no particular regulatory driving concern or event- prior to 1999 had only very minor compliance issues with no major charges or litigation (and have kept clean record) 
- at start there were 8 people in Environment Office, of which 3.5 people were full time on EMS development ( 1.5 years)

- rough calculation is that given staff time + travel + incidentals the implementation costs could be estimated at $\$ 100,000$ US

\section{Resources}

- they did not use any outside consultants, other than as offered as part of the NEPT program ie. free training/workshops/access to experts and did not have to specifically hire new staff

\section{Public Policy}

- NEPT program gave in return vague promises for "low priority enforcement", flexibility on some regulations (ie. allowed to hold hazardous waste beyond strict regulatory limits)

- some states $(\sim 13)$ have since established their own similar programs

- in Arizona's version, the state actually has a memorandum of understanding with participants that makes explicitly agrees to 14 incentives including (a) advanced enforcement notices, (b) streamlined permit processes, and (c) reduced inspection frequencies

- state has used federal program requirements (had an agreement with EPA to receive their application documentation)

- Without the NEPT program would you have a formal EMS right now? "No."

- PEER center has attempted to "pool" public sector EMS auditors by facilitating cross-organizational auditing (essentially auditors from one city going to another, for mutual benefit- cheaper and gain experience)

\section{Certification}

- "drivers just aren't there" 
- seems that NEPT program (which doesn't require 14001 registration, only some form of outside auditing) has replaced need to obtain 14001 certification (recognition, and access to third party auditing)

- already have such a green reputation for city, certification would not add much more (nothing to prove)

- LEED: Scottsdale has initiated their own green building program so that businesses can opt to use their custom standard instead

- said to give business a choice, avoid bureaucracy, and avoid a national one size fits all standard

- (their custom standard takes in to account unique geography, water demands) - interesting parallels to 14001

- even though they are not absolutely required to follow 14001 for certification, they found 3 years ago that their system would benefit from moving more in that direction to enable auditing functions

* even though he feels they have had to make system "less understandable" it was deemed worth it so that it could be objectively audited (by outsiders and internally)

- there is a reported tradeoff between having a system that is perfectly suited to them and having it strictly follow the standard and be auditable

\section{Organizational / Learning}

- currently facing high turnover issues with pressures for city to transition from 14 different departments to 8 divisions- thinks it would be easy for programs to be lost in this sort of change but thinks something "well thought out, comprehensive, mitigates against risk" will be received well by management and therefore be more likely to stick around.

\section{Other Notes}

- interesting similarities to Calgary- affluence and water scarcity (both which have contributed to high environmental awareness among citizens) 
- keep all system procedures online (transparency high)

- have had delegates from Egypt, Japan, interested in using tools that they have developed (ie. for analyzing legal requirements) 
[Edmonton, July 3 2009]

Manager, Environmental Management Group, City of Edmonton

\section{Background}

- Office of the Environment and Energy consists of (1) Enviro Management Group [3 staff- auditor, himself, support person]; (2) Strategic Planning/Policy [3 engineers- GHG, contaminated sites, air quality]; Community GHG [5]

- group plays a central coordinating role for the EMS (internal audits, maintaining city-wide procedures, facilitate coordination between units)

- not around for original system implementation / push to expansion

- currently 9 units have EMSs implemented, 7 certified; other 2 plan to certify in 2010

- they decided to limit EMSs to operationally relevant units and have left out administrative units

- although they have considered their planning unit for eventual inclusion but for now remains out

- note: Edmonton stacks up quite closely to Calgary in terms of GDP etc.

\section{EMS Development}

- in his opinion, going in to it, cities like Edmonton and Calgary probably didn't know much about EMS or 14001 but were looking for something to deal with regulatory and environmental issues, and the standard was out there as a framework to use; was not fully appreciated as a management system

- major driver was to comply with regulatory requirements 
- significant incident took place during World Championship in Athletics in 2001, when there was a PCB release resulting from problems with lighting fixtures, created a stir with Alberta Environment from which charges were laid but they were later (several years) found not guilty; incident created questions internally about the ability to deal with environmental and related legal responsibilities

- push did not come from political level, rather the recommendation came from (small) environment office which was within the waste branch at the time -> after drainage and waste units were looking at it -> had looked at Calgary experience

1. first unit to move forward was Drainage ( $~ 8$ years ago)

- they brought in help from a consultant, Stantech, for guidance, gap analyses

2. then waste unit ( 1.5 years after Drainage)

3. then office of environment decided to put idea forward to apply EMS to all operationally relevant units, wrote a proposal to city council

4. 7 full time people were brought in from mostly private sector /w EMS/14001 experience

- these 7 people were assigned to 7 divisions,

- making up a working committee but reporting directly to their respective units, not the central environment group (purposeful strategy)

- at this point many of them have expanded responsibilities focused on project management; one in transit has taken on $1 / 2$ enviro, $1 / 2$ safety

- approach was incremental, with a corporate set of procedures built to apply for everyone, with wiggle room for each unit to add on their additional procedures

- no detailed cost/benefit analysis was conducted but council was open to idea 
- quantifying the cost of implementation would be tricky because the duties formally added to people's roles are things that have to be (or should have been) done anyway, incremental costs can be said to be "just good management"

- major obstacle- fact that the many divisions/units at the City essential operate as independent businesses- they are very distinct and this is probably the case at other City organizations

\section{Organizational / Learning}

- coordination occurs from central group through coordinators in each unit (ie. developing action plans and involving other employees as necessary)

- the system "becomes invisible"... ie. "that's not ISO 14001, that's records management"

- similar to experience in Calgary, the generic management system concepts have proven useful in as translated to the rest of organization (ie. records, training, for non-enviro)

- system allows them to ask questions of themselves in a formal way

- good example is with regards to "competency", standard requires that they document processes for how competency is ensured and training programs flow from this (they have had to define competency for various roles, which has been a learning process for all)

- accountability has been enhanced through annual reporting (they aim for an accountability exercise rather than a PR exercise) and auditing/targets

- so enhanced learning can be said to come from (1) competency and training; and (2) accountability measures

- constraints/"prisoner effects" 
- "we are not prisoners to the standard, we make it work for us"- by proper understanding of non-prescriptive nature of 14001

- the key is to ensure managers have opportunity to challenge/critique/contribute

- they have "Enviso for managers" a few times a year which gives managers a chance to answer, for various parts of the system, "does this add value?"

- if answer is no, then there is a chance to make changes- if something doesn't pass cost/benefit test than it probably isn't necessary and should be confronted (examples- will email for followup)

\section{Auditing / Certification}

- as far as maintaining momentum after certification

- system is only as strong as the management buy-in/perception so this is a challenge

- particulary an issue where turnover is concerned and moreso in units with less environmentally relevant operations

- strategy for overcoming this is simply to make sure the system continues to assist managers in doing their job (if it ceases to do this, momentum is lost)

- $3^{\text {rd }}$ part certification is the only real way to verify if you are pursuing best practices

- best way to ensure best practice is to bring in outsiders

- real value of the extra certification step:

- so top management can rely on an independent source of assurance

- brings in the competitive benefits

- engages council who otherwise is not very involved in the EMS

- choice of auditor was done through a public RFP, and they have decided to open it up again next year 
- sees no case at all for ISO 14001 being inadequate to municipal organizations- is written broadly enough to apply as appropriate

\section{Stakeholders / Transparency}

- 14001 is fairly clear that anyone working on your behalf is treated as essentially your employee, so contractors have definitely been an issue if they are to obtain/maintain certification

(In 2008, Alberta Transportation, and The Cities of Calgary and Edmonton developed a common Environmental Construction Operations (ECO) Plan Framework (the Framework) to meet the needs of the three organizations)

- stakeholder participations has been limited but they have made efforts to communicate the system (stickers on city vehicles, brochure mailings)

- annual report goes to media each year

- standard responsibility requirements can be said to be a framework for accountability 


\section{Appendix D EMAS VERSUS ISO 14001}

\begin{tabular}{|c|c|c|}
\hline & EMAS & ISO/EN ISO 14001 \\
\hline Status & $\begin{array}{l}\text { Under legal bases (EU Member States } \\
\text { and EEA countries). } \\
\text { Regulation of the European Parliament } \\
\text { and the Council under public law }\end{array}$ & $\begin{array}{l}\text { Under no legal bases. } \\
\text { (International: world wide) iso standard } \\
\text { under private law }\end{array}$ \\
\hline Organisation & $\begin{array}{l}\text { The entity to be registered shall not } \\
\text { exceed the boundaries of the Member } \\
\text { State, and it is intended to go towards } \\
\text { entities and sites }\end{array}$ & Does not go towards entities or sites \\
\hline Environmental policy & $\begin{array}{l}\text { Included commitment to continual } \\
\text { improvement of environmental } \\
\text { performance of the organisation }\end{array}$ & $\begin{array}{l}\text { Does not include a commitment to the } \\
\text { continual improvement of environmen- } \\
\text { tal performance but of the performance } \\
\text { of the system }\end{array}$ \\
\hline $\begin{array}{l}\text { Initial environmental } \\
\text { review }\end{array}$ & $\begin{array}{l}\text { Obligatory preliminary review, when } \\
\text { is the first time that the organisation } \\
\text { sets its environmental status }\end{array}$ & $\begin{array}{l}\text { Initial review is recommended, but not } \\
\text { required }\end{array}$ \\
\hline Environmental aspects & $\begin{array}{l}\text { Identification and evaluation of the } \\
\text { environmental aspects (direct and } \\
\text { indirect). } \\
\text { Etablishment of criteria for assessing } \\
\text { the significance of the environmental } \\
\text { aspects }\end{array}$ & $\begin{array}{l}\text { Required anly a procedure able to } \\
\text { identify environmental aspects }\end{array}$ \\
\hline legal compliance & $\begin{array}{l}\text { Obligatory to demonstrate it. } \\
\text { Required full legal compliance. There } \\
\text { is a compliance-audit }\end{array}$ & $\begin{array}{l}\text { Only commitment to comply with } \\
\text { applicable legal requirements. There is } \\
\text { no compliance-audit }\end{array}$ \\
\hline $\begin{array}{l}\text { External } \\
\text { communication }\end{array}$ & $\begin{array}{l}\text { Open dialogue with the public. } \\
\text { Public Environmental Statement } \\
\text { (validated for verifiers) }\end{array}$ & $\begin{array}{l}\text { Not open dialogue with the public. Only } \\
\text { is required to respond to relevant } \\
\text { communication from external interested } \\
\text { parts. } \\
\text { Control by public is not possible }\end{array}$ \\
\hline $\begin{array}{l}\text { Continual } \\
\text { improvement }\end{array}$ & Required annual improvement & $\begin{array}{l}\text { Required periodically improvement } \\
\text { without a defined frequency }\end{array}$ \\
\hline Management review & $\begin{array}{l}\text { Is wider and requires an evaluation of } \\
\text { the environmental performance of the } \\
\text { organization, based in a } \\
\text { performance-audit }\end{array}$ & $\begin{array}{l}\text { Required an environmental } \\
\text { performance in the management, but } \\
\text { not through a performance audit }\end{array}$ \\
\hline $\begin{array}{l}\text { Contractors and } \\
\text { suppliers }\end{array}$ & $\begin{array}{l}\text { Required influence over contractors } \\
\text { and suppliers }\end{array}$ & $\begin{array}{l}\text { Relevant procedures are communicated } \\
\text { to contractors and suppliers }\end{array}$ \\
\hline $\begin{array}{l}\text { Employees } \\
\text { involvement }\end{array}$ & $\begin{array}{l}\text { Active involvement of employees and } \\
\text { their representatives }\end{array}$ & No \\
\hline $\begin{array}{l}\text { Internal envir onmental } \\
\text { auditing }\end{array}$ & $\begin{array}{l}\text { Includes: system-audit, a } \\
\text { performance-audit (= evaluation of } \\
\text { environmental performance) and an } \\
\text { environmental compliance-audit (= } \\
\text { determination of legal compliance) }\end{array}$ & $\begin{array}{l}\text { Included only system audit against the } \\
\text { requirements of the standard }\end{array}$ \\
\hline Auditor & $\begin{array}{l}\text { Required the independence of the } \\
\text { auditor }\end{array}$ & $\begin{array}{l}\text { Advised the independence of the } \\
\text { auditor }\end{array}$ \\
\hline
\end{tabular}

Source: EU, EMAS Factsheet, May 2008, downloadable at:

http://ec.europa.eu/environment/emas/pdf/factsheet/fs_iso_en.pdf 


\section{Appendix E ISO 14001 ELEMENTS}

\begin{tabular}{|c|c|}
\hline $\begin{array}{l}\text { Element } \\
\text { Number }\end{array}$ & Title \\
\hline 4.1 & General requirements \\
\hline 4.2 & Environmental policy \\
\hline 4.3 & Planning \\
\hline 4.3.1 & Environmental aspects \\
\hline 4.3 .2 & Legal and other requirements \\
\hline 4.3.3 & Objectives and targets \\
\hline 4.3.4 & Environmental management programs \\
\hline 4.4 & Implementation and operation \\
\hline 4.4.1 & Structure and responsibility \\
\hline 4.4.2 & Training, awareness and competence \\
\hline 4.4.3 & Communication \\
\hline 4.4.4 & Environmental management system \\
\hline 4.4.5 & Document control \\
\hline 4.4.6 & Operational control \\
\hline 4.4.7 & Emergency preparedness and response \\
\hline 4.5 & Checking and corrective action \\
\hline 4.5.1 & Monitoring and measurement \\
\hline 4.5 .2 & $\begin{array}{l}\text { Nonconformance and corrective and } \\
\text { preventive action }\end{array}$ \\
\hline 4.5.3 & Records \\
\hline 4.5.4 & Environmental management system audit \\
\hline 4.6 & Management review \\
\hline
\end{tabular}

Adapted from: ISO, 2007 


\section{Appendix F Selected local Authorities: ems Status}

\begin{tabular}{|c|c|c|}
\hline & Scope & $\begin{array}{l}\text { Standard (certified }= \\
\text { y/n/unverified) }\end{array}$ \\
\hline \multicolumn{3}{|l|}{ [Canada] } \\
\hline Calgary, AB & Corporation-wide & ISO $14001(y, S G S)$ \\
\hline Edmonton, AB & $\begin{array}{l}\text { Asset Management and Public Works } \\
\text { Department (Drainage Services, } \\
\text { Parks Branch); Fire Rescue Services; } \\
\text { Mobile Equipment Services; Roads } \\
\text { Design and Construction Branch and } \\
\text { the Transportation Operations } \\
\text { Branch; Edmonton Transit; Waste } \\
\text { Management Branch. }\end{array}$ & ISO $14001(y, C G S B)$ \\
\hline Hamilton-Wentworth, ON & Planning Division & \\
\hline Toronto, ON & Water* & Unclear/undecided (n) \\
\hline Waterloo, ON & Waste & Unclear/undecided (n) \\
\hline York, ON & Waste-Water & \\
\hline Kitchener, ON & Fleet Maintenance Services & ISO $14001(y, B S I)$ \\
\hline St. Albert & Transit Department & ISO $14001(y, B S I)$ \\
\hline \multicolumn{3}{|l|}{ [United States] } \\
\hline Scottsdale, AZ & Corporation-wide & ISO $14001(n)$ \\
\hline Dallas, TX & Corporation-wide & ISO $14001(y)$ \\
\hline $\begin{array}{l}\text { Town of Londonderry, New } \\
\text { Hampshire }\end{array}$ & Department of Public Works & ISO 14001 (unverified) \\
\hline City of Lowell, Massachusetts & Wastewater Treatment & ISO 14001 (unverified) \\
\hline Wayne County, Michigan & Wastewater Treatment & ISO 14001 (unverified) \\
\hline City of Indianapolis, Indiana & Department of Public Works & ISO 14001(unverified) \\
\hline City of Gaithersburg, Maryland & Department of Public Works & ISO 14001 (unverified) \\
\hline New York City Transit & Capital Programs Management & ISO 14001(unverified) \\
\hline \multicolumn{3}{|l|}{ [Europe] } \\
\hline Copenhagen, Denmark & Road and Park Department & EMAS \\
\hline $\begin{array}{l}\text { Eskilstuna; Kalmar; Vasteras, } \\
\text { Sweden** }\end{array}$ & Whole municipality & ISO 14001 \\
\hline Gothenberg, Sweden & All divisions, not centrally & ISO 14001 \\
\hline Hereford City** & Whole municipality & ISO 14001 \\
\hline Leeds City, UK & Whole municipality & ISO 14001 \\
\hline
\end{tabular}




\begin{tabular}{|l|l|l|}
\hline Newcastle, UK & Whole corporation & EMAS \\
\hline Ohanes, Spain & Entire LA** & ISO 14001 \\
\hline Stockholm, Sweden & 4 departments & ISO 14001 \& EMAS \\
\hline Vasteras, Sweden & Entire LA** & $(\mathrm{n})$ \\
\hline & & \\
\hline [Asia] & & ISO 14001 \\
\hline Tokyo, Japan & Tokyo Metropolitan Area \\
\hline \multicolumn{2}{|l|}{$*$ in development, ** LAs of limited size (< 200k pop) }
\end{tabular}

Source: Accumulated Research 


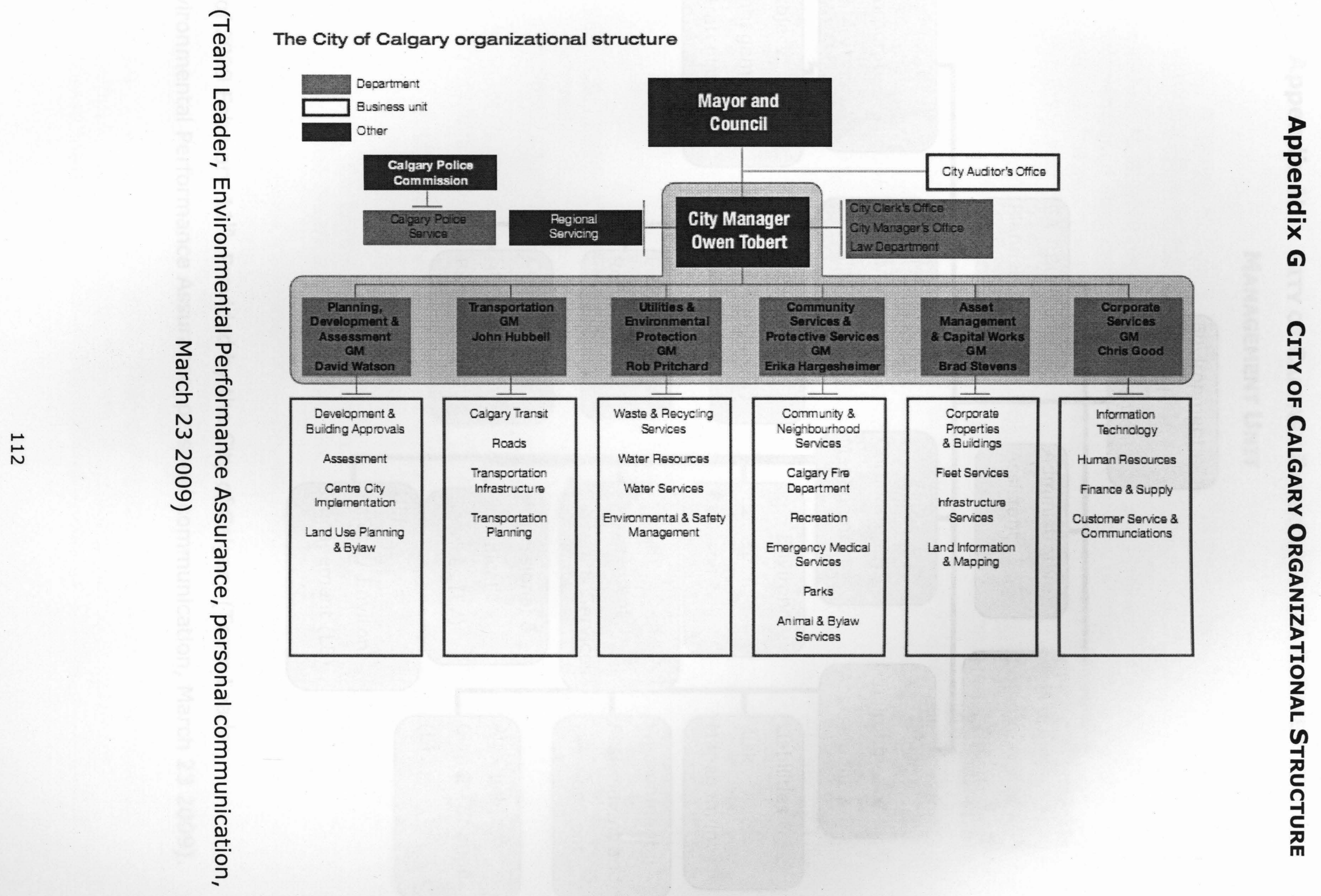




\section{Appendix h City of Calgary Environmental \& Safety}

\section{MANAgement UNIT}

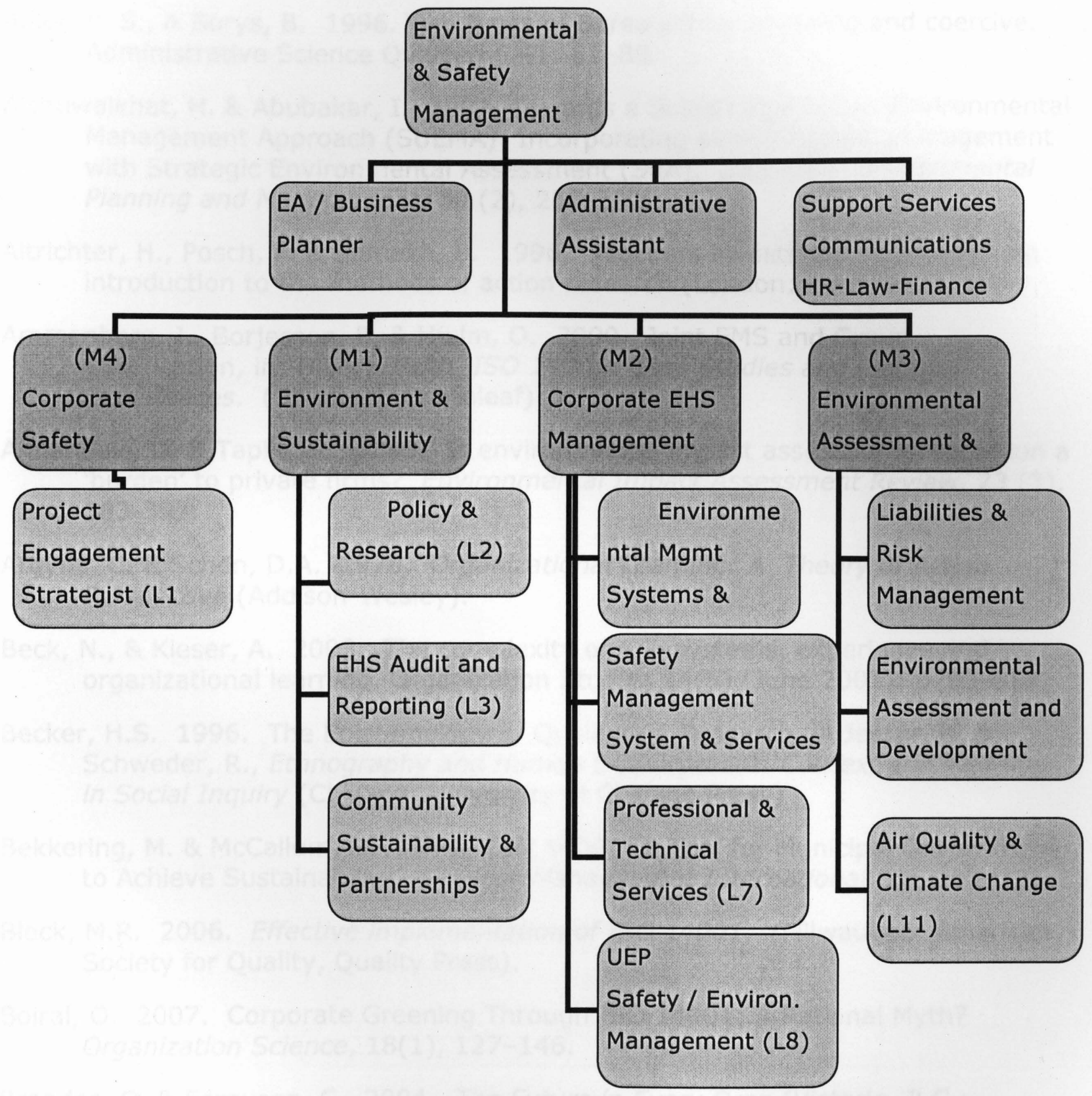

As of 2009 February $11^{\text {th }}$. Provided by the City of Calgary (Team Leader,

Environmental Performance Assurance, personal communication, March 23 2009). 


\section{REFERENCES}

Adler, P. S., \& Borys, B. 1996. Two types of Bureaucracy: Enabling and coercive. Administrative Science Quarterly, 41: 61-89.

Alshuwaikhat, H. \& Abubakar, I. 2007. Towards a Sustainable Urban Environmental Management Approach (SUEMA): Incorporating environmental management with Strategic Environmental Assessment (SEA). Journal of Environmental Planning and Management, 50 (2), 257-270.

Altrichter, H., Posch, P. \& Somekh, B. 1996. Teachers investigate their work: An introduction to the methods of action research (London: Routledge).

Ammenberg, J., Borjesson, B, \& Hjelm, O. 2000. Joint EMS and Group Certification, in: Hillary, Ruth, ISO 14001: Case Studies and Practical Experiences. (Sheffield, Greenleaf).

Annandale, D. \& Taplin, R. 2003. Is environmental impact assessment regulation a 'burden' to private firms? Environmental Impact Assessment Review, 23 (3), 383-397.

Argyris, C. \& Schon, D.A. 1978. Organizational Leaming: A Theory of Action Perspective (Addison-Wesley).

Beck, N., \& Kieser, A. 2003. The complexity of rule systems, experience and organizational learning. Organization Studies 24(5) (June 2003): p793-614.

Becker, H.S. 1996. The Epistemology of Qualitative Research, in Jessor, R. \& Schweder, R., Ethnography and Human Development: Context and Meaning in Social Inquiry (Chicago: University of Chicago Press)

Bekkering, M. \& McCallum, D. 1999. ISO 14001: A Tool for Municipal Government to Achieve Sustainability. Greener Management International, 28, 103-100.

Block, M.R. 2006. Effective implementation of ISO 14001. (Milwaukee: American Society for Quality, Quality Press).

Boiral, O. 2007. Corporate Greening Through ISO 14001: A Rational Myth? Organization Science, 18(1), 127-146.

Brandes, O. \& Ferguson, C. 2004. The Future in Every Drop (Victoria, B.C.: University of Victoria).

Burström, F. 2000. Environmental Management Systems and Co-operation in Municipalities. Local Environment, 5 (3), 271-284.

Christmann, P. \& Taylor, G. 2006. Firm self-regulation through international certifiable standards: determinants of symbolic versus substantive implementation. Journal of International Business Studies, 37, 863-878. 
Cialdini, R. 1993. The psychology of influence and persuasion (New York: Quill).

City of Calgary. 2004. EnviroSystem Frequently Asked Questions. Available: http://www.calgary.ca/docgallery/bu/environmental_management/iso_faq_ju ne_04.pdf.

City of Calgary. 2000. Short-Term Growth Management Strategy - Residential Information Update 2000-2004. Growth Management Technical Committee. Available: www.calgary.ca/DocGallery/BU/planning/pdf/Residential\%20_stgms_20002004.pdf.

City of Edmonton. 2009. Environmental Construction Operations (ECO) Plans. Accessed July 22009. http://www.edmonton.ca/environmental/enviso_iso14001/7829.aspx

City of Scottsdale. 2009. Environmental Management System. Accessed July 8 2009. http://www.scottsdaleaz.gov/ecosystem.asp

Cockrean, B. 2000. Success and Failures: National guidance for New Zealand local authorities, in: Hillary, Ruth, ISO 14001: Case Studies and Practical Experiences (Sheffield, Greenleaf).

Coglianese C., Nash J. 2001. Regulating from the inside: Can environmental management systems achieve policy goals? (Washington, DC: Resources for the Future).

Cohen, L., \& Manion, L. 1986. Research methods in education (London: Croom Helm).

Connaughton, James. 2002. The United States Federal Government and Its Uptake of the ISO 14000 Series of Environmental Management Standards. White House Council on Environmental Quality. February 13, 2002.

Cook, T.D. \& Campbell, D.T. 1979. Quasi-Experimentation: Design and Analysis for Field Settings (Chicago, Illinois: Rand McNally).

Corbett, C. \& Kirsch, D. 2000. ISO 14000: An Agnostic's Report from the Front Line. ISO 9000 + ISO 14000 News, February, 4-16.

Corporate Knights. 2009. Third-Annual Most Sustainable Cities in Canada Ranking. Accessed June 15 2009. http://www.corporateknights.ca/magazineissues/79-2009-responsible-investing-issue/332-the-third-annual-mostsustainable-cities-in-canada-ranking.html

Denzin, N. 1978. Sociological Methods: A Sourcebook (New York: McGraw Hill, 2nd ed.).

Ecojustice. 2009. Flushing out the Truth: Sewage Dumping in Ontario. June.

Economist. 2007. Pocket World in Figures 2007 (London: Economist Books). 
Emilsson, S. \& Hjelm, O. 2002a. Implementation of standardized environmental management systems in Swedish local authorities: reasons, expectations and some outcomes. Environmental Science \& Policy, 5, 443-448.

Emilsson, S. \& Hjelm, O. 2002b. Mapping environmental management system initiatives in Swedish local authorities-a national survey. Corporate Social Responsibility and Environmental Management, 9 (2), 107-115.

Emilsson, S. \& Hjelm, O. 2004. Different Approaches to Standardized Environmental Management Systems in Local Authorities - Two Case Studies in Gothenburg and Newcastle. Corporate Social Responsibility and Environmental Management $11,48-60$.

Epstein, M. \& Roy, M. 1997. Using ISO 14000 for improved organizational learning and environmental management. ISO: Environmental Quality Management 7(1), 21-30.

Erdmenger, C. 2008. From Business to Municipality - and back. Local Environment, 3 (3), 371-380.

EURO-EMAS. 2001. Implementing EMAS in Europe's Local Authorities. Final Technical Report. October.

European Commission. 2006. The Thematic Strategy on the Urban Environment. Accessed 11 April 2009.

http://ec.europa.eu/environment/urban/thematic_strategy.htm

Feagin, J., Orum, A., \& Sjoberg, G. (Eds.). 1991. A case for case study (Chapel Hill, NC: University of North Carolina Press).

Federation of Canadian Municipalities (FCM). 2009. FCM's Green Municipal Fund. Accessed July 2 2009. http://www.sustainablecommunities.fcm.ca/GMF/

Fischer, T. B. 2003. Strategic Environmental Assessment in post-modern times, Environmental Impact Assessment Review, 23, 155 - 170.

Global Environment \& Technology Foundation (GETF). 2000. The US EPA Environmental Management Pilot Program for Local Government Entities. January 28.

Greenbaum, A, Wellington, A. 2008. Environmental Law and Policy: Canadian Perspectives (Toronto: Captus Press).

Gunningham, N., \& Rees, J. 1997. Industry Self-Regulation: An Institutional Perspective. Law and Policy, 19(4): 363-414.

Harrison, R. 1972. Understanding your organisation's character. Harvard Business Review, 50, 119-128.

International Organisation for Standardisation (ISO). 2009. Business benefits of ISO 14000. 
http://www.iso.org/iso/iso_catalogue/management_standards/iso_9000_iso_ 14000/business_benefits_of_iso_14001.htm. Accessed 14 May 2009.

International Organisation for Standardisation (ISO). 2007. The ISO Survey of Certifications - 2007. Accessed 13 January 2009. http://www.iso.org/iso/survey2007.pdf.

International Organisation for Standardisation (ISO). 2004a. EN ISO 14001:2004.

International Organisation for Standardisation (ISO). 2004b. Standardization and related activities: General vocabulary. ISO/IEC Guide 2:2004.

King, A., Lenox, M., \& Terlaak, A. 2005. The Strategic Use of Decentralized Insititutions: Exploring Certification with the ISO 14001 Management Standard. Academy of Management Journal. 48(6), 1091-1106.

Keen, M. \& Sullivan, M. 2005. Aiding the environment: the Australian Development Agency's experience of implementing an environmental management system. Environmental Impact Assessment Review, 25, 628 649.

Krut R, Gleckman H. 1998. ISO 14001: A Missed Opportunity for Sustainable Global Industrial Development (London: Earthscan).

Leetham, K \& MacLeod, D. 2004. Municipal Environmental Management Systems Benchmarking Survey Results. City of Toronto, Environmental Services, Technical Services, Works and Emergency Services. September 2.

Leonard-Barton, D. 1995. Wellsprings of Knowledge: Building and sustaining the sources of innovation (Harvard Business School Press).

Lozano, M. \& Valls, J. 2007. An analysis of the implementation of an environmental management system in a local public administration. Journal of Environmental Management, 82(4), 495-511.

Mazzini Consultants. 2007. Investing and Trading in China. Accessed October 28, 2008, http://www.goinvestchina.com/guide/hz/EDZ/heda.htm.

McIntosh, M. \& Smith, R. 2001. The EMAS case studies in Britain, in: H. Heinelt, T. Malek, R. Smith \& A. E. Toller (Eds) European Union Environment Policy and New Forms of Governance, 259-288

Morrow, D. \& Rondinelli, D. 2002. Adopting corporate Environmental Management Systems: motivations and results of ISO 14001 and EMAS certification. European Management Journal, 20(2), 159 - 171.

Moxen, J. \& Strachan, P. 2000. ISO 14001: A Case of Cultural Myopia. EcoManagement and Auditing, 7, 82-90. 
Netherwood, A. \& Shayler, M. 1996. The role of environmental management systems in local government, in: R. J. Welford (Ed.) Corporate Environmental Management, 1 (London: Earthscan).

New Castle City Council. 2009. Eco-Management and Audit Scheme (EMAS). Accessed June 25 2009. http://www.newcastle.gov.uk/core.nsf/a/nsemas

Noren, H. \& von Malmborg, F. 2002. Are standardised EMSs useful in local authorities?, in: Proceedings of the 11th Business Strategy and the Environment Conference, 16-17 September, Manchester.

Pagano, M. \& Perry, D. 2008. Financing Infrastructure in the 21st Century City. Public Works Management Policy 13, 22-38.

Pedersen, C. \& Nielsen, B. 2000. Maintaining the momentum: EMS after the certifier has left, in: Hillary, Ruth, ISO 14001: Case Studies and Practical Experiences (Sheffield: Greenleaf).

Potoski, M., \& Prakash, A. 2004. Green Clubs and Voluntary Governance: ISO 14001 and Firms' Regulatory Compliance. American Journal of Political Science, 49, 245-248.

Public Entity EMS Resource Center (PEER). 2008. EMS News: Environmental Management Systems in the Public Sector. May.

Public Entity EMS Resource Center (PEER). 2009. About the PEER Center. Accessed July 4 2009. http://www. peercenter.net/

R. v. Calgary (City) A.J. No 1112 [2000].

Riglar, N. 1997. Eco-Management and Audit Scheme for UK local authorities, in ISO 14001 and Beyond: Environmental Management Systems in the Real World, Sheldon C (ed.) (Greenleaf: Sheffield).

Rondinelli, D.A., \& Vastag, Gyula. 1996. International environmental standards and corporate policies: An integrative framework. California Management Review. 39(1).

Senge, P. M. 1990. The Fifth Discipline (London: Century Business).

Sheldon, C. (Ed.) 1997. ISO 14001 and Beyond: Environmental Management Systems in the Real World (Sheffield: Greenleaf Publishing).

Silverman, D. 2000. Doing qualitative research: A practical handbook (London: Sage Publications).

Srinivas, H. \& Yashiro, M. 1999. Cities, Environmental Management Systems and ISO 14001: A View from Japan. Paper prepared for the International Symposium on Sustainable City Development. Seoul, South Korea - 6 and 7 October.

Stake, R. 1995. The art of case research (Thousand Oaks, CA: Sage Publications). 
Steger, U. 2000. Environmental Management Systems: empirical evidence and further perspectives, European Management Journal, 18(1), 23-37.

Stripple, J. \& Lövbrand, E. 2008. Verification as Justification: Private StandardSetting and Regulation in the Global Carbon Market. Paper presented at the annual meeting of the ISA's 49th Annual Convention, Bridging Multiple Divides, Hilton San Francisco, CA, USA.

Switzer, J., Ehrenfeld, J., \& Milledge, V. 2000. ISO 14001 and Environmental Performance: The management goal link, in: Hillary, Ruth, ISO 14001: Case Studies and Practical Experiences (Sheffield, Greenleaf).

Taylor, D. 1994. Piloting the EC Eco-management and auditing regulation in local authorities, in: 3rd Annual Membership Conference of the Institute of Environmental Assessment, 20-21 September, York, UK.

Tsang, E. 1997. Organizational Learning and the Learning Organization: A Dichotomy Between Descriptive and Prescriptive Research. Human Relations, 50(1), 73.

United Nations. 2007. Population Division of the Department of Economic and Social Affairs of the United Nations Secretariat, World Population Prospects: The 2006 Revision and World Urbanization Prospects: The 2007 Revision, http://esa.un.org/unup, accessed Tuesday, January 27, 2009.

United Nations Environment Programme (UNEP). 2000. Environmental Management Systems (EMS) for local authorities. Expert meeting. http://www.unep.org/Documents.Multilingual/Default.asp?DocumentID1/417 4\&ArticleID1/42609\&l1/4en. Accessed 15 December 2008.

United States Environmental Protection Agency (US EPA). 2006. EPA's Commitment to the Integration and Utilization of Environmental Management Systems. Signed by Stephen L. Johnson on Oct. 162006.

United States Environmental Protection Agency (US EPA). 2008. Executive Order 13148. Retrieved October 28, 2008, from http://www.epa.gov/ems/position/eo13148.htm.

Vaux. H., \& Sanford, R. 2006. Rosenberg International Forum on Water Policy: Synopsis and Lessons for Canada and Alberta. Banff: Rosenberg International Forum on Water Policy.

Von Malmborg, F. 2003. Environmental Management Systems: What is in it for Local Authorities? Journal of Environmental Policy \& Planning, 5 (1), 3-21.

Webb, K. 1999a. Private Third Party Auditing of Government Environment Enforcement Activities: Lessons from the Private Sector? in North American Free Trade Agreement Commission of Environmental Cooperation, Indicators of Effective Environmental Enforcement, 43-45 (Montreal: NAFTA CEC). 
Webb, K. 1999b. Voluntary Initiatives and the Law, in R. Gibson, ed., Voluntary Initiatives: The New Politics of Corporate Greening (Peterborough, Ontario: Broadview Press).

Webb, K. 2002. Voluntary Codes: Private Governance, the Public Interest and Innovation, ed. Carleton U Carleton University Research Unit for Innovation, Science and the Environment, Chapter 1, 3-27.

Webb, K. \& A. Morrison. 2004. The Law and Voluntary Codes: Examining the Tangled Web, in Webb, K. ed., Voluntary Codes: Private Governance, the Public Interest and Innovation (Ottawa: Carleton Research Unit for Innovation, Carleton University).

Webb, K. 2009. Environmental Standards-Setting and the Law in Canada, in Greenbaum, A., Pushchak, R., \& Wellington, A. ed., Canadian Issues in Environmental Law and Policy (Captus Press, forthcoming).

Weber, M. 1968. Economy and society. An outline of interpretative sociology, Vols 1-3. Guenther Roth and Claus Wittich (eds) (New York: Bedminster).

Wood, S. \& Johannson, L. 2008. Six Principles for Integrating Non Governmental Environmental Standards into Smart Regulation. Osgoode Hall Law Journal, $46,345-396$

World Bank. 2008. World Development Report 2009: Reshaping Economic Geography. Chapter 4. Published November 6.

Wristen, K., and M. Bonner. 1999. The National Sewage Report Card (Number Two) (Canada: Sierra Legal Defence Fund).

Yamell, P. 1999. "Implementing an ISO 14001 Environmental Management System: A Case Study of Environmental Training and Awareness at the Vancouver International Airport Authority", M.A. diss., Simon Fraser University.

Yin, R.K. 1994. Case study research: Design and methods, 2nd ed. (Thousand Oaks, CA: Sage Publishing).

Zbaracki, M. J. 1998. The rhetoric and reality of total quality management. Administrative Science Quarterly, 43, 602-638.

Zutshi, A., \& Sohal, A. 2004. Environmental management system adoption by Australasian organizations: part 1: reasons, benefits and impediments. Technovation, 24(4), 335-357. 